US Army Corps

of Engineers

Prepared for the U.S. Army Corps of Engineers, Portland District,

under an Interagency Agreement with the U.S. Department of Energy

Contract DE-AC05-76RL01830

\title{
An Evidence-Based Evaluation of the Cumulative Effects of Tidal Freshwater and Estuarine Ecosystem Restoration on Endangered Juvenile Salmon in the Columbia River
}

FINAL REPORT

December 2013

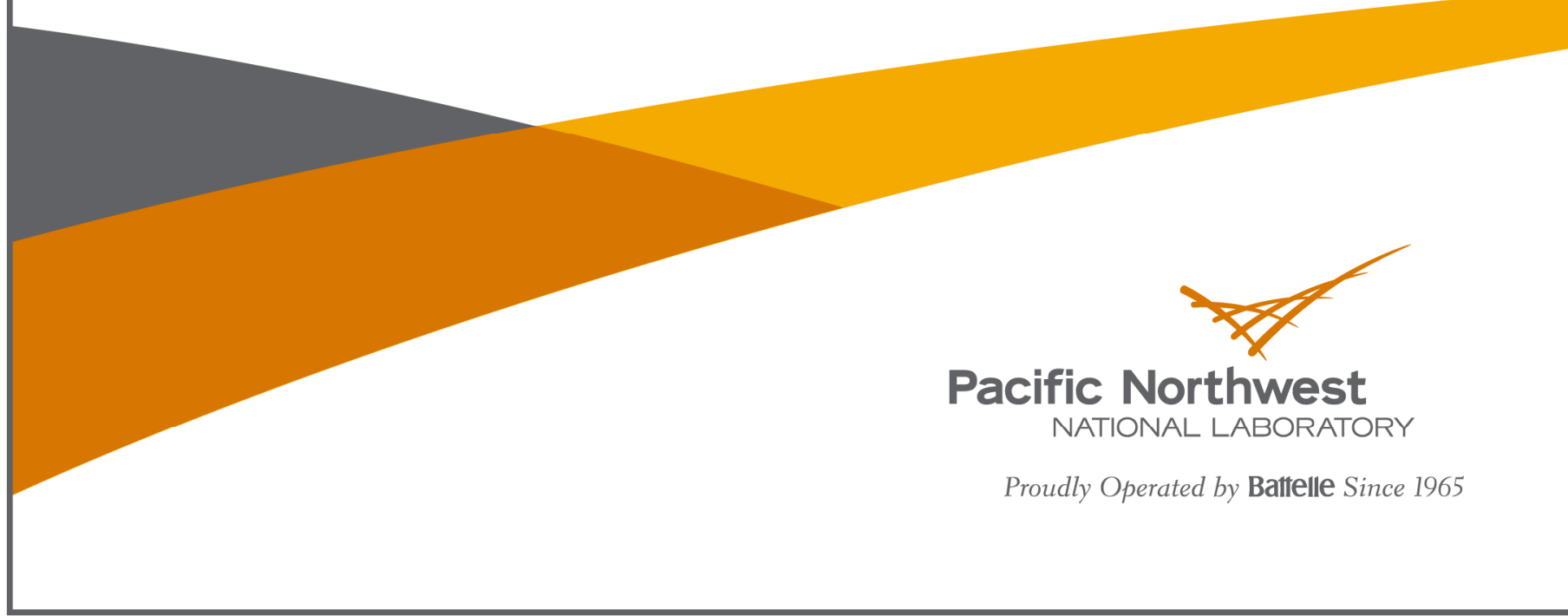




\title{
DISCLAIMER
}

This report was prepared as an account of work sponsored by an agency of the United States Government. Neither the United States Government nor any agency thereof, nor Battelle Memorial Institute, nor any of their employees, makes any warranty, express or implied, or assumes any legal liability or responsibility for the accuracy, completeness, or usefulness of any information, apparatus, product, or process disclosed, or represents that its use would not infringe privately owned rights. Reference herein to any specific commercial product, process, or service by trade name, trademark, manufacturer, or otherwise does not necessarily constitute or imply its endorsement, recommendation, or favoring by the United States Government or any agency thereof, or Battelle Memorial Institute. The views and opinions of authors expressed herein do not necessarily state or reflect those of the United States Government or any agency thereof.

\author{
PACIFIC NORTHWEST NATIONAL LABORATORY \\ operated by \\ BATTELLE \\ for the \\ UNITED STATES DEPARTMENT OF ENERGY \\ under Contract DE-AC05-76RL01830
}

Printed in the United States of America
Available to DOE and DOE contractors from the Office of Scientific and Technical Information,
P.O. Box 62, Oak Ridge, TN 37831-0062;
ph: (865) 576-8401
fax: $(865) 576-5728$
email: reports@adonis.osti.gov
Available to the public from the National Technical Information Service
5301 Shawnee Rd., Alexandria, VA 22312
ph: (800) 553-NTIS (6847)
email: orders@ntis.gov <http://www.ntis.gov/about/form.aspx>
Online ordering: http://www.ntis.gov

This document was printed on recycled paper. 


\section{An Evidence-Based Evaluation of the Cumulative Effects of Tidal Freshwater and Estuarine Ecosystem Restoration on Endangered Juvenile Salmon in the Columbia River}

FINAL REPORT

HL Diefenderfer ${ }^{1}$

GE Johnson ${ }^{1}$

RM Thom ${ }^{1}$

AB Borde ${ }^{1}$

CM Woodley ${ }^{1}$

LA Weitkamp ${ }^{2}$

KE Buenau ${ }^{1}$

RK Kropp ${ }^{1}$

December 2013

Prepared for the U.S. Army Corps of Engineers, Portland District, under an Interagency Agreement with the U.S. Department of Energy Contract DE-AC05-76RL01830

Pacific Northwest National Laboratory

Marine Sciences Laboratory

Sequim, Washington 99382

\footnotetext{
${ }^{1}$ Pacific Northwest National Laboratory, Marine Sciences Laboratory, Sequim, Washington

${ }^{2}$ NOAA Fisheries, Northwest Fisheries Science Center, Newport Field Station, Newport, Oregon
} 



\section{Abstract}

The listing of 13 salmon and steelhead stocks in the Columbia River basin (hereafter collectively referred to as "salmon") under the Endangered Species Act of 1973, as amended, has stimulated tidal wetland restoration in the lower 235 kilometers of the Columbia River and estuary for juvenile salmonhabitat functions. The purpose of the research reported herein was to evaluate the effect on listed salmon of the restoration effort currently being conducted under the auspices of the federal Columbia Estuary Ecosystem Restoration Program (CEERP). Linking changes in the quality and landscape pattern of tidal wetlands in the lower Columbia River and estuary (LCRE) to salmon recovery is a complex problem because of the characteristics of the ecosystem, the salmon, the restoration actions, and available sampling technologies. Therefore, we designed an evidence-based approach to develop, synthesize, and evaluate information to determine early-stage ( $\sim 10$ years) outcomes of the CEERP.

The primary hypothesis was that habitat restoration activities in the LCRE have a cumulative beneficial effect on juvenile salmon. There were two necessary conditions of the hypothesis: 1) habitatbased indicators of ecosystem controlling factors, processes, and structures show positive effects from restoration actions, and 2) fish-based indicators of ecosystem processes and functions show positive effects from restoration actions and habitats undergoing restoration. We identified a set of 12 ancillary hypotheses regarding habitat and salmon response. Each ancillary hypothesis states that the response metric will trend toward conditions at relatively undisturbed reference sites.

Our evidence-based approach to evaluate the primary hypothesis incorporated seven lines of evidence, most of which are drawn from the LCRE, and included: spatial and temporal synergies, cumulative net ecosystem improvement, estuary-wide meta-analysis, offsite benefits to juvenile salmon, landscape condition evaluation, and evidence-based scoring of global literature. The general methods included field measurements, data analyses, modeling, meta-analysis, and reanalysis of previously collected data sets. We synthesized the evidence for and against the two necessary conditions by using eleven causal criteria: strength, consistency, specificity, temporality, biological gradient, plausibility, coherence, experiment, analogy, complete exposure pathway, and predictive performance. Our final evaluation included cumulative effects assessment because restoration is occurring at multiple sites and the collective effect is important to salmon recovery.

We concluded that all five lines of evidence from the LCRE indicated positive habitat-based and fishbased responses to the restoration performed under the CEERP, although tide-gate replacements on small sloughs were an exception. Our analyses suggested that hydrologic reconnections restore access for fish to move into a site to find prey produced there. Reconnections also restore the potential for the flux of prey from the site to the main-stem river, where our data show that they are consumed by salmon. We infer that LCRE ecosystem restoration supports increased juvenile salmon growth and enhanced fitness (condition), thereby potentially improving survival rates during the early ocean stage. However, countervailing influences are also present, such as urbanization and decreased forest cover. Several data sets (e.g., dike breaches versus wetted area) illustrated nonlinear, synergistic, and/or pulsed characteristics of hydrologic reconnection, suggesting that the cumulative effects of restoration are complex in space and time. In general, though, tidal wetlands in the LCRE support juvenile salmon, including interior basin salmon. The beneficial effect of restoring tidal wetlands is expected to increase over time as existing restoration projects mature and new ones are implemented. 



\section{Preface}

This research was performed under the U.S. Army Corps of Engineers Columbia River Fish Mitigation Program, Anadromous Fish Evaluation Program (study code EST-P-02-04). The study was funded by the U.S. Army Corps of Engineers, Portland District (USACE) (Ref.

No. AGRW66QKZ80031101) under agreements with the U.S. Department of Energy and the U.S. Department of Commerce for work by Pacific Northwest National Laboratory (PNNL) and National Oceanic and Atmospheric Administration (NOAA), respectively. This is the last report of a series that started with the 2004 annual report (report date 2005) under PNNL project 46201.

Suggested Citation: Diefenderfer HL, GE Johnson, RM Thom, AB Borde, CM Woodley, LA Weitkamp, KE Buenau, and RK Kropp. 2013. An Evidence-Based Evaluation of the Cumulative Effects of Tidal Freshwater and Estuarine Ecosystem Restoration on Endangered Juvenile Salmon in the Columbia River. PNNL-23037. Final report prepared for the U.S. Army Corps of Engineers Portland District, Portland, Oregon, by Pacific Northwest National Laboratory and NOAA Fisheries. Richland, Washington. 



\section{Executive Summary}

The listing of 13 salmon and steelhead stocks in the Columbia River basin (hereafter collectively referred to as "salmon") under the Endangered Species Act of 1973, as amended, has stimulated tidal wetland restoration in the lower 235 kilometers of the Columbia River and estuary for juvenile salmonhabitat functions. The purpose of the research reported herein was to evaluate the effect on listed salmon of the restoration effort currently being conducted under the auspices of the federal Columbia Estuary Ecosystem Restoration Program (CEERP). Linking changes in the quality and landscape pattern of tidal wetlands in the lower Columbia River and estuary (LCRE) to salmon recovery is a complex problem because of the characteristics of the ecosystem, the salmon, the restoration actions, and available sampling technologies. Therefore, we designed an evidence-based approach to develop, synthesize, and evaluate information to determine early-stage (approximately the first 10 years) outcomes of the CEERP.

\section{Evidence-Based Approach}

We developed an ecosystem conceptual model and from that, a primary hypothesis that habitat restoration activities in the LCRE have a cumulative beneficial effect on juvenile salmon. There are two necessary conditions of the hypothesis:

- Habitat-based indicators of ecosystem controlling factors, processes, and structures show positive effects from restoration actions.

- Fish-based indicators of ecosystem processes and functions show positive effects from restoration actions and habitats undergoing restoration.

The reconnection of former tidal wetlands to the main-stem river has the potential to have immediate effects on salmon and to catalyze changes in the habitat that can affect salmon during all phases of a habitat restoration trajectory (Figure ES-1).

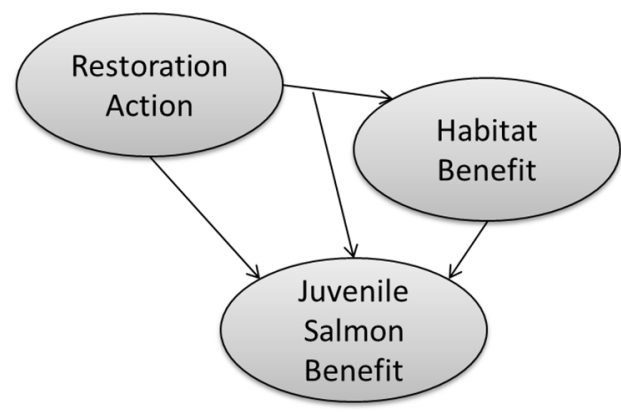

Figure ES.1. General model of pathways for effects of restoration actions on salmon.

Our evidence-based approach to evaluate the primary hypothesis incorporated seven lines of evidence, most of which are drawn from the LCRE (Table ES-1). 
Table ES.1. Description of the seven lines of evidence evaluated in this study.

\begin{tabular}{|c|c|c|c|c|}
\hline & $\begin{array}{c}\text { Line of } \\
\text { Evidence }^{(a)}\end{array}$ & Description & $\begin{array}{l}\text { Cumulative } \\
\text { Effects } \\
\text { Category }^{(b)}\end{array}$ & General Methods (Analyses) \\
\hline \multicolumn{5}{|c|}{ Evidence from the Lower Columbia River and Estuary (LCRE) Floodplain } \\
\hline 1 & $\begin{array}{l}\text { Spatial and } \\
\text { temporal } \\
\text { synergies } \\
\text { ("synergies") }\end{array}$ & $\begin{array}{l}\text { Interaction among multiple effects to } \\
\text { produce an outcome that is greater or } \\
\text { less than the sum of the individual } \\
\text { effects }\end{array}$ & $\begin{array}{l}\text { Synergistic, } \\
\text { space } \\
\text { crowding, } \\
\text { indirect, time } \\
\text { lags, cross- } \\
\text { boundary, } \\
\text { nonlinear, } \\
\text { compounding }\end{array}$ & $\begin{array}{l}\text { Analysis of field data from } \\
\text { historically reconnected sites, } \\
\text { hydrodynamic modeling of } \\
\text { inundation patterns and of } \\
\text { particulate organic matter } \\
\text { transport; detections of interior } \\
\text { Columbia salmon in the LCRE }\end{array}$ \\
\hline 2 & $\begin{array}{l}\text { Cumulative net } \\
\text { ecosystem } \\
\text { improvement } \\
\text { ("CNEI") }\end{array}$ & $\begin{array}{l}\text { Change in ecological function from } \\
\text { the areas restored across multiple } \\
\text { sites with various probabilities of } \\
\text { success }\end{array}$ & $\begin{array}{l}\text { Landscape, } \\
\text { compounding }\end{array}$ & $\begin{array}{l}\text { Additive modeling of change in } \\
\text { function, restored area, and } \\
\text { probability of success }\end{array}$ \\
\hline 3 & $\begin{array}{l}\text { Site-scale } \\
\text { ecological } \\
\text { relationships } \\
\text { ("relationships") }\end{array}$ & $\begin{array}{l}\text { Cause/effect associations between } \\
\text { one or more independent variables } \\
\text { and a response (dependent) variable }\end{array}$ & $\begin{array}{l}\text { Indirect, time } \\
\text { lags, } \\
\text { compounding }\end{array}$ & $\begin{array}{l}\text { Summarization of concurrent } \\
\text { advances in the state of the } \\
\text { restoration science in LCRE; use } \\
\text { of new information to improve the } \\
\text { LCRE ecosystem conceptual } \\
\text { model }\end{array}$ \\
\hline 4 & $\begin{array}{l}\text { Estuary-wide } \\
\text { meta-analysis } \\
\text { ("meta-analysis") }\end{array}$ & $\begin{array}{l}\text { Use of statistical (quantitative) and } \\
\text { non-statistical (qualitative) methods } \\
\text { to summarize multiple site-scale } \\
\text { monitoring results to make } \\
\text { inferences at an estuary-wide scale }\end{array}$ & $\begin{array}{l}\text { Landscape, } \\
\text { time lags }\end{array}$ & $\begin{array}{l}\text { Compilation and systematic } \\
\text { qualitative assessment of results } \\
\text { of action-effectiveness studies in } \\
\text { the LCRE }\end{array}$ \\
\hline 5 & $\begin{array}{l}\text { Offsite benefits to } \\
\text { juvenile salmon } \\
\text { ("offsite") }\end{array}$ & $\begin{array}{l}\text { Beneficial effects on juvenile salmon } \\
\text { from ecosystem restoration that are } \\
\text { realized indirectly at locations away } \\
\text { from the restoration site, e.g., in the } \\
\text { main-stem river }\end{array}$ & $\begin{array}{l}\text { Cross- } \\
\text { boundary, } \\
\text { indirect, } \\
\text { compounding }\end{array}$ & $\begin{array}{l}\text { Comparative analysis of salmon } \\
\text { stomachs; particulate organic } \\
\text { matter export modeling; CNEI of } \\
\text { prey production }\end{array}$ \\
\hline \multicolumn{5}{|c|}{ Evidence from the LCRE Landscape and Analogous Ecosystems Outside the LCRE } \\
\hline 6 & $\begin{array}{l}\text { Landscape } \\
\text { condition } \\
\text { evaluation } \\
\text { ("landscape") }\end{array}$ & $\begin{array}{l}\text { Description of trends in indicators of } \\
\text { aquatic ecosystem condition at the } \\
\text { landscape scale, specifically, the } \\
\text { watershed context within which } \\
\text { wetlands on the LCRE floodplain are } \\
\text { being restored }\end{array}$ & Landscape & $\begin{array}{l}\text { Remote-sensing data analysis to } \\
\text { determine land-cover change } \\
\text { trajectories of forest cover and } \\
\text { urbanization in the contributing } \\
\text { watersheds to the LCRE }\end{array}$ \\
\hline 7 & $\begin{array}{l}\text { Evidence-based } \\
\text { scoring of global } \\
\text { literature ("global } \\
\text { literature") }\end{array}$ & $\begin{array}{l}\text { Systematic global literature search, } \\
\text { filtering, review, and scoring based } \\
\text { on formal criteria applied to selected } \\
\text { response variables }\end{array}$ & $\begin{array}{l}\text { Not } \\
\text { applicable to } \\
\text { cumulative } \\
\text { effects }\end{array}$ & Literature review and scoring \\
\hline & $\begin{array}{l}\text { es of evidence } \\
\text { mulative effects }\end{array}$ & $\begin{array}{l}\text { from Diefenderfer et al. (2011) } \\
\text { tegories are from CEQ (1997) }\end{array}$ & & \\
\hline
\end{tabular}


The general methods we used to develop information for the lines of evidence included field measurements, data analyses, modeling, meta-analysis, and reanalysis of previously collected data sets. We identified a set of 12 ancillary hypotheses regarding habitat and salmon response (Figure ES-2), rooted in the understanding of the ecosystem represented by the ecosystem conceptual model. Each ancillary hypothesis states that the response metric will trend toward conditions at relatively undisturbed reference sites. Furthermore, each ancillary hypothesis represents a monitored indicator that has been measured and reported in relevant studies in the peer-reviewed literature.

We synthesized the evidence for and against the two necessary conditions (that habitat and fish indicators reflect effects from restoration actions) by using 11 causal criteria: strength, consistency, specificity, temporality, biological gradient, plausibility, coherence, experiment, analogy, complete exposure pathway, and predictive performance. Our final evaluation included cumulative effects assessment because restoration is occurring at multiple sites and the collective effect is important to salmon recovery. For example, the direct and indirect interactions of juvenile salmon with restored tidal wetlands can include multiple visits and effects from many restored sites.

a

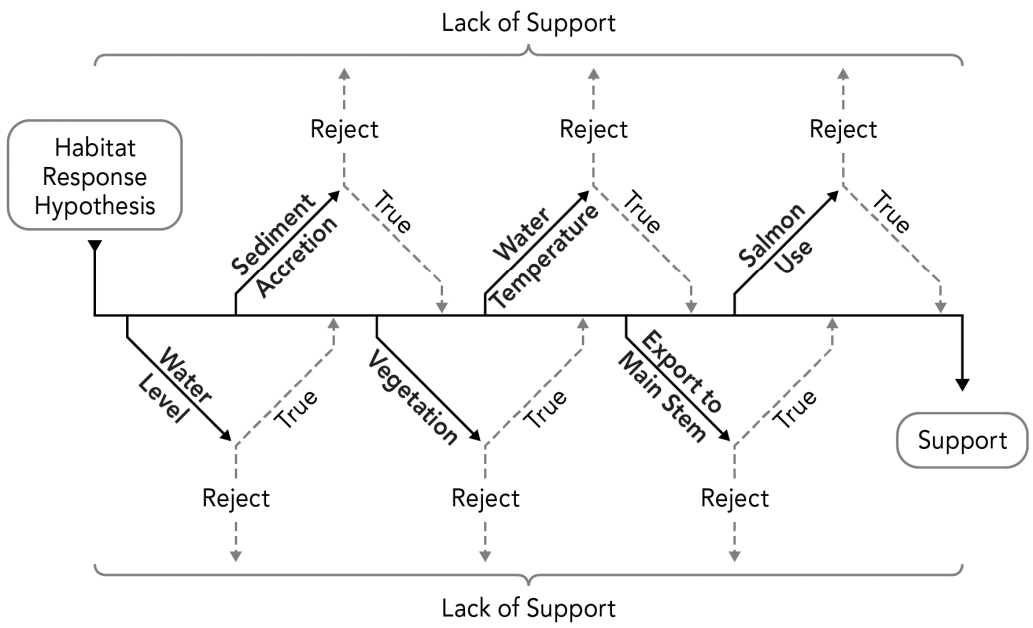

b

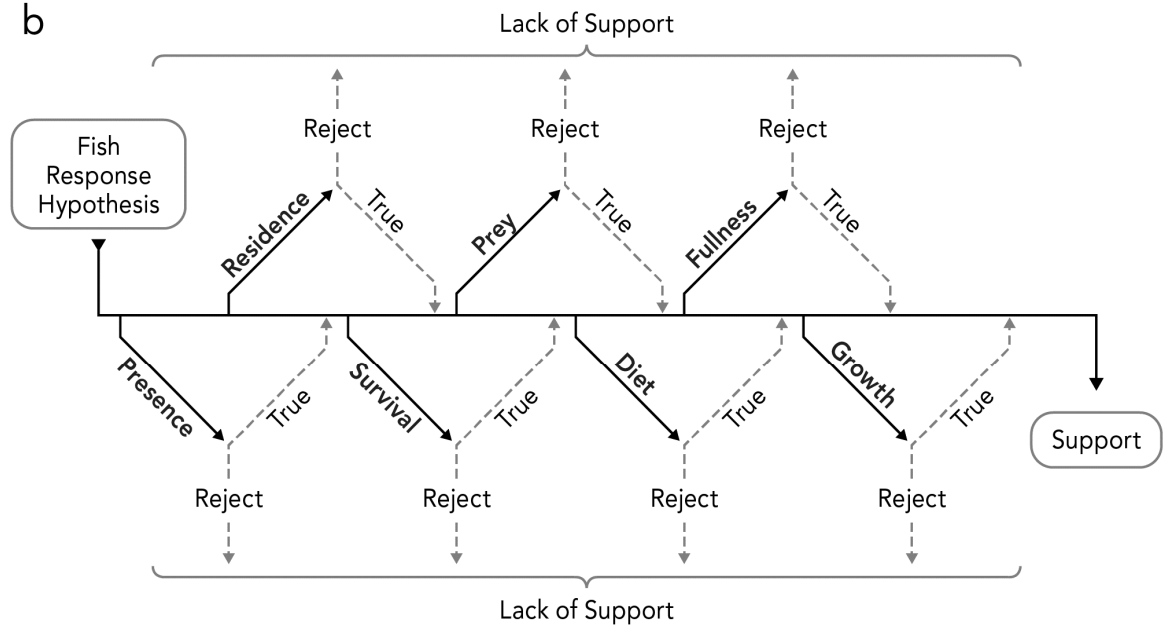

Figure ES.2. Main and ancillary hypotheses. 
In summary, the evidence-based approach we developed incorporates 7 lines of evidence, each including 1 or more analyses regarding 12 ancillary hypotheses, and the results are synthesized relative to 11 causal criteria pertaining to cause-and-effect associations (Figure ES.3).

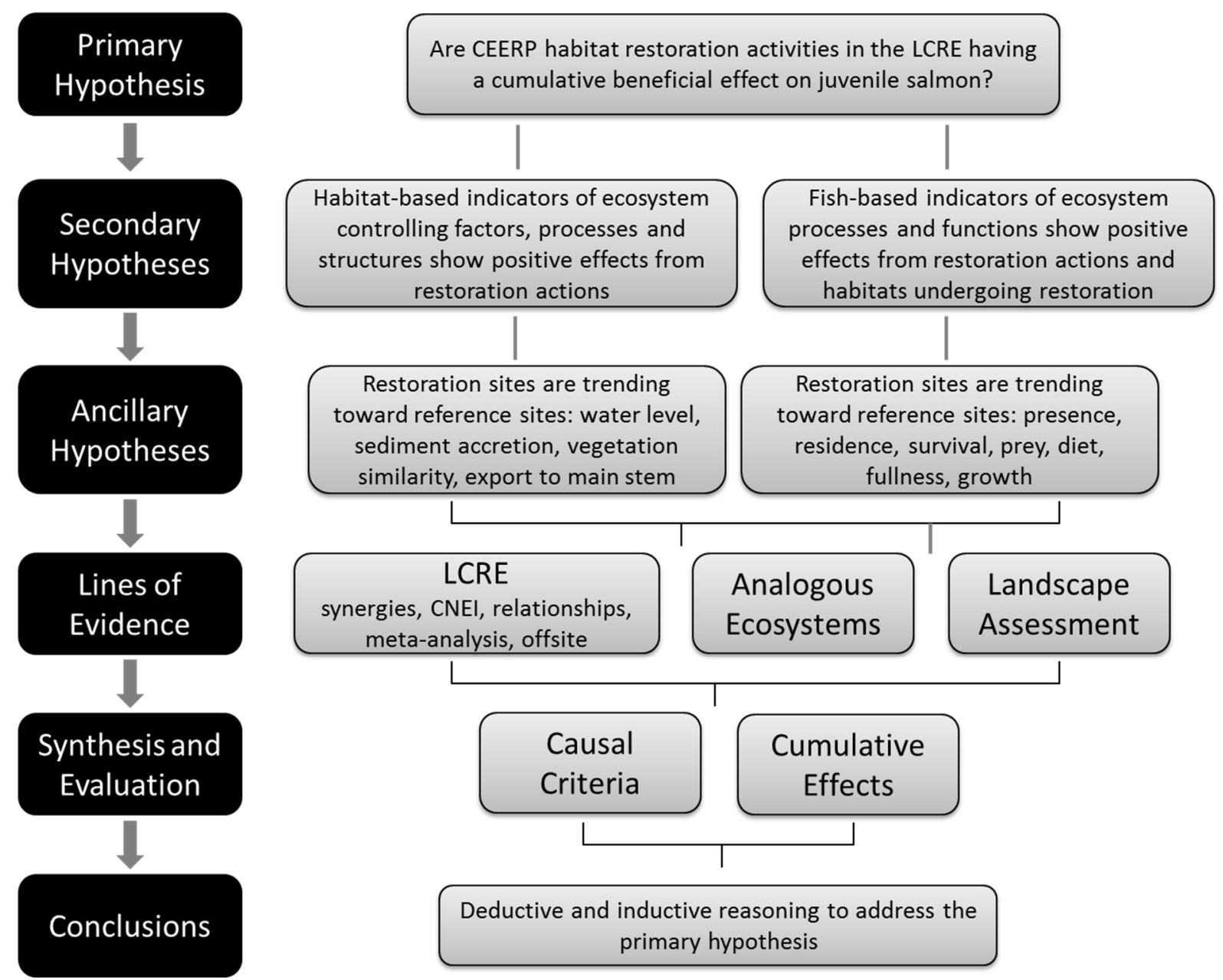

Figure ES.3. Schematic of the evidence-based approach to evaluate evidence for and against the primary hypothesis, which is the subject of this report.

\section{Key Results from Analyses of the Lines of Evidence}

Our analyses provide strong support for the concept that juvenile salmon benefit directly and indirectly from tidal wetland restoration. This idea - outlined in a conceptual model in this report - is also supported by the increasing body of evidence from the LCRE since the outset of this study in 2004, which is summarized in the "relationships" line of evidence in the report. The key results from the analyses we conducted to develop information for the lines of evidence are presented in the executive summary, each including three parts: the result, the method, and caveats or limitations. The short title for the line of evidence (Table ES-1) is in parentheses. The results are summarized in Table ES-2.

Historically Reconnected Sites ("Synergies"). At three historically reconnected sites, all the plants identified were wetland species and all other environmental characteristics measured were within the ranges of values seen at reference marshes in the LCRE except for unusually deep channels (mean $3.4 \mathrm{~m}$ 
at the mouth). The percentage of time over a year that these channels were inundated to a minimum depth of $50 \mathrm{~cm}$ at the mouth, which is an indicator of fish access potential, was relatively high: $100 \%, 99.7 \%$, and $95.4 \%$. Methods involved following standard field protocols for the LCRE to collect data at three historically reconnected sites located between rkm 22.5 and 42.6, where dikes had been breached without human action and not repaired. The purpose was to improve predictions of the long-term effects of restoration beyone the duration of our study. The marshes were at Haven Island on the Youngs River (breached $\sim 10$ years before sampling), Fort Clatsop on the Lewis and Clark River (breached $\sim 50$ years before sampling), and Karlson Island in Cathlamet Bay (breached $\sim 60$ years before sampling). The salmon sampling effort occurred in May, June, August, and September and constituted eight hauls at two sites. It is important to acknowledge, however, that historical conditions may not be adequate to predict those in the future because of trends in relative sea-level rise on the Pacific Northwestern coast.

Cumulative Effects of the Number and Spatial Pattern of Reconnections ("Synergies"). The cumulative effects of the spatial pattern of dike-breach reconnections were demonstrated in three ways. First, the incremental return of floodplain wetted area was a function of distance from the main-stem Columbia River. Second, the proportion of historical channels breached had a synergistic effect on the proportion of floodplain area inundated in response. Third, a positive effect of "space crowding" (reconnecting properties that are close to each other) was observed, whereby particulate organic matter (POM) can be produced in and transported from one restoration site into the channels of another nearby restoration site. Methods included development of a hydrodynamic model to simulate the Grays River, including the Kandoll Farm restoration site, Seal Slough, and Grays Bay, based on water-surface elevation data we collected in these water bodies. Using the model, we examined the aggregate effects of reestablishing hydrologic connections of different numbers and spatial configurations. We also captured key POM processes needed to simulate flux from the system, calibrated by aboveground herbaceous plant biomass data we collected at the restoration site. Given the spatial variability of the hydrologic regime and vegetation in the LCRE, it is important to recognize that these findings are from a tidal river tributary near the mouth of the Columbia River and a restoration site about $7-8 \mathrm{~km}$ up the tributary. Although it has been demonstrated that connectivity between restoration sites and the main-stem Columbia River affects the food-web conditions encountered by migrating salmon, the variability and extent of this connectivity throughout the LCRE are not well understood.

Flux of Particulate Organic Matter to the Main Stem Columbia River ("Synergies"). We found that approximately $52 \%$ of the mobilized POM at the Kandoll Farm restoration site would be exported to the main-stem Columbia River 7-8 km downstream annually based on the modeled year 2006-2007. The cumulative effects of marsh restoration fueled primary productivity that, because of reconnection, became available to the main-stem river ecosystem. Methods incorporated the physics-based modeling described above, which was used to estimate flux of POM from the restoration site into the Grays River and Columbia River. This research involved a single restoration site on a tidal tributary to the Columbia River, and associated biomass production and flow conditions over one particular year.

\section{Detections of Known Interior Columbia Evolutionarily Significant Units (ESUs) and Distinct} Population Segments (DPSs) in Shallow, Off-Channel Habitats in the LCRE ("Synergies"). Juvenile salmon from interior Columbia ESUs/DPSs were observed in shallow, off-channel tidal freshwater and estuarine ecosystems below Bonneville Dam. Stocks included Snake River spring/summer and fall Chinook salmon, Snake River steelhead, and mid/upper Columbia River spring Chinook salmon. Methods incorporated prior detections of juvenile salmon from interior Columbia ESUs/DPSs in shallow, off-channel habitats across the LCRE using PIT (passive integrated transponder) technology and genetic- 
stock identification, which we summarized. Fish, however, were tagged and sampled for study-specific objectives not necessarily related to this study or the use of off-channel areas in the LCRE.

Cumulative Net Ecosystem Improvement Model ("CNEI"). For representative primary and secondary productivity indicators, we estimated the maximum potential productivity increase resulting from areas restored by the CEERP between rkm 0 and 136 to be 8,529 metric tons annual herbaceous plant biomass flux, based on summer and winter measurements, and 7 billion dipterans $/ 48 \mathrm{~h}$ based on fallout trap data collected in the months of April-June. Additionally, to contextualize results of the model, we estimated that $\sim 10.8 \mathrm{~km}^{2}$ or $\sim 3.1 \%$ of restorable area had been restored by hydrologic reconnection methods under the CEERP, which represents $\sim 0.4 \%$ of the historical floodplain area including the main-stem river and rarely connected floodplain habitats. Methods involved development of a CNEI model to represent foodweb contributions of tidal wetlands, an aspect of ecological function. We multiplied areal estimates of herbaceous plant biomass flux and prey presence in reference marshes by the area of restored marshes in the LCRE. These are estimated future conditions assuming a functional wetland ecosystem, which could occur when existing early-stage restoration sites have matured, not the currently realized effects of restoration. Limitations in the spatial and temporal extent of field data prevent estimating values between rkm 137 and 235 or extrapolating beyond the period of data collection (e.g., $\leq 48 \mathrm{~h}$ ). The prey associated with communities of the invasive plant reed canary grass, which is widely dominant in the LCRE, could not be identified based on past sampling designs. Data on the areal effect of restoration were missing for 22 of 34 projects and estimated for the purpose of this model.

\section{Estuary-Wide Qualitative Meta-Analysis of Restoration Project Effectiveness ("Meta-Analysis").} Of 24 data points, 13 indicated support for the respective ancillary hypothesis, 6 indicated lack of support, and 5 were inconclusive. Methods involved the qualitative meta-analysis of restoration action effectiveness. We identified and compared seven sites with paired restoration and reference data for one fish-based and four habitat-based monitored indicators to address ancillary hypotheses that postrestoration conditions were on a trajectory toward conditions at a reference site. This comparison revealed 24 useable combinations of project site and monitored indicator, e.g., Crims Island/water-surface elevation. Sites were in the early stages of the restoration trajectory and data available permitted only qualitative assessment because action-effectiveness monitoring (and research) had been limited. Sufficient data were available to assess just one of seven ancillary hypotheses related to salmon, although some data on salmon diet, residence, prey, and growth were available for a few restoration sites in the LCRE, and they were not inconsistent with findings from the evaluation of global literature.

Offsite Benefits to Juvenile Salmon: Active Feeding in the LCRE ("Offsite"). Stomachs of Chinook salmon and steelhead near the mouth of the estuary (river kilometer ( $\mathrm{rkm}) 15, \mathrm{n}=580$ ) were substantially fuller than those of fish exiting the hydropower system (at rkm 236 and rkm 349, near Bonneville and John Day dams, $n=2,821$ ). Stomach contents of juvenile salmon sampled at rkm 15 also contained large quantities of presumed marsh-produced dipteran insects. Given rapid transit times of many juvenile salmon in the LCRE, this finding suggests that although some fish did not enter marshes, they fed on prey likely produced in marshes while moving through the main-stem river. Methods included comparative reanalysis of our previously collected stomach contents data sets from these three locations, which were collected for different studies using comparable standard methods. A stomach fullness $>24 \%$ with identifiable prey was defined as "actively feeding" to account for gastric evacuation times and transit times, and to ensure that fullness at rkm 15 represented feeding in the LCRE. This method is an integrative measurement of prior feeding, not an estimate of feeding at a particular location, and it cannot specify where in the LCRE the salmon were feeding. 
Landscape Assessment: Floodplain and Contributing Watersheds ("Landscape"). From 1996 to 2006 , trends in the watersheds contributing to the LCRE showed 1) urbanization of $48.4 \mathrm{~km}^{2}$, a $4.6 \%$ increase; 2) a net decrease in forest cover of $189.0 \mathrm{~km}^{2}$ or $2.3 \%$; and 3) a $642.7 \mathrm{~km}^{2}$ cumulative decrease in forest cover. On the floodplain, total measured urbanization was $8.3 \mathrm{~km}^{2}$ or a $2.5 \%$ increase; the net change in forest cover was $-13.3 \mathrm{~km}^{2}$; and cumulative forest cover loss was $-17.7 \mathrm{~km}^{2}$. To assess cumulative impacts, we compared this result to the result of the CNEI model, which showed that CEERP restoration on the floodplain has reconnected $\sim 10.8 \mathrm{~km}^{2}$ of land area. Our additional analyses showed that many LCRE wetlands have prograded over the last 100 years, indicating that wetland distribution responds to Columbia River flow and sea level. Thus, a shifting baseline is an important factor in the LCRE, although changes in population and climate and industrial development are outside of the control of the CEERP program. Methods included analyses of forest cover and urbanization, which are landscape indicators used to assess the condition of aquatic processes downstream. We reclassified NOAA Coastal Change Analysis Program 30-m land-cover data from 1996, 2001, and 2006 and analyzed changes in forest cover and urbanization at the floodplain and contributing watershed scales. Comparable land-cover data were not available for years more recent than 2006, so the change analysis for the decade 1996-2006 provides recent historical context for trends in the LCRE region. Cumulative loss, an indicator of disturbance, is defined as the sum of the decreases in a cover type for all analysis periods, while net change is defined as the sum of all decreases and increases in a cover type for all analysis periods.

Analysis of Literature from Analogous Ecosystems ("Global Literature”). The evidence from the global literature on restoration in tidal areas where salmon exist showed scant indication of juvenile salmon mortality, and strong support for benefits to salmon as measured by three salmon indicators: presence, prey, and diet. This support was overwhelmingly consistent, with virtually no evidence against these ancillary hypotheses. Insufficient evidence existed to evaluate four other salmon indicators in analogous systems (survival, fullness, growth and residence time). However, evidence reported by five studies supported growth of juvenile salmon, and evidence against growth was found at just one of three sites in one study. Evidence reported by four studies supported residence time, and no evidence against residence time was reported. Therefore, evidence for both growth and residence time is highly consistent. Only three studies evaluated fullness and two studies evaluated survival, and evidence was inconsistent. Methods involved an evidence-based evaluation of published papers. To be included in the body of literature we scored, a publication had to be peer-reviewed and involve a hydrologic restoration action that occurred in a tidal ecosystem where original data on salmon were collected. The searches of bibliographic databases returned 709 results of which 27 were found to possibly meet the relevance criteria based on the abstract and title; subsequent review of the main text identified 15 of the 27 that met the criteria. Based on these criteria, only eight world rivers were included in the final set: the Skjern in Denmark, the Sacramento in California, and in the Pacific Northwest the Chehalis, Duwamish, Fraser, Columbia (Grays), Puyallup, and Snohomish. We scored these using a three-part process used in evidence-based assessments in many disciplines.

\section{Summary of Lines of Evidence Results}

Each of the reported analyses that contributed to the lines of evidence, with the exception of landcover change, involved 1 or more of 12 indicators of fish or habitat response that we identified in the evidence-based approach (Figure ES-2). The number of indicators treated by each analysis was constrained by either the type of analysis, the availability of data, or both. We summarized the general effect observed on each relevant indicator, i.e., whether it was positive, negative, or ambiguous 
(Table ES-2). We assessed these results relative to the framework for the evidence-based assessment; i.e., if an indicator was expected to be evaluated by a particular analysis and could not be, then it had "insufficient data," whereas if it was not meant to be evaluated it was "not applicable." There were few or no data on response metrics for juvenile salmon, including residence time, growth, diet, prey, fullness, and survival, collected within CEERP restoration sites. Even considering the global literature review, data were lacking to evaluate salmon growth and survival. Evidence generally supported positive responses by all other indicators, except in the case of tide-gate replacement.

Table ES.2. Summary of the results of 10 analyses of habitat-based and fish-based monitored indicators. Except for the global literature analysis, the analyses are of data collected in the LCRE.

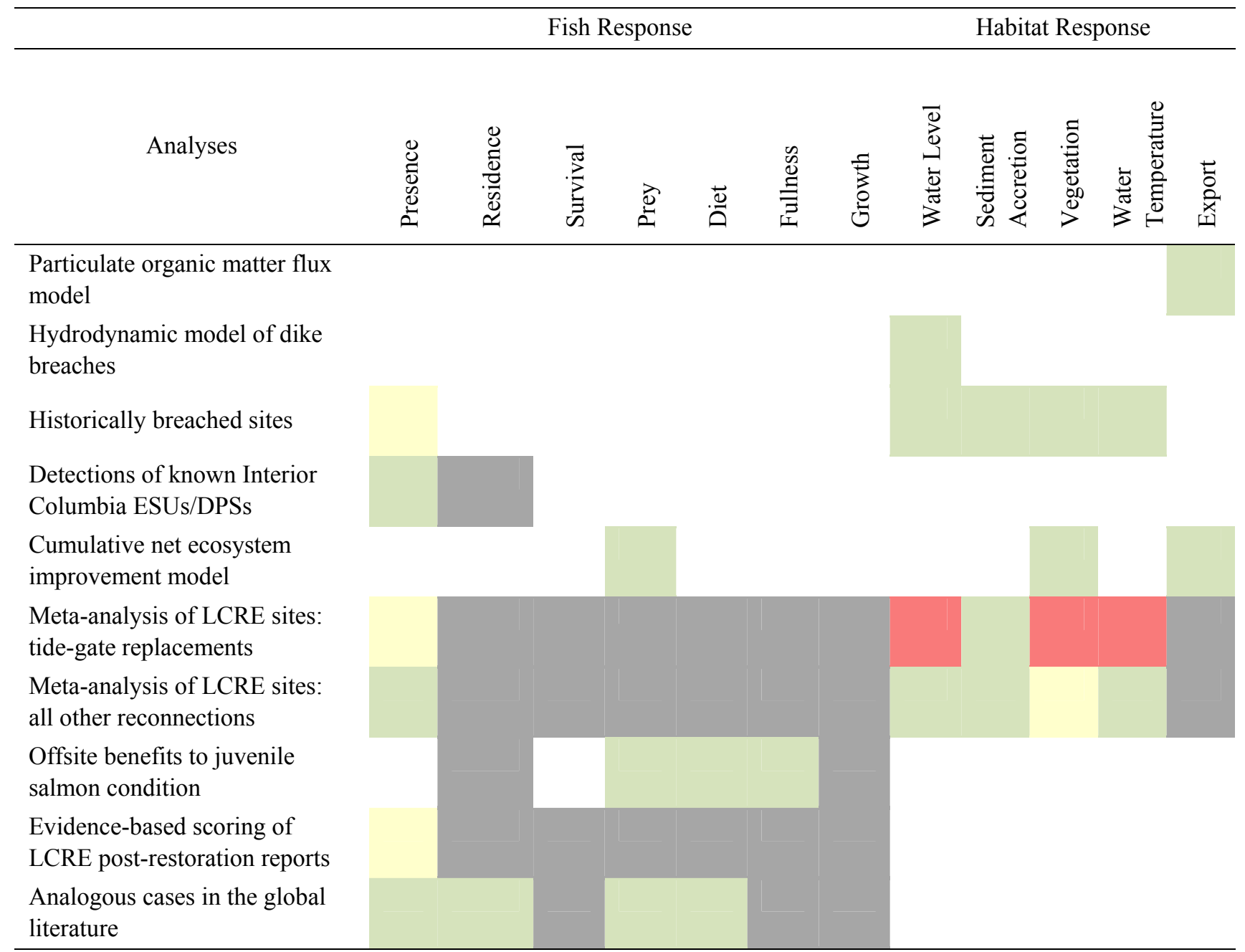

Key: Green = support; red = lack of support; yellow = inconclusive; dark gray = insufficient or no data; white $=$ not applicable, or not collected under the sampling design, for this evidence-based evaluation. 


\section{Causal Criteria Synthesis}

The evidence supported all nine of the causal criteria that were evaluated: strength and consistency of association, biological plausibility, biological gradient, specificity of association, temporality, analogy, coherence, and complete exposure pathway (Table ES-3). Two criteria (experimentation and predictive performance) were not evaluated because they have not been implemented in the CEERP; however, we suggest retaining them in the evaluative framework because in our view it would be beneficial for the adaptive management aspect of the program to include them.

Table ES.3. Summary of the causal criteria synthesis of the lines of evidence results.

\begin{tabular}{|c|c|c|c|}
\hline Causal Criterion & Short Definition & Result & Comment \\
\hline $\begin{array}{l}\text { Strength and } \\
\text { Consistency of } \\
\text { Association }^{\text {(a) }}\end{array}$ & $\begin{array}{l}\text { The magnitude of the effect of an } \\
\text { exposure relative to non-exposure } \\
\text { and its repeated observation in } \\
\text { varied times and circumstances by } \\
\text { multiple observers }\end{array}$ & Supported & $\begin{array}{l}\text { At early-stage sites, fast-response environmental } \\
\text { indicators are trending toward conditions at } \\
\text { reference sites, and on longer time scales, } \\
\text { evidence from analogous ecosystems and } \\
\text { historically reconnected sites indicates marsh and } \\
\text { salmon response to reconnection. }\end{array}$ \\
\hline $\begin{array}{l}\text { Biological } \\
\text { Plausibility }\end{array}$ & $\begin{array}{l}\text { Knowledge of the mechanism (not } \\
\text { a necessary condition of causation } \\
\text { because it depends on the state of } \\
\text { the science) }\end{array}$ & Supported & $\begin{array}{l}\text { The indirect and direct ecological relationships } \\
\text { between tidal wetlands and salmon outlined in the } \\
\text { ecosystem conceptual model are reasonable based } \\
\text { on the body of evidence from the LCRE and } \\
\text { analogous ecosystems. }\end{array}$ \\
\hline $\begin{array}{l}\text { Biological } \\
\text { Gradient }\end{array}$ & $\begin{array}{l}\text { The level of response is associated } \\
\text { with a gradient in the hypothesized } \\
\text { cause }\end{array}$ & Supported & $\begin{array}{l}\text { Hydrologic connectivity, biological fluxes, and } \\
\text { salmon-habitat access are modified on a gradient } \\
\text { by tide gates, dike breaches, dike removal, etc. }\end{array}$ \\
\hline Experimentation & $\begin{array}{l}\text { Manipulation of the hypothesized } \\
\text { cause }\end{array}$ & $\begin{array}{l}\text { Not } \\
\text { evaluated }\end{array}$ & On-the-ground experimentation has not occurred. \\
\hline $\begin{array}{l}\text { Specificity of } \\
\text { Association and } \\
\text { Temporality }\end{array}$ & $\begin{array}{l}\text { Limitation of the association to } \\
\text { particular causes and effects; the } \\
\text { effect is shown to follow the } \\
\text { hypothesized cause. }\end{array}$ & Supported & $\begin{array}{l}\text { With hydrologic reconnection, both the specificity } \\
\text { of association and its temporality are clear. }\end{array}$ \\
\hline Analogy & Comparison to similar systems & Supported & $\begin{array}{l}\text { By analogy to other similar ecosystems, results of } \\
\text { the global literature review showed strong support } \\
\text { for the salmon-response hypothesis based on four } \\
\text { indicator categories: salmon presence, residence, } \\
\text { prey, and diet. }\end{array}$ \\
\hline Coherence & $\begin{array}{l}\text { Lack of serious conflict between } \\
\text { the cause-and-effect interpretation } \\
\text { and known facts about the case } \\
\text { under consideration }\end{array}$ & Supported & $\begin{array}{l}\text { We found no conflict with the state of the science } \\
\text { in concluding that hydrologic reconnection of } \\
\text { tidal floodplain habitats with a main-stem river } \\
\text { has a beneficial effect on juvenile salmon. }\end{array}$ \\
\hline $\begin{array}{l}\text { Complete } \\
\text { Exposure } \\
\text { Pathway }\end{array}$ & $\begin{array}{l}\text { Ability of the cause to physically } \\
\text { reach the biological or ecological } \\
\text { receptor }\end{array}$ & Supported & $\begin{array}{l}\text { The evidence and known ecosystem processes and } \\
\text { functions indicate viable exposure pathways via } \\
\text { hydrologic connectivity to realize benefits to } \\
\text { juvenile salmon from habitat restoration. }\end{array}$ \\
\hline $\begin{array}{l}\text { Predictive } \\
\text { Performance }\end{array}$ & $\begin{array}{l}\text { Ability to accurately and precisely } \\
\text { predict restoration outcomes }\end{array}$ & $\begin{array}{l}\text { Not } \\
\text { evaluated }\end{array}$ & $\begin{array}{l}\text { The ability to correctly predict restoration } \\
\text { outcomes cannot be evaluated with existing } \\
\text { action-effectiveness monitoring data. }\end{array}$ \\
\hline
\end{tabular}

(a) Two causal criteria are included in these rows. 


\section{Future Considerations}

We recommend that a full-scale assessment of this type be conducted again after the body of evidence has substantially increased. The LCRE post-restoration monitoring data set should be substantially larger, in particular the fish-based indicators residence time, survival, prey, diet, fullness, and growth at restoration and reference sites. In the meantime, some lines of evidence we examined would be conducive to systematic tracking through the CEERP adaptive management program's annual synthesis memorandum, as new evidence emerges. For instance, the CNEI model of prey and plant biomass flux could be expanded in terms of habitat types, spatial coverage, and temporal variability as new data are reported from the CEERP monitoring program. Most importantly, ecosystem and salmon monitoring data from restoration projects throughout the LCRE could be collected and analyzed to support a rigorous, quantitative meta-analysis of restoration action effectiveness.

For future assessments of this type, some refinements to the lines of evidence could be helpful. We recommend strengthening the assessment of offsite benefits to juvenile salmon. This could be facilitated by coordinating sampling of juvenile salmon stomach contents at the lower dams and near the mouth of the Columbia River under one sampling design, and sampling at points in between to identify reaches in which salmon feed and associations with ecosystem restoration. Additionally, the assessment of direct benefits could be substantially improved by the collection and analysis of measurements of salmon residence time and growth at restoration and reference sites, particularly because data in the literature from analogous ecosystems suggested that growth occurs but were not conclusive in this regard.

It would also be beneficial to develop research based on the lines of evidence. Investigations in three areas appear to be particularly relevant to the evidence-based approach for ESA-listed salmon: 1) stockspecific migration patterns for interior Columbia ESUs/DPSs in the LCRE; 2) the variability of POM flux with hydrological regime, salmon migration timing, connectivity, and distance from the main-stem river; and 3) effects of invasive plant reed canary grass on primary and secondary production and fish use of tidal wetland habitat.

\section{Conclusion}

We concluded that all five lines of evidence from the LCRE indicated positive habitat-based and fishbased responses to the restoration performed under the CEERP, although tide-gate replacements on small sloughs were an exception. We have conducted analyses incorporated in seven lines of evidence and synthesized the results relative to eleven criteria pertaining to cause-and-effect associations. Data from five lines of evidence in the LCRE provided local confirmation of evidence in the literature for analogous ecosystems that tidal river habitats provide forage for juvenile salmon. Our analyses suggested that hydrologic reconnections restore access for fish to move into a site to find prey produced there. Reconnections also restore the potential for the flux of prey from the site to the main-stem river, where our data show that they are consumed by salmon. We infer that LCRE ecosystem restoration supports increased juvenile salmon growth and enhanced fitness (condition), thereby potentially improving survival rates during the early ocean stage. However, countervailing influences are also present. The land-cover change analysis of contributing watersheds and the floodplain from 1996 to 2006 indicated ongoing cumulative impacts from urbanization and decreased forest cover, which although outside of the control of the CEERP, could impair the development of resilient ecosystems on the river floodplain. 
We conducted this assessment at an early stage of the CEERP; relatively few of the planned restoration projects had been implemented, relatively little post-restoration data were available, and the projects that had been implemented were at early phases of an ecosystem restoration trajectory. Thus, the meta-analysis of restoration monitoring data was necessarily qualitative not quantitative, and the assessment incorporated and relied upon other lines of evidence based on analyses of data from within and outside of the study region. Several data sets (e.g., dike breaches versus wetted area, flood-driven export of organic matter, salmon presence in wetlands, rapid early accretion rates) illustrated nonlinear, synergistic, and/or pulsed characteristics of hydrologic reconnection. This suggests that the cumulative effects of restoration are complex in space and time, and prediction of the trajectories of development of restoring systems and their benefits to juvenile salmon must consider this mix of linear and nonlinear aspects. All lines of evidence, while robust, could be strengthened. This is particularly important for lines of evidence that relied upon data from small areas of the LCRE, which we extrapolated to larger areas. The LCRE is a dynamic region with high spatial variability in ecosystem processes and structures, making such extrapolations problematic but necessary in the absence of better data.

Based on the evidence, we concluded that the primary hypothesis was supported, i.e., that the habitat restoration activities in the LCRE are likely having a cumulative beneficial effect on juvenile salmon, including interior basin salmon. Salmon in restored wetland areas are directly affected by the habitat structures and processes. Salmon actively transiting main-stem river habitats are indirectly affected through the food web by allochthonous materials from floodplain wetlands. The beneficial effect of restoring tidal wetlands is expected to increase over time as existing restoration projects mature and new ones are implemented. 



\section{Acknowledgements}

We appreciate the financial support of the U.S. Army Corps of Engineers, Portland District. Data collection by L Weitkamp was funded by the NOAA Fisheries, Northwest Fisheries Science Center. We are grateful to B Ebberts for originating and establishing the multi-year study that is culminating with the evidence-based evaluation reported herein, C Studebaker for coordinating completion of the research, and principal investigators $\mathrm{R}$ Thom and $\mathrm{C}$ Roegner for their leadership. We especially thank A Cameron, A Coleman, V Cullinan, E Dawley, B Ebberts, J Johnson, L Johnson, K MacNeale, K Marcoe, R McNatt, D Putman, M Russell, N Sather, J Skalski, and K Sobocinski for their contributions to this research over the years, as well as the many scientists who helped in the field and laboratory. 



\section{Acronyms and Abbreviations}

7DADmax

ASTM

BARI

BARR

$\mathrm{BC}$

CA

CEERP

CEQ

$\mathrm{C}: \mathrm{N}$

CNEI

CPUE

$\mathrm{CV}$

DO

DPS

ELHD

ESA

ESU

ET

EP

FOT

GIS

GSI

$\mathrm{h}$

ISAB

ISI

$\mathrm{KF}$

LCRE

MT

NOAA

NWR

PIT

POM

TOC

USACE 7-day running average of the daily maximum

ASTM International, formerly American Society for Testing and Materials

before-after-reference-impact

before-after-reference-restoration

benthic core

catchment area

Columbia Estuary Ecosystem Restoration Program

Council on Environmental Quality

carbon to nitrogen ratio

cumulative net ecosystem improvement

catch per unit effort

coefficient of variation

dissolved oxygen

Distinct Population Segment

early life history diversity

Endangered Species Act

Evolutionarily Significant Unit

emergent trap

Lower Columbia Estuary Partnership

fallout trap

geographic information system(s)

genetic stock identity

hour(s)

Independent Scientific Advisory Board

Institute for Scientific Information

Kandoll Farm

lower Columbia River and estuary

metric ton(s)

National Oceanic and Atmospheric Administration

National Wildlife Refuge

passive integrated transponder

particulate organic matter

total organic carbon

U.S. Army Corps of Engineers 



\section{Contents}

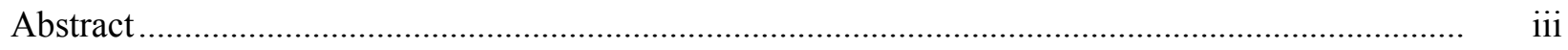

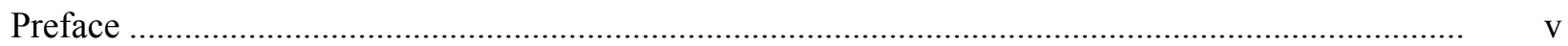

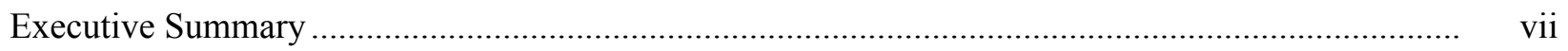

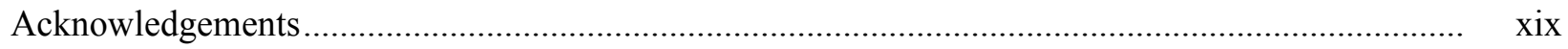

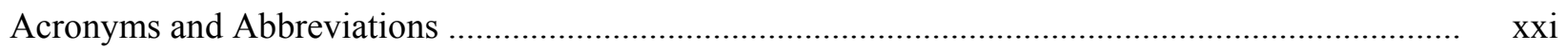

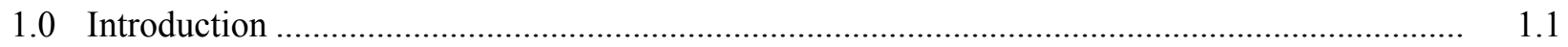

1.1 Endangered Salmon in the Lower Columbia River and Estuary ...................................... 1.1

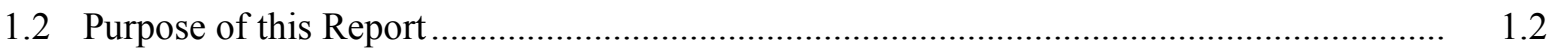

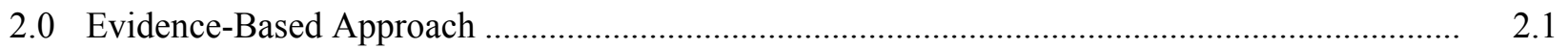

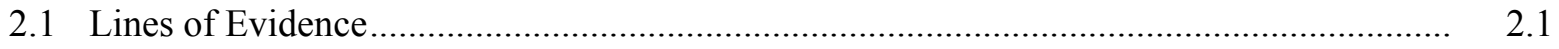

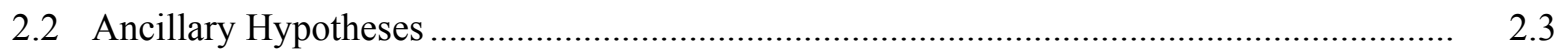

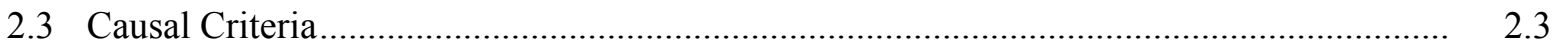

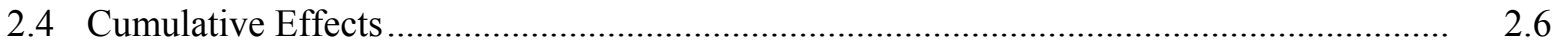

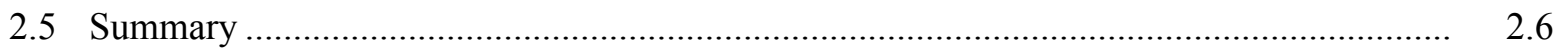

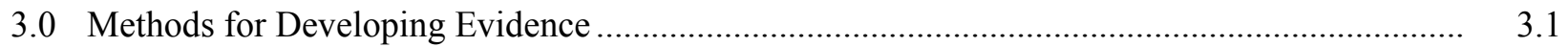

3.1 Analysis of Evidence from the Lower Columbia River and Estuary ............................... 3.2

3.1.1 Spatial and Temporal Synergies Among Restoration Projects............................... 3.2

3.1.2 An Additive Model of Net Ecosystem Improvement............................................ 3.3

3.1.3 Estuary-Wide Qualitative Meta-Analysis of Restoration Project Effectiveness ....... 3.5

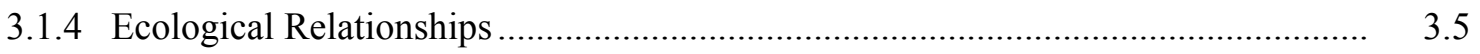

3.1.5 Offsite Benefits to Juvenile Salmon ..................................................................... 3.6

3.2 Analysis of Literature from Analogous Ecosystems ...................................................... 3.7

3.3 Landscape Assessment: Floodplain and Contributing Watersheds ................................. 3.10

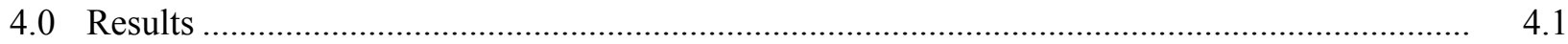

4.1 Analysis of Evidence from the Lower Columbia River and Estuary ................................ 4.1

4.1.1 Spatial and Temporal Synergies Among Restoration Projects................................ 4.1

4.1.2 An Additive Model of Net Ecosystem Improvement............................................... 4.3

4.1.3 Estuary-Wide Qualitative Meta-Analysis of Restoration Project Performance ........ 4.6

4.1.4 Ecological Relationships .................................................................................... 4.7

4.1.5 Offsite Benefits to Juvenile Salmon................................................................ 4.8

4.2 Analysis of Literature from Analogous Ecosystems ....................................................... 4.10

4.3 Landscape Assessment: Contributing Watersheds ..................................................... 4.13

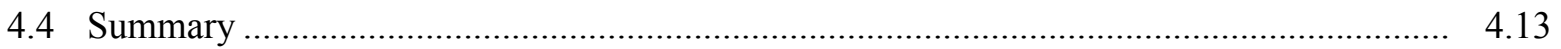

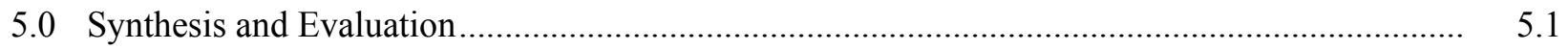

5.1 Causal Criteria Synthesis ....................................................................................... 5.2

5.1.1 Strength and Consistency of Association ....................................................... 5.2

5.1 .2 Biological Plausibility .................................................................................. 5.3 


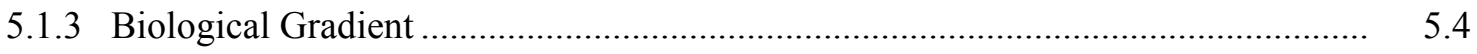

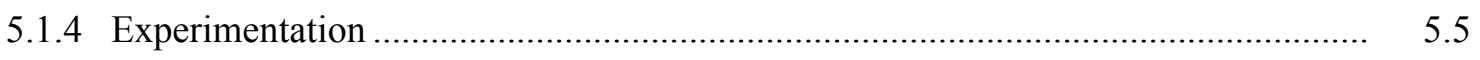

5.1.5 Specificity of Association and Temporality ….................................................... 5.5

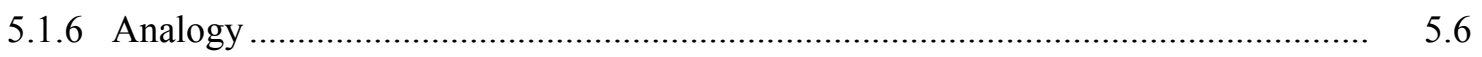

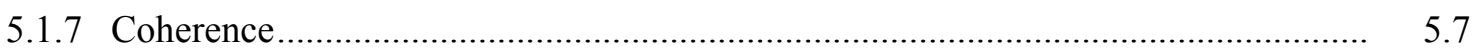

5.1.8 Complete Exposure Pathway ........................................................................... 5.7

5.1.9 Predictive Performance .................................................................................... 5.7

5.1.10 Summary of Causal Criteria Synthesis.............................................................. 5.8

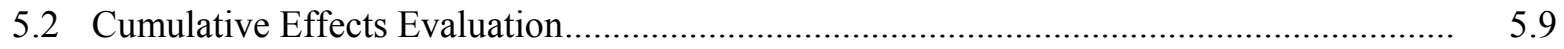

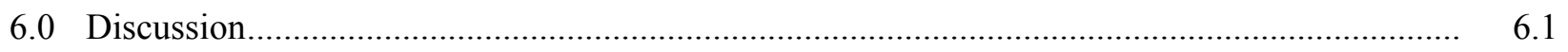

6.1 Juvenile Salmon and Ecosystem Restoration in the LCRE ............................................ 6.1

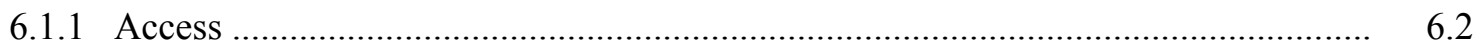

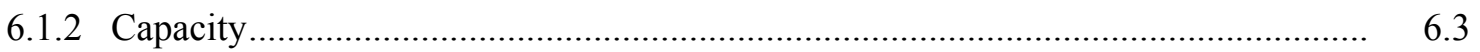

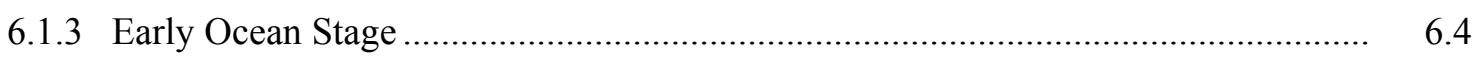

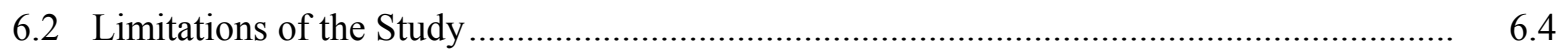

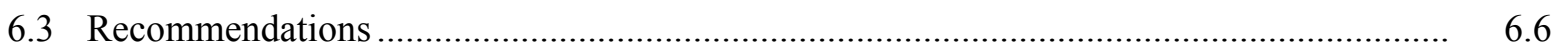

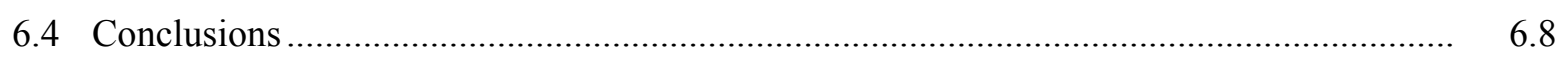

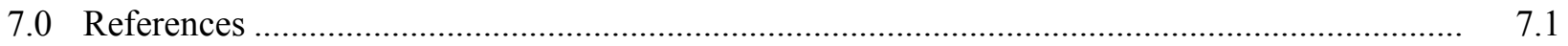




\section{Figures}

1 Lower Columbia River and Estuary study area

2 Conceptual model of the potential benefits of estuarine habitat restoration for juvenile salmon showing the general model and detail of trophic and physical pathways affecting salmon

3 Secondary and ancillary hypotheses .

4 Schematic of the evidence-based approach to evaluate evidence for and against the primary hypothesis, which is the subject of this report.

5 Sampling locations designated by line of evidence.

6 Percentage of juvenile salmon actively feeding in the Columbia River measured near John Day Dam, Bonneville Lock and Dam, and river kilometer 15 in the estuary....

\section{Tables}

1 Description of the seven lines of evidence evaluated in this study

2 Definition and use of causal criteria in this study.

3 Within-LCRE detections of PIT-tagged fish and estimates of genetic stock identity for juvenile salmon and steelhead known to have originated in the interior Columbia River basin, including the Snake River

4 Salmon prey data from studies between 2002 and 2010 and aboveground herbaceous plant biomass data from 1980 and 2011.

5 Cumulative net ecosystem improvement model of the effects of increased restored area on primary and secondary productivity

6 Qualitative meta-analysis based on comparisons between paired restoration and reference sites for five response metrics

7 Percentage of juvenile salmon actively feeding, average stomach fullness, and percentage wet weight of identifiable prey made up of Americorophium and insects.

8 Causal criteria scoring of the literature: analogous cases, tidal rivers, and LCRE

9. Summary of the results of 10 analyses of habitat-based and fish-based monitored indicators. Except for the global literature analysis, the analyses are of data collected in the LCRE.

10 Summary of the causal criteria synthesis of the lines of evidence results. 



\subsection{Introduction}

Great rivers and estuaries are among the most threatened ecosystems of the world, and pressure for services they provide, such as irrigation, transportation, hydroelectric power production, and fisheries, is continually increasing. In the U.S.A., billions of dollars have been invested in the restoration of these ecosystems, largely driven by the Endangered Species Act (ESA). Despite this, at geographic scales from the region to the site level, and from federal to local governmental levels, numerous studies have found these restoration programs wanting in effectiveness monitoring and ultimately in justification of the costs expended (Roni et al. 2002; Bernhardt et al. 2005; Borja et al. 2010). On balance, at the start of a recovery program, the state of the science regarding threatened or endangered species frequently is insufficient for management decisions (Tear et al. 1995). Yet when the species' existence is in peril and stressors have been identified to the extent possible, there is rarely time to wait for establishment of the science needed to confirm primary agents of recovery before undertaking protective actions.

\subsection{Endangered Salmon in the Lower Columbia River and Estuary}

In one such case, the ESA listing of 13 Pacific salmon and steelhead stocks (hereafter collectively referred to as "salmon") in the Columbia River basin has stimulated tidal wetland restoration in the lower 235 kilometers of the Columbia River and estuary (LCRE) (Figure 1). Within the 724,025 $\mathrm{km}^{2}$ Columbia basin, at least part of the populations of most of the 13 ESA-listed stocks originates in the interior basin (NMFS 2008), which by definition includes the basin above Bonneville Dam. Yet all 13 stocks migrate through the LCRE to the Pacific Ocean as juveniles, a critical and potentially limiting stage in their life cycle (Kareiva et al. 2000), spending on the order of days to months in the region. Since the late 1800s, a high percentage of shallow-water habitats in the LCRE have been lost through flow alterations and diking (Thomas 1983; Kukulka and Jay 2003a, b). Therefore, as mitigation for the impacts of the Federal Columbia River Power System, a restoration effort began in earnest in 2000, involved removing barriers on the river floodplain in rural areas of Washington and Oregon. Its primary purpose is to benefit juvenile salmon by restoring habitats in the LCRE, one of the most extensive wetland complexes on the West Coast (Callaway et al. 2012).

By regulation (NMFS 2008), the effect of the federal Columbia Estuary Ecosystem Restoration Program (CEERP) on ESA-listed salmon stocks must be periodically evaluated, which is the purpose of this report. At the outset of this assessment development process in 2004, data associating habitat restoration in the LCRE and salmon were unavailable because the restoration effort was in its infancy. Furthermore, our initial review of the global literature, including sources outside the LCRE, found evidence of salmon-estuarine habitat relationships but sparse literature about the central question of the association between estuarine habitat restoration and the recovery of the ESA-listed species: Chinook salmon (Oncorhynchus tshawytscha), chum salmon (O. keta), coho salmon (O. kisutch), sockeye salmon (O. nerka), and steelhead (O. mykiss) (Diefenderfer et al. 2005; Diefenderfer 2007; Diefenderfer et al. 2011).

Linking changes in the quality and landscape pattern of tidal wetlands to salmon recovery is a complex problem for several reasons. First, floodplains and estuaries are some of the most dynamic and spatially variable ecosystems known, and this is a particularly large $\left(1,468 \mathrm{~km}^{2}\right)$ floodplain study area with extremely dynamic tidal-fluvial hydrology and widely varying vegetative cover types (Borde et al. 2012a, b; Jay et al. In Revision). Second, juvenile salmon interact with these habitats during early life 
stages from the fry to the smolt, a period of the life history during which spatial and temporal components of estuarine and tidal freshwater habitat use vary widely by the species, stock, and individual (Roegner et al. 2012). Third, tagging technologies to date have been inadequate to capture the complex interactions of these habitats and salmon life history patterns. Fourth, habitat restoration actions take several forms (e.g., dike breaching, tide-gate or culvert installation) that have different effects and varying degrees of success, and the full development of ecosystem structure and function at restored sites depends on ecosystem processes and may be achieved only after multiple years (Simenstad and Thom 1996; Thom 1997; Pickett et al. 2001; Thom et al. 2002; Levings 2004). For these reasons, we concluded that direct detection of the effect of LCRE tidal wetland restoration on listed salmon populations would be problematic. However, we observed that some evidence was suitable to infer the effects of restoration on juvenile salmon and more could be developed.

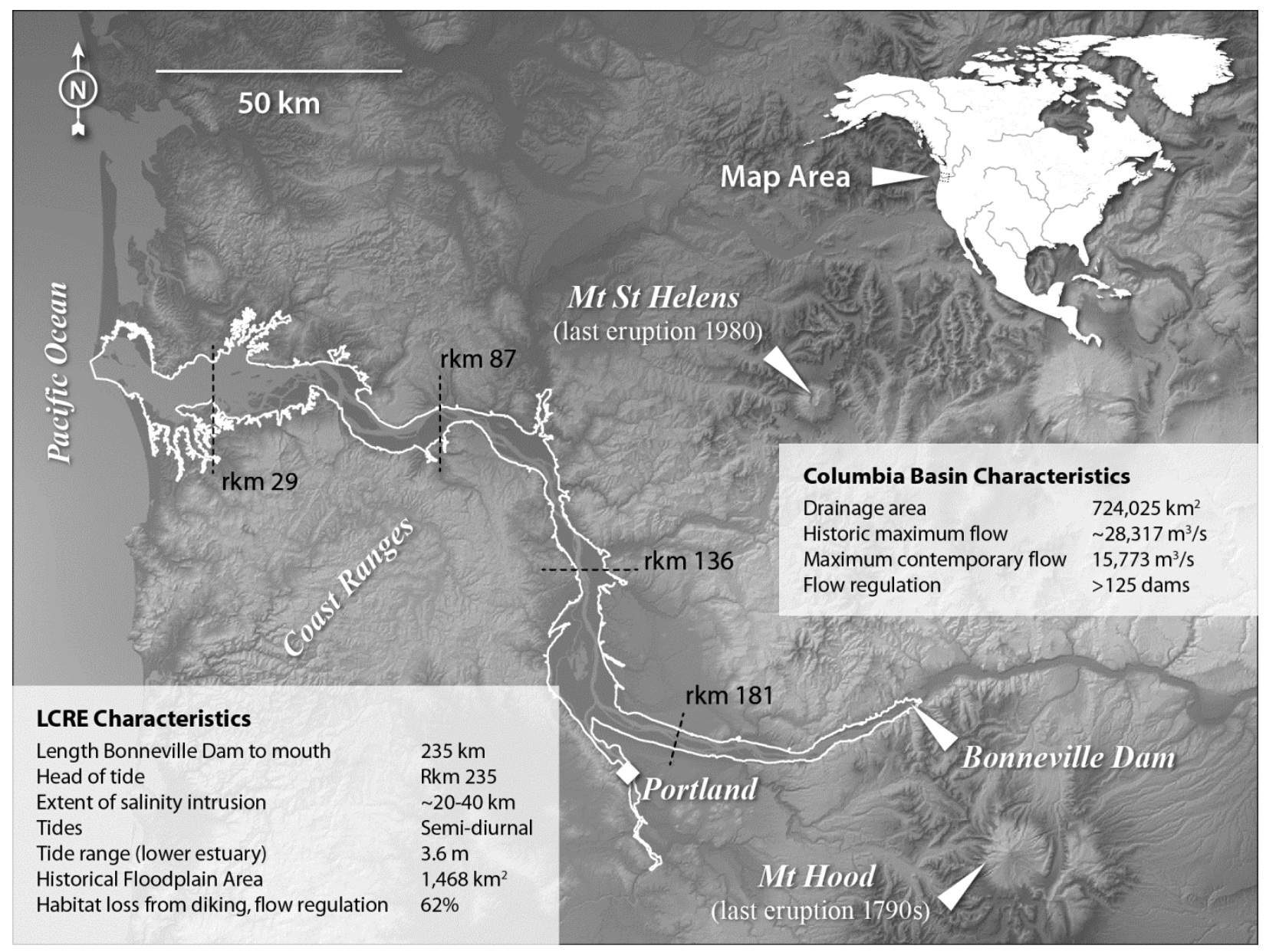

Figure 1. Lower Columbia River and Estuary (LCRE) study area. Historical floodplain perimeter (in white) courtesy of JE O'Connor, U.S. Geological Survey. Zonation of hydrology and vegetation (dashed lines) from Jay et al. (In Review).

\subsection{Purpose of this Report}

To address this problem, we designed a formal approach to evaluate the accumulated evidence of the outcomes of the CEERP restoration program and contribute new understandings for adaptive management of the LCRE ecosystem restoration effort (Diefenderfer et al. 2011). The approach incorporates seven 
lines of evidence and uses causal criteria (Hill 1965) in two ways: first, in a review of the literature, and second, as the basis for synthesizing the lines of evidence. We developed a primary hypothesis: the habitat restoration activities in the LCRE have a cumulative beneficial effect on juvenile salmon. This hypothesis contains two elements that must be true for the hypothesis to be supported, and we call these necessary conditions "secondary hypotheses": 1) habitat-based indicators of ecosystem controlling factors, processes, and structures show positive effects from restoration actions, and 2) fish-based indicators of ecosystem processes and functions show positive effects from restoration actions and habitats undergoing restoration.

We further developed a set of testable ancillary hypotheses. Development of these hypotheses was rooted in an understanding of the ecosystem, represented by a conceptual model that we developed early in this effort (Thom et al. 2004; Roegner et al. 2009). On floodplains, the physical environment sets the stage for primary productivity, which fuels secondary productivity in the form of salmon prey and salmon (Welcomme 1979). We have refined the model as our understanding of critical linkages relative to juvenile salmon has increased. It focuses on three areas: salmon-habitat opportunity, habitat capacity, and realized function (Simenstad et al. 2000; Simenstad and Cordell 2000). The current model (Figure 2) illustrates the opportunity for salmon to access tidal wetlands (e.g., wetted area and depth distribution) and the capacity of those sites to support them (e.g., water temperature and prey). In addition to these direct habitat functions provided by restored tidal wetlands to fish that access the sites, the model represents a subset of functions that are in effect exported from the sites as allochthonous contributions to the food web of the main-stem river (e.g., vegetative organic matter and salmon prey). Salmon-habitat function (e.g., growth) can occur through two pathways - direct habitat access or indirect access to exported materials in the main-stem river. These materials affect the habitat functions of the main-stem LCRE used by actively migrating juvenile salmon.

The purpose of this paper is to perform an early-stage, evidence-based assessment using a formal reasoning method to infer whether the restoration of habitat in the LCRE through hydrologic reconnection with the main-stem river (e.g., dike breaching, tide-gate installation, channel excavation) is having a beneficial effect on juvenile salmon and steelhead, especially the 13 listed salmon and steelhead stocks in the Columbia basin. Here, "early-stage" refers to the duration of the habitat restorative process, which will take decades. Interim results we have published during an 8-year study are incorporated by reference and synthesized with a large body of unpublished research led by multiple investigators.

The specific objectives of this report are to 1) analyze research and monitoring data from the LCRE for five lines of evidence; 2) score evidence in the literature from analogous ecosystems worldwide; 3 ) assess trends in landscape condition; 4) synthesize the results of these analyses using causal criteria; 5) evaluate the cumulative effects of ecosystem restoration on juvenile salmon; and 6) develop recommendations for adaptive management of the CEERP. In our view, this framework is transferrable to other ecosystem restoration programs for threatened and endangered species with adjustments as needed for species' life history and habitat relationships. In a larger sense, our intent in this report is to argue for an evidence-based science of restoration ecology. 


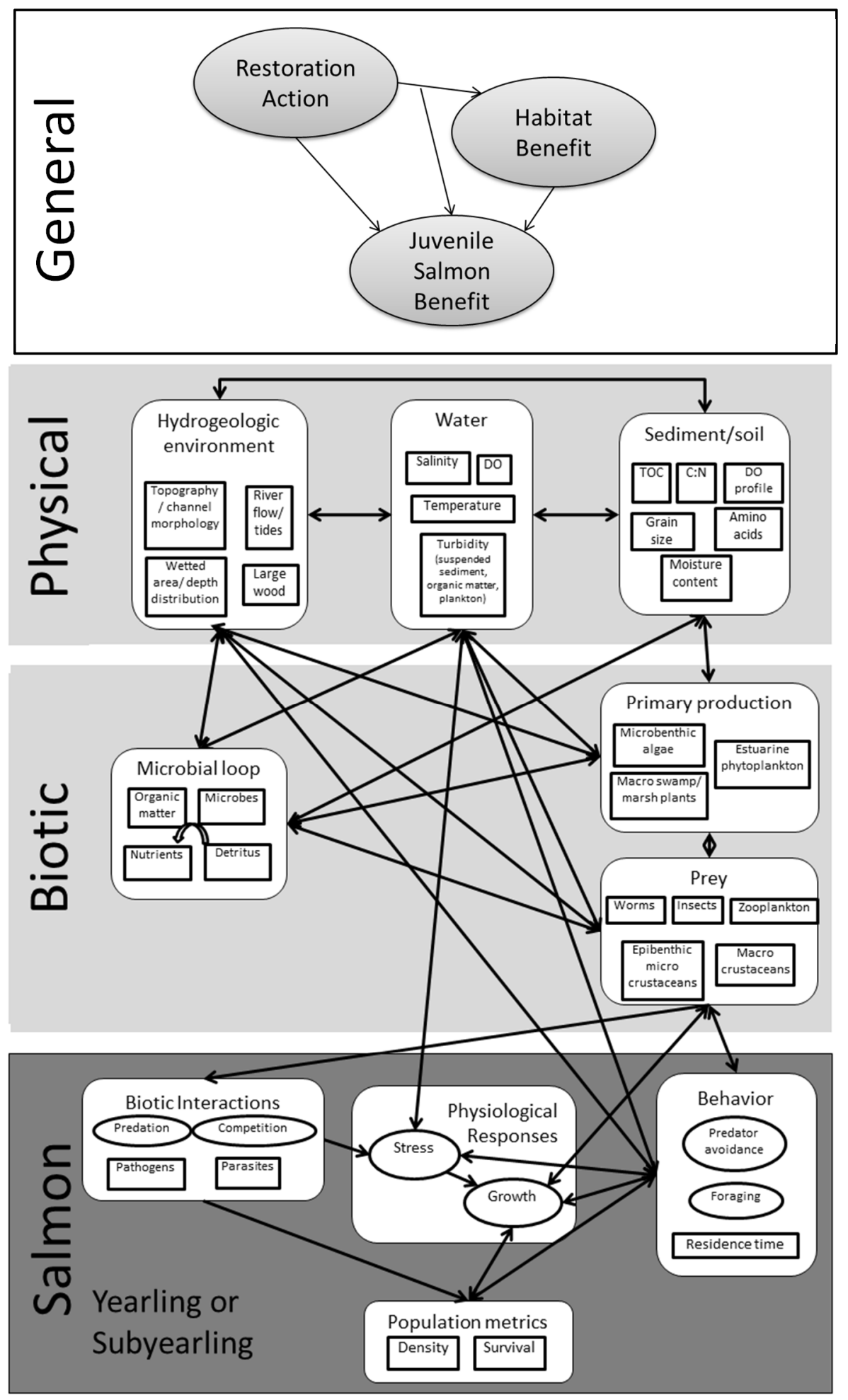

Figure 2. Conceptual model of the potential benefits of estuarine habitat restoration for juvenile salmon showing the general model (above) and detail of trophic and physical pathways affecting salmon (below). 


\subsection{Evidence-Based Approach}

The primary focus of our approach is on the considerations for determining when a cause-and-effect interpretation of an association is acceptable. These considerations were described in the sciences of occupational health and epidemiology by Hill (1965) and by the United States Department of Health, Education, and Welfare (USDHEW 1964), and have later come to be called "Hill's criteria," the "Bradford Hill criteria," or "causal criteria" (Weed 1997; Downes et al. 2002). Evaluation of evidence using these criteria has migrated from an origin in the health sciences some 50 years ago to fields including ecoepidemiology (Fox 1991), ecotoxicology and stressors in aquatic systems (Dorward-King et al. 2001; Suter et al. 2002, 2010), and recently freshwater and wetlands ecology (Greet et al. 2011; Webb et al. 2012). We use a total of 11 aspects of the association between variables to reason from observations to conclusions: strength, consistency, specificity, temporality, biological gradient, plausibility, coherence, experiment, analogy, complete exposure pathway, and predictive performance (Hill 1965; Dorward-King et al. 2001).

As currently framed in other scientific disciplines, the application of such criteria solely concerns the systematic review of a published body of evidence to score evidence by the strength of individual study designs. In contrast, our approach was designed for ecological restoration and responds to the imperative to act quickly to begin habitat restoration and avoid jeopardizing the existence of these economically and culturally critical species (Diefenderfer et al. 2011). Thus, in addition to the systematic review of global literature, our approach incorporates lines of evidence based on unpublished data from the LCRE gathered concurrently with implementation of on-the-ground restoration. Implementation, in this case, consists of a multi-agency, multi-project ecosystem restoration program, CEERP, scheduled to continue to at least 2018.

\subsection{Lines of Evidence}

Five lines of evidence from the LCRE are augmented by one at the landscape scale and one from analogous systems for a total of seven lines of evidence (Table 1). The lines of evidence from the LCRE are 1) analyses of spatial and temporal synergies among projects, 2) a cumulative net ecosystem improvement model, 3) identification of ecological relationships at the site scale, 4) qualitative metaanalysis of restoration project effectiveness, and 5) assessment of offsite benefits to juvenile salmon. A sixth line of evidence represents conditions of the landscape within which the LCRE is nested and the seventh is the review and scoring of global literature. We use the term "lines" of evidence because they are not inherently ranked like levels. These lines of evidence are deliberately constructed to be able to capture both additive and synergistic cumulative ecosystem responses to the restoration actions taken at multiple sites, and to incorporate the evolving understanding of the LCRE ecosystem expected for periodic future assessments (Diefenderfer et al. 2011). Collectively, the evidence is intended to represent the temporal dynamics and spatial variability of the ecosystem and its landscape, as well as the great diversity of the salmon in their habitat interactions.

With this approach, the systematic literature review that is the core of evidence-based assessments becomes just one of seven lines of evidence, which are collectively assessed using critical thinking strategies (Glaser 1941) and in particular, Hill's criteria, from a cumulative effects perspective (President's Council on Environmental Quality [CEQ] 1997). This is novel in the literature of evidence-based assessment. Furthermore, because we apply this approach to an ecosystem restoration problem, the 
Table 1. Description of the seven lines of evidence evaluated in this study.

\begin{tabular}{|c|c|c|c|}
\hline Line of Evidence ${ }^{(a)}$ & Description & $\begin{array}{l}\text { Cumulative Effects } \\
\text { Category }^{(b)}\end{array}$ & $\begin{array}{l}\text { General Methods } \\
\text { (Analyses) }\end{array}$ \\
\hline \multicolumn{4}{|c|}{ Evidence from the Lower Columbia River and Estuary (LCRE) Floodplain } \\
\hline $\begin{array}{l}1 \text { Spatial and temporal } \\
\text { synergies } \\
\text { ("synergies") }\end{array}$ & $\begin{array}{l}\text { Interaction among multiple } \\
\text { effects to produce an outcome } \\
\text { that is greater or less than the } \\
\text { sum of the individual effects }\end{array}$ & $\begin{array}{l}\text { Synergistic, space } \\
\text { crowding, indirect, } \\
\text { time lags, cross- } \\
\text { boundary, nonlinear, } \\
\text { compounding }\end{array}$ & $\begin{array}{l}\text { Analysis of field data from } \\
\text { historically reconnected sites, } \\
\text { hydrodynamic modeling of } \\
\text { inundation patterns and of } \\
\text { particulate organic matter } \\
\text { transport; detections of interior } \\
\text { Columbia salmon in the LCRE }\end{array}$ \\
\hline $\begin{array}{l}2 \text { Cumulative net } \\
\text { ecosystem } \\
\text { improvement } \\
\text { ("CNEI") }\end{array}$ & $\begin{array}{l}\text { Change in ecological function } \\
\text { from the areas restored across } \\
\text { multiple sites with various } \\
\text { probabilities of success }\end{array}$ & $\begin{array}{l}\text { Landscape, } \\
\text { compounding }\end{array}$ & $\begin{array}{l}\text { Additive modeling of change in } \\
\text { function, restored area, and } \\
\text { probability of success }\end{array}$ \\
\hline $\begin{array}{l}3 \text { Site-scale ecological } \\
\text { relationships } \\
\text { ("relationships") }\end{array}$ & $\begin{array}{l}\text { Cause/effect associations } \\
\text { between one or more } \\
\text { independent variables and a } \\
\text { response (dependent) variable }\end{array}$ & $\begin{array}{l}\text { Indirect, time lags, } \\
\text { compounding }\end{array}$ & $\begin{array}{l}\text { Summarization of concurrent } \\
\text { advances in the state of the } \\
\text { restoration science in the LCRE; } \\
\text { use of new information to } \\
\text { improve the LCRE ecosystem } \\
\text { conceptual model }\end{array}$ \\
\hline $\begin{array}{l}4 \text { Estuary-wide meta- } \\
\text { analysis (“meta- } \\
\text { analysis") }\end{array}$ & $\begin{array}{l}\text { Use of statistical (quantitative) } \\
\text { and non-statistical (qualitative) } \\
\text { methods to summarize multiple } \\
\text { site-scale monitoring results to } \\
\text { make inferences at an estuary- } \\
\text { wide scale }\end{array}$ & Landscape, time lags & $\begin{array}{l}\text { Compilation and systematic } \\
\text { qualitative assessment of results } \\
\text { of action-effectiveness studies in } \\
\text { the LCRE }\end{array}$ \\
\hline $\begin{array}{l}5 \text { Offsite benefits to } \\
\text { juvenile salmon } \\
\text { ("offsite") }\end{array}$ & $\begin{array}{l}\text { Beneficial effects on juvenile } \\
\text { salmon from ecosystem } \\
\text { restoration that are realized } \\
\text { indirectly at locations away } \\
\text { from the restoration site, e.g., } \\
\text { in the main-stem river }\end{array}$ & $\begin{array}{l}\text { Cross-boundary, } \\
\text { indirect, } \\
\text { compounding }\end{array}$ & $\begin{array}{l}\text { Comparative analysis of salmon } \\
\text { stomachs; particulate organic } \\
\text { matter export modeling; CNEI of } \\
\text { prey production }\end{array}$ \\
\hline \multicolumn{4}{|c|}{ Evidence from the LCRE Landscape and Analogous Ecosystems Outside the LCRE } \\
\hline $\begin{array}{l}6 \text { Landscape condition } \\
\text { evaluation } \\
\text { ("landscape") }\end{array}$ & $\begin{array}{l}\text { Description of trends in } \\
\text { indicators of aquatic ecosystem } \\
\text { condition at the landscape } \\
\text { scale, specifically, the } \\
\text { watershed context within which } \\
\text { wetlands on the LCRE } \\
\text { floodplain are being restored }\end{array}$ & Landscape & $\begin{array}{l}\text { Remote-sensing data analysis to } \\
\text { determine land-cover change } \\
\text { trajectories of forest cover and } \\
\text { urbanization in the contributing } \\
\text { watersheds to the LCRE }\end{array}$ \\
\hline $\begin{array}{l}7 \text { Evidence-based } \\
\text { scoring of global } \\
\text { literature ("global } \\
\text { literature") }\end{array}$ & $\begin{array}{l}\text { Systematic global literature } \\
\text { search, filtering, review, and } \\
\text { scoring based on formal criteria } \\
\text { applied to selected response } \\
\text { variables }\end{array}$ & $\begin{array}{l}\text { Not applicable to } \\
\text { cumulative effects }\end{array}$ & Literature review and scoring \\
\hline $\begin{array}{l}\text { (a) Lines of evidence } \\
\text { (b) Cumulative effects }\end{array}$ & $\begin{array}{l}\text { from Diefenderfer et al. (2011) } \\
\text { ategories are from CEQ (1997) }\end{array}$ & & \\
\hline
\end{tabular}


essential objective is also novel: assessing the effects of removing stressors rather than the impact of stressors on human or ecosystem health. (In this case, stressors are the prior conversion of wetlands for other land uses and the barriers to flow and fish passage posed by dikes.) The scoring of evidence from a global literature review is an important factor in our approach, as are the strong study designs for each line of evidence. However, weighted evidence alone is insufficient without an approach to interpretation that is open-minded and defensible, which is why we emphasize critical thinking using criteria that can inform differentiation of association and causation.

\subsection{Ancillary Hypotheses}

Following our originally proposed approach (Diefenderfer et al. 2011), we have developed and implemented methods for gathering data that inform reasoning from seven lines of evidence concerning a suite of ancillary hypotheses (Figure 3). The ancillary hypotheses are testable, although available data were not always sufficient to permit them to be tested in this early-stage assessment of the CEERP. Each ancillary hypothesis for habitat response (Figure 3a) states that the response metric will trend toward conditions at relatively undisturbed reference sites.

Reference sites are models for restoration project planning and evaluation (Society for Ecological Restoration International 2004). Generally, they exhibit environmental conditions similar to those desired at the restoration site and are as little disturbed by human activity as possible. Restoration sites are places where restorative actions have been taken to initiate the ecosystem restoration trajectory (cf. Simenstad and Thom 1996). Most restoration sites in the LCRE do not have paired reference sites where both have been monitored. However, wetland sites comparable to the CEERP restoration objectives for tidal freshwater and estuarine wetland habitats, including marshes, shrub-dominated wetlands, and forested wetlands, have been monitored in recent years (Borde et al. 2012a). This suite of reference sites is being used to increase understanding of the range of natural conditions in the LCRE, and develop quantitative bounds of the characteristics that restoration sites may in time develop (Diefenderfer et al. 2013). This is consistent with the "composite description" of reference condition recommended by the Society for Ecological Restoration International (2004), to avoid undue influence by the stochastic events that influence the development of any particular site.

We assume reference site conditions (Borde et al. 2012a) are beneficial to juvenile salmon based on previously published research regarding the importance of estuarine habitat during early life stages (Reimers 1973; Healey 1980, 1982; Levy and Northcote 1982; Levings et al. 1986, 1991; Levings 1994; Levings and Bouillon 1997; Thorpe 1994; Magnusson and Hilborn 2003). Each ancillary hypothesis for fish response (Figure $3 \mathrm{~b}$ ) represents a salmon-response metric that has been measured and reported in relevant studies in the peer-reviewed literature. Note that the habitat-response diagram includes a general fish-response category, "salmon use" (Figure 3a), which we see as integrating the ancillary hypotheses for fish response. Thus there are a total of 12 ancillary hypotheses.

\subsection{Causal Criteria}

The lines of evidence were designed to address Hill's criteria (Hill 1965) and two criteria later developed in the field of ecotoxicology. The latter are the complete exposure pathway, the original purpose of which concerned the ability of the stressor to physically reach the biological or ecological receptor, and predictive performance, or "the ability to make and confirm predictions" (Dorward-King et al. 2001). We have reconceptualized these criteria for the science of ecological restoration (Table 2). 


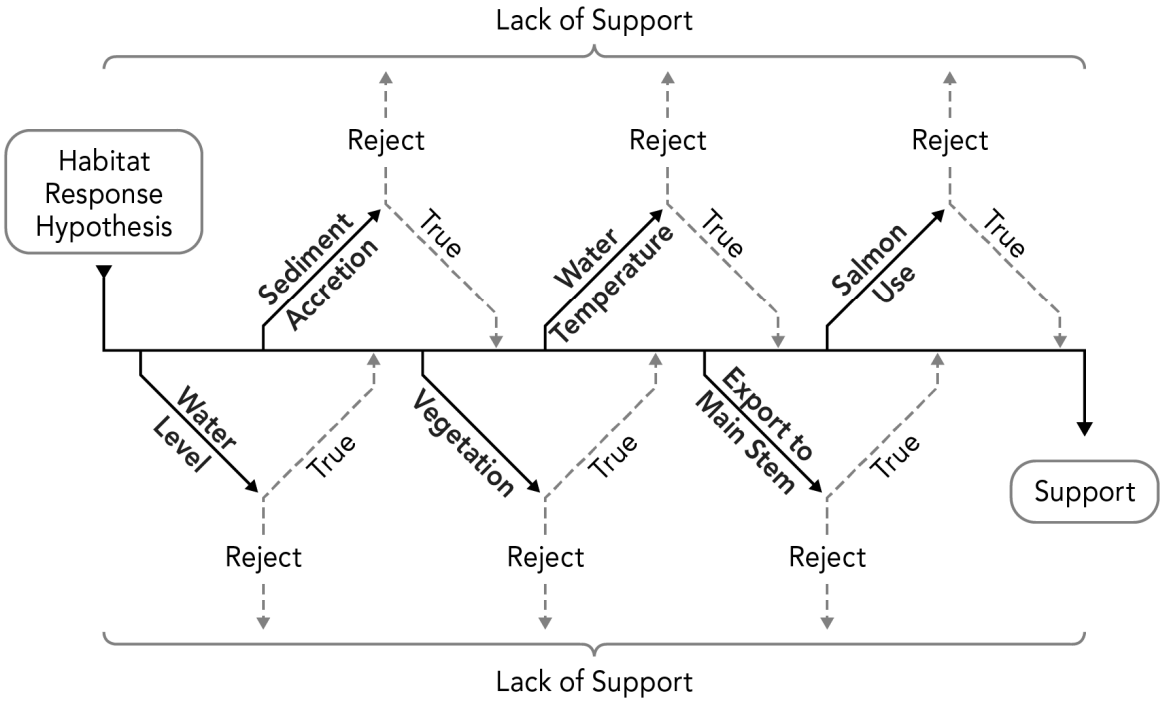

b

L Lack of Support

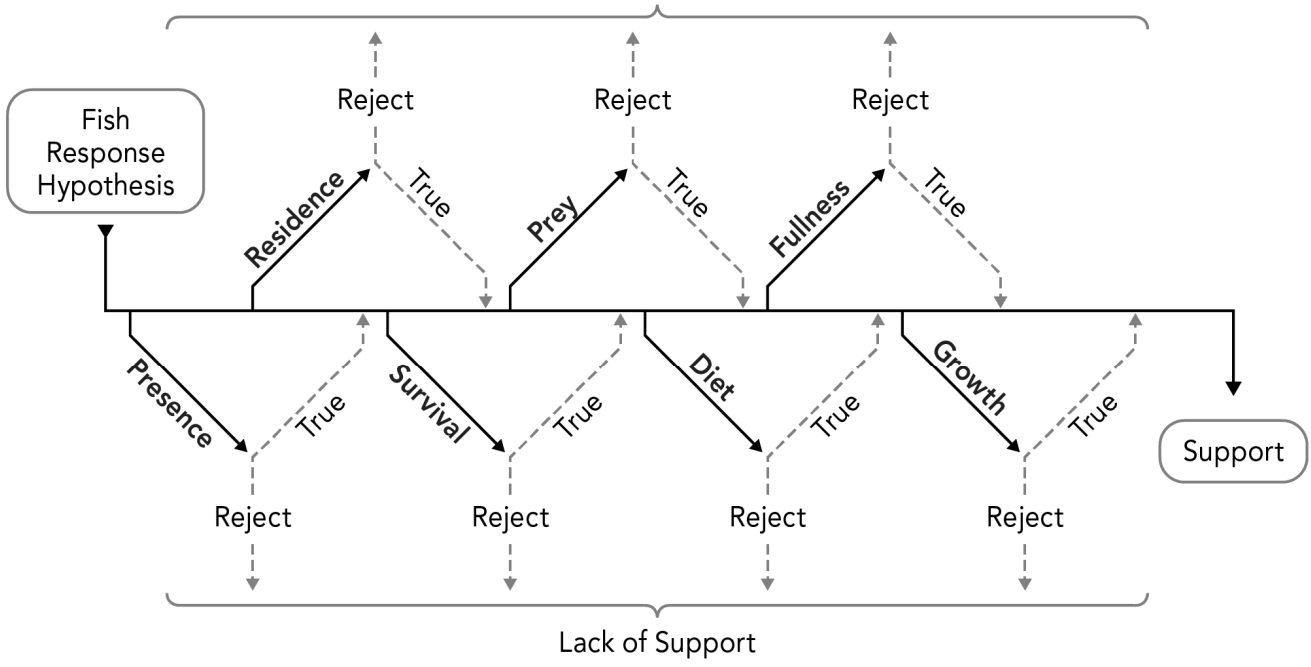

Figure 3. Secondary and ancillary hypotheses. Adapted from Diefenderfer et al. (2011).

The lines of evidence do not map one-to-one on to Hill's criteria or the criteria used in cumulative effects assessments (CEQ 1997). Rather, most address multiple criteria (Table 2). For example, the estuary-wide meta-analysis is a measure of the strength, consistency and specificity of association in the LCRE, and informs our understanding of biological gradient, coherence and predictive performance. The global literature review addresses the strength, consistency and specificity of association in analogous cases and predictive performance. The assessment of change in landscape conditions informs evaluation of evidence by the criteria plausibility and coherence and cumulative effects associated with fragmentation. Conditions at historical breaches address strength, consistency and temporality of association and compounding and indirect cumulative effects associated with time lags. The analysis of offsite effects on migrating salmon addresses biological plausibility, biological gradient and complete exposure pathway, and indirect or cross-boundary cumulative effects. 
Table 2. Definition and use of causal criteria in this study.

\begin{tabular}{|c|c|c|c|c|}
\hline & $\begin{array}{l}\text { Causal Criterion } \\
\text { (CC) }\end{array}$ & Short Definition & $\begin{array}{l}\text { Applicable } \\
\text { Line(s) of } \\
\text { Evidence } \\
\text { (Table 1) }\end{array}$ & $\begin{array}{c}\text { Information for which cause and effect is } \\
\text { evaluated in this study }\end{array}$ \\
\hline 1 & $\begin{array}{l}\text { Strength of } \\
\text { association }\end{array}$ & The magnitude of the effect & $1,4,7$ & $\begin{array}{l}\text { Global literature, analyses of historically } \\
\text { reconnected sites in LCRE, and effectiveness } \\
\text { of early-stage restoration sites in the LCRE }\end{array}$ \\
\hline 2 & $\begin{array}{l}\text { Consistency of } \\
\text { association }\end{array}$ & $\begin{array}{l}\text { The repeated observation of } \\
\text { the association in varied } \\
\text { times and circumstances by } \\
\text { multiple observers }\end{array}$ & $1,4,7$ & Ibid. \\
\hline 3 & $\begin{array}{l}\text { Biological } \\
\text { plausibility }\end{array}$ & $\begin{array}{l}\text { Knowledge of the } \\
\text { mechanism (not a necessary } \\
\text { condition of causation } \\
\text { because knowledge } \\
\text { depends on state of the } \\
\text { science [Hill 1965]) }\end{array}$ & $1,2,5,6$ & $\begin{array}{l}\text { Conceptual model of the potential benefits of } \\
\text { estuarine habitat restoration for juvenile } \\
\text { salmon (Figure 2); CNEI and offsite benefits } \\
\text { analyses; field and modeling data }\end{array}$ \\
\hline 4 & $\begin{array}{l}\text { Biological } \\
\text { gradient }\end{array}$ & $\begin{array}{l}\text { The level of response is } \\
\text { associated with a gradient } \\
\text { in the hypothesized cause }\end{array}$ & $1,4,5$ & $\begin{array}{l}\text { Hydrologic modeling of alternative restoration } \\
\text { designs and operations; meta-analysis of } \\
\text { varying levels of hydrologic reconnection; gut } \\
\text { fullness comparison for Bonneville Dam } \\
\text { versus near river mouth }\end{array}$ \\
\hline 5 & Experimentation & $\begin{array}{l}\text { Manipulation of the } \\
\text { hypothesized cause }\end{array}$ & $\mathrm{n} / \mathrm{a}$ & $\begin{array}{l}\text { Insufficient experimental evidence available } \\
\text { from the study area to evaluate }\end{array}$ \\
\hline 6 & Temporality & $\begin{array}{l}\text { The effect is shown to } \\
\text { follow the hypothesized } \\
\text { cause }\end{array}$ & 1,3 & $\begin{array}{l}\text { Analysis of historically breached sites; } \\
\text { ecological relationships between reconnection } \\
\text { and fish presence; change analysis of remote } \\
\text { sensing of land cover at the landscape scale }\end{array}$ \\
\hline 7 & $\begin{array}{l}\text { Specificity of } \\
\text { association }\end{array}$ & $\begin{array}{l}\text { Limitation of the } \\
\text { association to particular } \\
\text { causes and effects }\end{array}$ & $3,4,7$ & $\begin{array}{l}\text { Ecological relationships between reconnection } \\
\text { and fish presence; meta-analysis of hydrologic } \\
\text { reconnection projects; global literature }\end{array}$ \\
\hline 8 & Analogy & $\begin{array}{l}\text { Comparison to similar } \\
\text { systems }\end{array}$ & 7 & $\begin{array}{l}\text { Global literature on restoration in other tidal } \\
\text { ecosystems with salmon. }\end{array}$ \\
\hline 9 & Coherence & $\begin{array}{l}\text { Lack of serious conflict } \\
\text { between the cause-and- } \\
\text { effect interpretation and } \\
\text { known facts about the case } \\
\text { under consideration }\end{array}$ & all & $\begin{array}{l}\text { Assessment of potential for conflicting or } \\
\text { contradictory logic or information within and } \\
\text { between all analyses (see Table 1) }\end{array}$ \\
\hline 10 & $\begin{array}{l}\text { Complete } \\
\text { exposure } \\
\text { pathway }\end{array}$ & $\begin{array}{l}\text { In a floodplain river system } \\
\text { context, this is hydrologic } \\
\text { connectivity }\end{array}$ & $1,2,3,5$ & $\begin{array}{l}\text { POM (particulate organic matter) model } \\
\text { results; gut fullness studies }\end{array}$ \\
\hline 11 & $\begin{array}{l}\text { Predictive } \\
\text { performance }\end{array}$ & $\begin{array}{l}\text { Ability to accurately and } \\
\text { precisely predict restoration } \\
\text { outcomes }\end{array}$ & $3,4,7$ & $\begin{array}{l}\text { Insufficient evidence from the LCRE to } \\
\text { predict most fish-response metrics except } \\
\text { presence }\end{array}$ \\
\hline
\end{tabular}




\subsection{Cumulative Effects}

Our evaluation of evidence necessarily involves factors related to the assessment of the cumulative effects of restoration, for two reasons. First, restoration is occurring at multiple sites, yet the collective effect is what is important to salmon recovery. Second, the interaction of juvenile salmon with these wetland sites can include multiple visits to multiple sites, as well as both direct and indirect interactions with tidal wetlands as they migrate through the LCRE (Healey 1982a; Maier and Simenstad 2009). While no approach to assessing the ecosystem signature of the cumulative effects of multiple restoration projects was readily available when we began this research, aspects of reasoning concerning cumulative effects had been widely discussed. We included several of these in our approach, both in designing the collection of the evidence needed for the assessment, and in evaluating that evidence (Table 1). The reasoning includes time crowding (effects closely spaced in time), space crowding, time lags (delayed effects), cross-boundary effects, fragmentation (landscape pattern), and effects that are indirect (secondary), nonlinear (triggers and thresholds), or compounding (multiple sources or pathways) (CEQ 1997).

For the purposes of this evaluation, cumulative effects are defined as changes to salmon and the ecosystem resulting from collective actions of CEERP partners, unlike regulatory language, which defines cumulative effects according to the actor that made the change (e.g., State, federal, private) and when the change occurred or will occur. For Section 7 consultations under the ESA, cumulative effects are formally defined as "those effects of future State or private activities, not involving federal activities, that are reasonably certain to occur within the action area of the federal action subject to consultation" (50 CFR §402.02). The broader requirements under the National Environmental Policy Act, which include consideration of Federal activities and activities in the past and present, are not applicable under the ESA definition, as recently affirmed by the Ninth Circuit Court of Appeals (U.S. Fish \& Wildlife Service and National Marine Fisheries Service 1998; Conservation Congress v. U.S. Forest Service, No. 12-16452 [9th Cir. 2013]).

\subsection{Summary}

In summary, the evidence-based approach we developed incorporates seven lines of evidence, each including 1 or more inductive or deductive analysis regarding 12 ancillary hypotheses. The results are synthesized relative to 11 causal criteria pertaining to cause-and-effect associations and 8 cumulative effects categories. Finally, conclusions regarding the primary hypothesis are drawn on the basis of this collected evidence (Figure 4). 


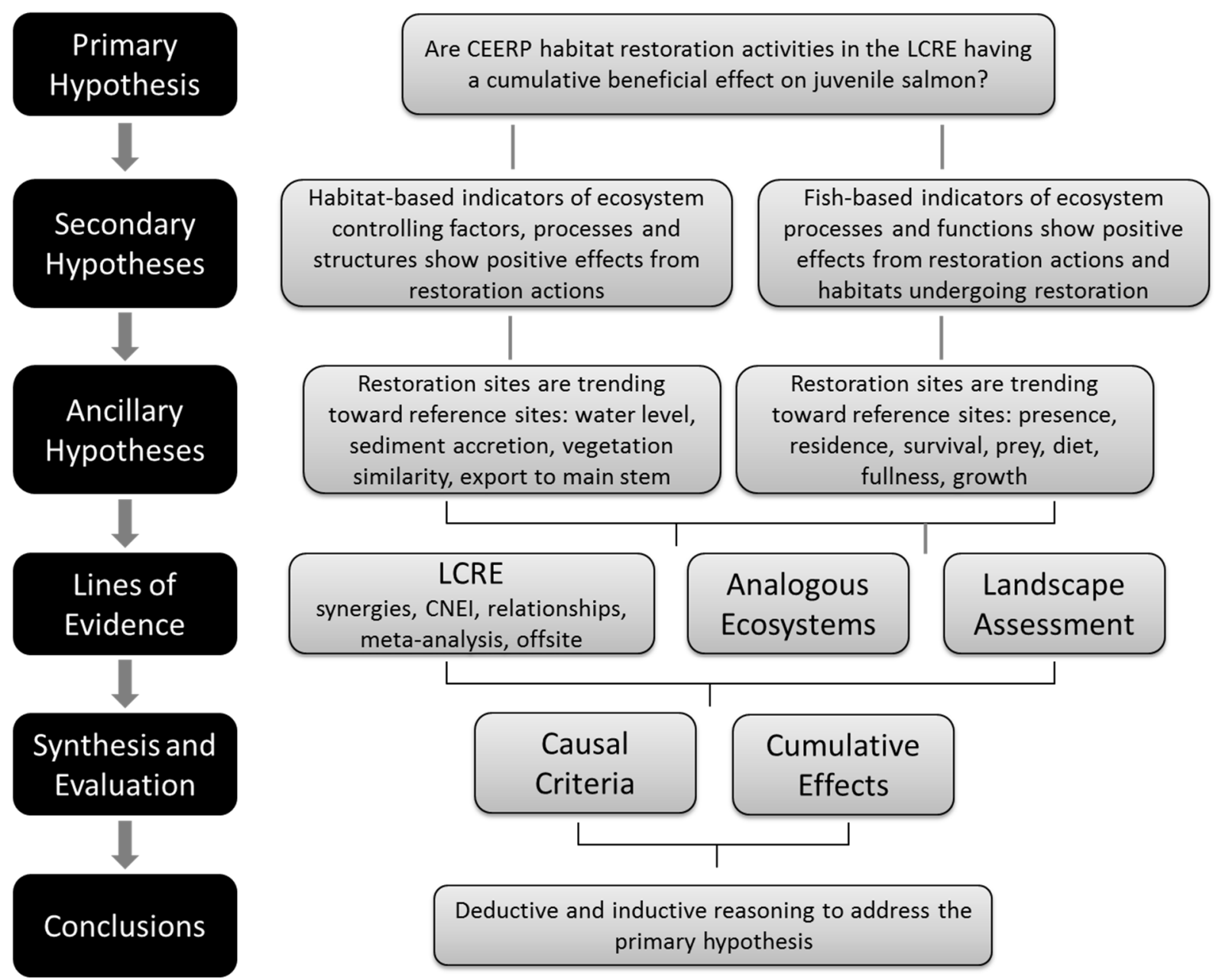

Figure 4. Schematic of the evidence-based approach to evaluate evidence for and against the primary hypothesis, which is the subject of this report. 



\subsection{Methods for Developing Evidence}

The general methods for analyzing and developing information for this evaluation are summarized in Table 1, and detailed in this section for five lines of evidence from the LCRE, one line of evidence from global literature, and one line of evidence from watersheds contributing to the LCRE ecosystem. Consistent with recommendations by Naiman et al. (2012) regarding the importance of the food web to restoration, the questions addressed include the effects of LCRE habitat restoration on the primary production of herbaceous vegetative biomass; secondary production of salmon prey; feeding by actively migrating juvenile salmon; habitat-response metrics (Figure 3a); and salmon-response metrics (Figure $3 \mathrm{~b}$ ). The field methods used to collect data on the response metrics are detailed in our peerreviewed protocols (Roegner et al. 2009). The methods incorporated a before-after-reference-restoration (BARR) sampling design (i.e., conceptually the same as before-after-reference-impact [BARI], StewartOaten and Murdoch 1986). Below we detail additional field methods where applicable, the analytical methods, and formal reasoning approaches that we used to synthesize evidence from throughout the LCRE (Figure 5).

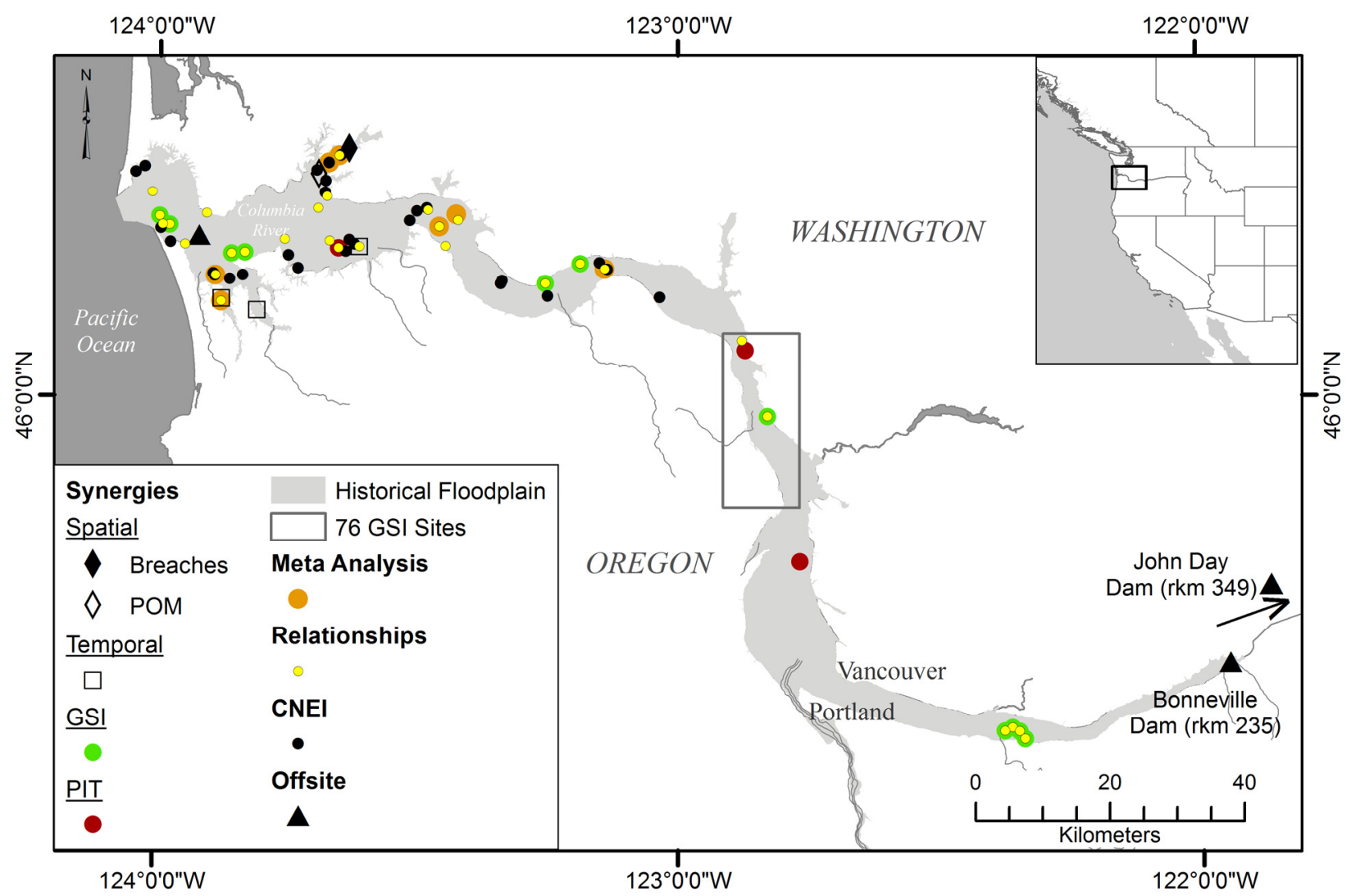

Figure 5. Sampling locations designated by line of evidence. 


\subsection{Analysis of Evidence from the Lower Columbia River and Estuary}

\subsubsection{Spatial and Temporal Synergies Among Restoration Projects}

We analyzed the potential for synergistic effects, space crowding, indirect effects, time lags, nonlinear effect, compounding effects and cross-boundary effects using four approaches.

1. We used physics-based modeling to estimate flux of particulate organic matter (POM) from the Kandoll Farm (KF) restoration site into the Grays River-Columbia River system (Thom et al. In Preparation-a). We employed the hydrodynamic model FVCOM (Chen et al. 2006), a threedimensional finite volume model that uses an unstructured grid, to simulate hydrodynamics of the Grays River, including the KF restoration site, Seal Slough, and Grays Bay. The modeling captured the key POM processes of mobilization from fluid shear stress during tidal exchange, flooding, and variable river flow; entrainment into the water column; transport via channel and overland flow; and entrapment as wetted surfaces dry. Within FVCOM, a sediment transport submodel simulated POM flux. Based on our vegetation sampling at the KF site, we estimated the loss of biomass $\left(\mathrm{kg} / \mathrm{m}^{2}\right)$ between the June 2006 and February 2007 analysis period and used this empirical estimate to calibrate the POM model via a loss rate coefficient. Methods and assumptions are detailed by Thom et al. (In Preparation-a).

2. We determined whether the effects of spatial configuration or cluster size of hydrologic reconnection restoration projects operate synergistically in a study of the lower Grays River. It was not possible to vary restoration treatments at the landscape scale so we used the FVCOM model described in the preceding method to experimentally examine the aggregation of hydrologic connections on the river floodplain, in multiple configurations that could not feasibly have been tested on the ground. Methods and assumptions are detailed by Diefenderfer et al. (2012).

3. We documented detections of juvenile salmon from interior basin stocks in shallow-water wetlands using two methods: passive integrated transponders (PITs; Skalski et al. 1998) and genetic-stock identification (Teel et al. 2009). We compiled and summarized detection results (presence/absence of juvenile salmon from interior Columbia Evolutionarily Significant Units/Distinct Population Segments (ESUs/DPSs)) in shallow, off-channel habitats across the LCRE. We included results from reports and personal communications with researchers who had installed PIT antennas or performed genetic-stock identifications for purposes of specific studies at various LCRE locations.

4. We collected data at three historically reconnected sites, where dikes had been breached without human action and not repaired, to improve predictions of long-term effects of restoration beyond the duration of our study. In order from most recent to oldest, the sites (located between rkm 22.5 and 42.6) were Haven Island on the Youngs River, Fort Clatsop on the Lewis and Clark River, and Karlson Island in Cathlamet Bay. Historically, breaching at these sites occurred $\sim 10,50$, and 60 years before present, respectively. We collected data following the protocols of Roegner et al. (2009) in 2007-2008 on several habitat and fish-response metrics: fish presence; channel morphology; frequency of inundation to a depth of $50 \mathrm{~cm}$ (i.e., physical accessibility to juvenile salmon based on water-surface elevation data and channel cross-section surveys); and percent total organic carbon in the top $10 \mathrm{~cm}$ of sediment (laboratory method ASTM D4129-82M). We did not sample each site at repeated points in time so it was not possible to analyze the trajectory of change. 
Resources precluded identifying and sampling paired reference sites with the historically reconnected sites, so we examined the suite of $\sim 60$ reference sites in the region for suitable comparisons. However, our analysis of the spatial and inter-annual variability of physical and biological factors at the suite of reference sites convinced us that no available site was suitable for statistical comparison with the three previously breached sites (Diefenderfer et al. 2013). Reasons include the fact that two of the sites are located on tributary rivers and few reference sites on tributaries have been sampled so we cannot make reliable comparisons; and tributary elevation data cannot be standardized to the Columbia River Datum as is the practice for main-stem river sites, so comparative analyses are further limited (Borde et al. 2012a, b). Furthermore, the complex spatial distribution of the controlling factors elevation, hydrology, and salinity makes reference site vegetation comparisons quite imperfect (Borde et al. 2012a, b, In Preparation). In summary, the results of these analyses of reference sites indicated that river position is a strong driver of physical and biological factors, so there is no reason to assume that the rate of succession would be the same throughout the river when in fact, it is likely governed by site-specific environmental conditions. A sample size of three historically breached sites that spans two plant zones (Borde et al. $2012 \mathrm{a}, \mathrm{b}$ ) and both tributary and main-stem regions is very low.

For the above reasons, we have chosen simply to report the physical and biological characteristics of historically breached sites to address temporal synergies.

\subsubsection{An Additive Model of Net Ecosystem Improvement}

To calculate cumulative net ecosystem improvement (CNEI) as an additive change in function, we used the general equation (Diefenderfer et al. 2011)

$$
\text { CNEI }=\sum_{i=1}^{n} \Delta F_{i} A_{i} P_{i}
$$

where

$$
\begin{aligned}
\mathrm{n} & =\text { number of restoration projects } \\
\Delta \mathrm{F} & =\text { change in ecological function } \\
\mathrm{A} & =\text { project size (area) } \\
\mathrm{P} & =\text { probability of success of the restoration action. }
\end{aligned}
$$

To represent an aspect of ecological function - the indirect (export offsite) and direct (onsite) foodweb effects of tidal wetlands - we selected as indicators annual herbaceous biomass production assessed by dry weight at or near peak summer aboveground biomass, and salmon prey collected over 48-hour periods in insect fallout traps and emergent traps, or in instantaneous benthic cores. Through a comprehensive review of prey data (number per square meter) in peer-reviewed reports from the LCRE, and our own data, we obtained prey data for 17 site-years collected between 2002 and 2008, including 3 restoration sites, 11 emergent marshes, 1 shrub wetland, and 5 forested wetlands, including our own data and other studies (Lott 2004; Ramirez 2008; Eaton 2010). These prey included the dipteran (fly) Family Chironomidae (non-biting midges), dipterans other than chironomids, hemipterans (true bugs), arachnids (spiders), and amphipods (scud). We restricted the dates of the data synthesized to an AprilJune window corresponding to offsite fish stomach fullness data (Section 3.1.5). We note that the prey data represent different years and specific sampling periods within the selected April-June sampling window. The sampling specifics are available in each study document. Through a similar review, we obtained biomass data for 41 site-years, including 7 restoration sites and 34 emergent marshes from our 
own 2005-2010 data and from MacDonald (1984) for 1980-1981. Restoration site data were collected within 5 years of hydrologic reconnection to the main-stem river.

For the CNEI analysis, we distinguished four reaches of the river - $\mathrm{a}$ lower ocean-influenced reach to rkm 29, an intermediate fluvial-tidal continuum reach from rkm 30 to 86, an upper fluvial-tidal reach from rkm 87 to 136, and an upriver reach from rkm 137 to 235 (Figure 1). The reaches are based on Borde et al. (2012a, b, In Preparation) and Jay et al. (In Revision, In Review), and the use of a single point (river kilometer) to mark the boundaries should not mask the fact that in reality they are transitional bands where the dominant plant species and hydrologic drivers shift. For example, as described by Jay et al. (In Review), the boundary between the lower two vegetation zones cannot be distinguished more accurately than somewhere between rkm 29 and 52 until more data on plant communities become available. It was necessary to constrain the primary analysis to the lower three vegetation zones or rkm 0-136 (Figure 1) because of the lack of available biomass and prey data for the fluvially dominated areas upriver, which our unpublished vegetation data indicate are statistically different in plant species composition (Diefenderfer et al. 2013).

We obtained data for restoration project size in geographic information systems (GIS) from coordinating agencies, mainly the Lower Columbia Estuary Partnership (Keith Marcoe, personal communication, multiple dates), which are current to September 2012. These data include all reaches of the LCRE, and we divided the uppermost zone at rkm 181 because prior analyses of vegetation suggested a transition at approximately $\mathrm{rkm} 181$; this is a preliminary hypothesis because so few vegetation sites have been sampled in the vicinity of the City of Portland (Borde et al. 2012a). We summed the total completed area of projects where hydrologic reconnection had occurred, by reach, and for sites where area data were not available we summed the total along-channel length, if available. Our calculation for total completed area did not include in-progress or planned projects; projects involving large woody debris or plantings without reconnection; and five low-connectivity projects, $>14.5 \mathrm{~km}$ from the mainstem river.

To illustrate the maximum potential primary and secondary productivity increase by the restoration program, CNEI, we extrapolated the biomass and prey data from reference sites across the best estimate of the existing restored area. That is, the delta-function term $(\Delta \mathrm{F})$ in Equation 3.1 is assessed using data from reference sites while the area term (A) is assessed using data from restoration sites. We caution that this method requires first up-scaling from the capture scale (meters) to the restoration site scale (e.g., mean area of $32 \mathrm{ha}$ ), and next up-scaling to the total restored area of each Columbia River reach (Figure 1) (on the order of square kilometers). While reported data-collection methods at specific sites incorporated random or haphazard spatial distribution of samples, this is not the case for the aggregated sampling of the entire LCRE or any river reach. We avoided extrapolation across time frames longer than those associated with data collection (48 hours or instantaneous), because the available data were collected monthly or twice monthly based on a calendar, not on any environmental features of time.

Additional assumptions made in this extrapolation are as follows: 1) we used emergent-marsh data from reference sites to estimate the maximum potential productivity in the near term, because recently reconnected pastures such as these restoration sites are unlikely to generate values associated with woody plants during the near future of restoration program implementation, although at some sites, trees and shrubs are planted following hydrologic reconnection; 2) provisionally, we assigned the probability of success of the restoration action term (P) in Equation 3.1 a " 1 " in the CNEI equation, based on the evidence from historically breached sites indicating that all sites have become marshes without any 
human intervention, but this does not mean that all plant species will be native or non-invasive (Section 3.1.1); and 3) we assumed that pre-restoration conditions had zero hydrologic connectivity, implying no access by juvenile salmon, as well as zero aquatic export of biomass and prey. Therefore, potential longterm $\Delta \mathrm{F}$ is represented by mean values at reference sites and current early-stage $\Delta \mathrm{F}$ is represented by mean values at restoration sites.

To contextualize the results of the CNEI model relative to the historical baseline as well as the potential for future habitat restoration, we used the following general equation:

$$
\mathrm{PRA}=\mathrm{HF}-\mathrm{DL}-\mathrm{EH}-\mathrm{MS}
$$

where

$$
\begin{aligned}
\text { PRA } & =\text { potential restorable area } \\
\mathrm{HF} & =\text { historical floodplain area } \\
\mathrm{DL} & =\text { developed area, never or unlikely to be restored } \\
\mathrm{EH} & =\text { existing accessible functioning floodplain habitat area } \\
\mathrm{MS} & =\text { main-stem river surface area, not including islands. }
\end{aligned}
$$

We calculated historical floodplain area in a GIS from the most recently available perimeter, delineated by the U.S. Geological Survey (USGS) (Jim O'Connor, USGS, personal communication, 23 July 2012). We calculated the other terms in the equation from the most recently available land-cover analysis by the Lower Columbia Estuary Partnership (EP) and compared the results to the EP's "potential recoverable area" calculation (Keith Marcoe, EP, personal communication, 28 June 2013; EP 2013).

\subsubsection{Estuary-Wide Qualitative Meta-Analysis of Restoration Project Effectiveness}

We compiled all available published and unpublished reports on restoration project effectiveness in the LCRE to identify tidal reconnection projects where paired restoration and reference site data relevant to the ancillary hypotheses were collected and reported. Although the number of studies would increase by at least five if paired restoration/reference sites was not a requirement of the ancillary hypothesis framework, the subjectivity of the results in this already qualitative meta-analysis would increase. Therefore, we refrained from including studies without reference sites. The resulting data set, which concerned seven restoration projects, was used in a qualitative meta-analysis of restoration effectiveness. The analysis was necessarily qualitative because the compiled data at this early stage of program implementation were too limited temporally and spatially for a quantitative meta-analysis. Recall, the ancillary hypotheses are whether conditions at restoration sites trend toward reference conditions (Figure 3a). The data set for the meta-analysis included these monitored indicators: water level, sediment accretion, water temperature, vegetation similarity, and salmon presence. Monitoring data were not collected or were collected at too few sites to address the other ancillary hypotheses. For purposes of this evidence-based evaluation, we expressed the results of the restoration/reference comparison to address a given ancillary hypothesis using five categories: support, lack of support, inconclusive, insufficient data, and not evaluated.

\subsubsection{Ecological Relationships}

Since constructing our preliminary conceptual model of the ecosystem and salmon benefits in 2004, additional discrete ecological relationships have been elucidated through field research and modeling 
directed at reducing uncertainties. The areas of focus included juvenile salmon use of restoring wetlands; sediment accretion rates at restoring wetlands; variation in response to restoration actions (dike breach, tide gate, culvert, channel excavation, and grading); spatial variability of water-level dynamics; primary production and export of biomass; ecosystem controlling factors on wetland restoration (hydrology and microtopography), and their seasonal and inter-annual dynamics; spatial variability in plant communities; and channel morphometry, morphology, and inundation. Ecological relationships revealing linkages between ecosystem controlling factors, structures, processes, and functions in the LCRE (Figure 2) are summarized herein. Due to space considerations, they are not reported in full but relevant reports and publications are cited. Methods are fully described in the reports and publications cited in the results (Section 4.1.4). The findings from all of these ecological relationships have been used iteratively to validate and improve the conceptual model and verify the biological plausibility of the hypotheses.

\subsubsection{Offsite Benefits to Juvenile Salmon}

The prey production and export components of offsite benefits were examined using the CNEI and POM models (Table 1), and the methods for comparative analysis of salmon stomachs to assess potential fish condition effects are described in this section. To address the proposition that upon leaving the hydropower system at Bonneville Dam, salmon could benefit from feeding in the LCRE prior to entering the ocean, we collected stomach fullness data from 2010-2012 at John Day Dam (rkm 349) and Bonneville Dam (rkm 235) (Woodley, unpublished data), and from 2007-2011 near the mouth of the Columbia River (rkm 15) (Weitkamp 2012, unpublished data). Of $>30,000$ Chinook and steelhead collected in juvenile bypass systems at the two dams and $>10,000$ actively migrating Chinook salmon, steelhead, and coho salmon collected by purse seine at the river mouth, we compared stomach fullness data for 2,247 stomachs' contents collected between April 20 and June 6 for yearling Chinook salmon, coho, and steelhead, and June 16 and July 20 for subyearling Chinook salmon. These constraints on sampling period helped to ensure that similar populations of these migratory fish were compared. Standard methods were used for stomach analysis (Bowen 1996). We defined the metric actively feeding as $>24 \%$ stomach fullness with identifiable prey (i.e., not including digested material and non-food such as vegetative matter) based on the ratio of identified to unidentified prey in the stomachs in our data sets and based on expected digestive rates. This definition accounts for reported gastric evacuation times (time from consumption to elimination) of $\sim 30 \mathrm{hr}$ (Brodeur and Pearcy 1987; Benkwitt et al. 2009), and reported transit times from Bonneville Dam to the mouth of $>3 \mathrm{~d}$ (Weitkamp, unpublished data) to ensure that stomach fullness at the river mouth reflected consumption within the 235-km LCRE. Stomach contents at rkm 15 should not be considered a point estimate, but rather an integrative measurement of prior feeding in the LCRE, given the rapid travel times $(>50 \mathrm{~km} / \mathrm{d})$ estimated for many juvenile salmon moving through the LCRE (Welch et al. 2008; Harnish et al. 2012; Weitkamp unpublished data). Fish with and without adipose fin clips were included because the objective is to determine the difference between fish exiting the hydrosystem and those near the river mouth, and the mean difference in active feeding between marked and unmarked groups was expected to be considerably less than the difference we report between upriver and downriver groups (Weitkamp, unpublished data). At all locations sampled, most of the salmon captured are hatchery-reared, including a substantial (and unknown) portion of the unmarked fish. The geographic scale of this analysis can be viewed as the LCRE, from the most downstream major dam to the mouth of the river. 


\subsection{Analysis of Literature from Analogous Ecosystems}

The methods for the analysis of literature from analogous ecosystems comprised two phases: selection and scoring. The criteria for each are detailed in this section.

We analyzed evidence from analogous tidal systems where hydrologic reconnection has occurred and salmon are a native species. The literature search of cases outside the LCRE was deliberately more restricted than the literature review we conducted during 2003-2004 (Diefenderfer et al. 2011), which included juvenile salmon-habitat relationships and the effects of impacts other than restoration. Those types of results were useful in developing the conceptual model and forming plausible hypotheses about ecological relationships and the likely effects of restoration. At the present stage, we only considered literature that directly addresses the critical condition of our primary hypothesis, i.e., the response of salmon to hydrologic reconnection in tidal areas including tidally influenced large-river floodplains. The results of the estuary-wide meta-analysis revealed a paucity of data and analysis for salmon at paired restoration and reference sites, which in our view increased the importance of literature from analogous ecosystems to this evaluation. Therefore, we systematically evaluated and scored evidence regarding effects of restoration actions and habitats undergoing restoration on fish-based indicators of ecosystem processes and functions.

Two new searches were conducted in September 2012 within the Institute for Scientific Information (ISI) Web of Science ${ }^{\circledR}$, the online equivalent to the Science Citation Index: 1) salmon AND (dike* OR dyke* OR levee* OR tidegate* OR tide gate*); and 2) salmon AND (restoration* OR creat*) AND (estuar* OR river* OR floodplain* OR tid* OR slough). We examined the title and abstract of the 709 papers returned by these searches to ensure the papers were relevant; i.e., that they met three criteria: 1) included original data on juvenile salmon; 2) pertained to tidal ecosystems including tidal freshwater and estuaries; and 3) concerned an anthropogenic action for the purpose of restoring aquatic habitat connectivity or an analogous habitat change. Notable categories of papers that were excluded from the causal criteria analysis phase by these criteria included studies of adult salmon, the effects of reduced aquatic connectivity, floodplains without tidal influences, juvenile salmon-habitat relationships in areas unaffected by restoration, juvenile salmon in areas where restoration was planned, and studies that were restricted to modeling methods. On the basis of the title and abstract, 27 of the papers were found to possibly meet the relevance criteria. In many cases the information in the abstract alone was insufficient to determine whether the criteria were met, and review of the full text identified 15 of 27 papers that met the three criteria for advancement to the causal criteria analysis.

To ensure the comprehensiveness of search results, we added redundancy to the approach by conducting the searches in ProQuest, thereby identifying peer-reviewed papers from all years, sources, document types, and languages in five of the available databases (Aquatic Science and Fisheries Abstracts, Water Resources Abstracts, BioOne Abstracts and Indexes, ProQuest Research Library, and ABI/INFORM Trade \& Industry). In summary, this search added a total of four papers to those advanced for review of full text and ultimately just one more to the final analysis. Thus, the total number of papers identified for causal criteria analysis at this stage of selection was 16 .

Additionally, the analysis of full text showed that several of the 16 papers cited prior research as a data source; we examined all of these unpublished reports or published papers to ensure that the original source of the data was included in this analysis. We established the principle that data from the same site on the same response metric published in two different reports could not both be used without skewing 
the result. On this basis, we decided that in the case of a different author publishing an earlier author's data, the earliest source that included the information required to weight the study type as described below should be included. In contrast, in the case of the same author publishing the same data repeatedly, the most recent source should be used because it was typically the most comprehensive and sophisticated data report. As a result, three were added to the total (Scott and Susanto 1993; Cordell et al. 2001b; Sommer et al. 2001b) and two of the papers identified by the initial literature search were excluded (Sommer et al. 2001a; Simenstad et al. 2005), leaving 17. Similarly, the fish survival data in one source (Pederson et al. 2007) were eliminated because they had been previously reported in a paper included in the analysis (Koed et al. 2006). Finally, Simenstad and Thom (1996) reported an additional 1-2 years of data from the same restoration site for the fish-response metrics (e.g., prey) previously reported in a paper included in this analysis (Shreffler et al. 1992), and to be conservative and not over-represent the site, the data collected later were not counted for the analysis.

In summary, the total number of papers identified by the above-described selection process was 15 . This is the number of papers from analogous ecosystems that we scored as described below. None of the papers treated all 7 fish-response metrics (Figure 3b), so necessarily, the number of papers scored for each metric was $<15$.

Scoring of the results of the literature review entailed the three-part process characteristic of evidence-based assessments in many disciplines: 1) score the study based on the number of replicates and the strength of the study design, 2) determine whether the results of the study support the hypothesis, and 3 ) total the scores of evidence for and against the hypothesis. We developed seven salmon indicator categories relevant to the hypothesis from the studies themselves, which represent all of the kinds of fish and prey data reported: presence (abundance, density, or catch per unit effort [CPUE]); residence time; survival; production of prey taxa at the restored site (species composition and abundance); and three indicators of feeding (diet composition, stomach fullness, and fish growth [measured or bioenergetics modeling]) (Figure 3b). As a general rule, we did not interpret the data further than authors did; e.g., diet composition was reported based on taxa not the energetic quality of the prey so we limited the analysis to the former.

To weight the studies, we determined how many restoration and reference sites were sampled, which could be less than reported by the authors, because we defined "effective" restoration and reference sites, as a matter of principle. This ensured that the only restoration sites included were those that met our review criterion for relevance that hydrologic reconnection had occurred (oftentimes, additional sites had only plantings), and that reference sites met generally applicable criteria for independence relative to the focus of our inquiry on salmon (i.e., independent from the restoration site as regards salmon access [salmon do not have to go through one to get to the other]). We applied rules from the most recent adaptation of evidence assessment for ecology by Norris et al. (2012) to assign scores to the study design type:

- After-only receives a 1 .

- Restoration/reference or before/after receives a 2.

- Restoration/reference and before/after receives a 4. 
We applied rules from the same paper to score the number of replicates in each study:

- For the effective number of reference sites, 0 sites receives a weight of 0,1 a weight of 2 , and $>1$ a weight of 3 .

- For the effective number of restoration sites, 1 site receives a weight of 0,2 a weight of 2 , and $>2$ a weight of 3.

Following Norris et al. (2012), the total weights for replicates (restoration sites + reference sites) were summed with the study design type weights for the "total study weight" we report.

For each indicator category, we evaluated whether the study supported the hypothesis in accordance with the study design type; e.g., if it was a restoration/reference design, then it was evaluated relative to reference conditions (if similar, then yes); if it was a before/after design, it was evaluated relative to before conditions (if changed, yes); if it was a BARR (before-after-restoration-reference) design, then both. Finally, we summed the total study weight of all papers that supported the hypothesis to determine the strength of support, and summed the total study weights of papers that did not support the hypothesis to determine the consistency of that support. We applied rules adapted from Norris et al. (2012) and Greet et al. (2011) to evaluate the results. Under these rules, we conclude

- support for the hypothesis if the total sum of study weights in favor of the hypothesis is $\geq 20$ and the total sum of study weights not in favor is $<20$

- support for the alternate hypothesis if the total sum of study weights in favor of the hypothesis is $<20$ and the total sum of study weights not in favor of the hypothesis is $\geq 20$

- insufficient evidence if the total sum of study weights in favor of the hypothesis is $<20$ and the total sum of study weights not in favor of the hypothesis is $<20$

- inconsistent evidence if the total sum of study weights in favor of the hypothesis is $\geq 20$ and the total sum of study weights not in favor of the hypothesis is $\geq 20$.

We added a rule to the Norris et al. (2012) scoring method: if more than one set of paired sites or more than one restoration site were sampled in a study and the different sites produced contradictory results, we recorded both results and apportioned the total study weight between them in the scoring; thus the information was not lost and contributed to the determination of both strength and consistency.

In a separate analysis, we applied the above scoring method to the six reports available from LCRE restoration sites. However, data were available for fewer response metrics than the global literature for analogous systems. Only one of the LCRE studies was peer-reviewed and therefore was also included in the scoring of the peer-reviewed global literature described above. Results from the LCRE were tallied separately because it would be inappropriate to include unpublished reports with the evidence-based assessment of published literature. 


\subsection{Landscape Assessment: Floodplain and Contributing Watersheds}

The analyses of the LCRE we have described, including the net ecosystem improvement model, incorporate geographic scales up to the historical floodplain. However, the LCRE floodplain itself is at the downstream end of tributary watersheds not managed by the restoration program, which have the potential to influence the floodplain (Allan 2004; Byrd et al. 2007; Independent Scientific Advisory Board [ISAB] 2011). Knowledge of landscape indicators of aquatic processes suggests that we cannot ignore the potential effects of this wider landscape on the outcome of the restoration program (Gergel et al. 2002; Hale et al. 2004). Forest cover is a landscape indicator of salmon-habitat condition in the Pacific Northwest (Booth et al. 2001, 2002; Andrew and Wulder 2011). Therefore, we conducted a landcover change analysis to assess whether conditions in the landscape were improving or declining, based on forest cover and urbanization, which is fully reported by Ke et al. (2013). Similar to Diefenderfer et al. (2009), we analyzed two landscape scales relevant to restoration sites: 1) the eight reaches of the LCRE floodplain (defined by Simenstad et al. [2011]), and 2) the contributing watersheds associated with each reach (i.e., tributaries to the LCRE).

We used 30-m resolution National Oceanic and Atmospheric Administration Coastal Change Analysis Program (NOAA C-CAP 2004, www.csc.noaa.gov) land-cover and land-change inventories to assess two, 5-year periods relevant to the CEERP. The 1996 data represent watershed conditions prior to inclusion of estuary restoration in the Biological Opinion; the 2001 data represent conditions at the time of the 2000 Biological Opinion, which included estuary restoration; and the 2006 data represent the early stages of the CEERP. The NOAA C-CAP product consists of 24 classes representing coastal land cover generated from Landsat Thematic Mapper imagery. We found that the 1-m resolution 2009 NOAA C-CAP data product, which was developed using a newer object-based classification method, could not be directly quantitatively compared with the 1996, 2001, and 2006 data.

For the purpose of this study, we reclassified the C-CAP products for 1996, 2001, and 2006 into broad classes of forest, wetland, urban, and other. Three land-cover data sets distinguishing forest/nonforest, wetland/non-wetland, and urban/non-urban were created for each of the 3 years. We used the differences between the reclassified data in 1996 and 2001, and in 2001 and 2006, to create change maps and calculated differences at the watershed and floodplain scales. 


\subsection{Results}

The results section includes material about the analysis of evidence from the LCRE, analysis of literature from analogous systems, landscape assessment of contributing watersheds, and a summary.

\subsection{Analysis of Evidence from the Lower Columbia River and Estuary}

\subsubsection{Spatial and Temporal Synergies Among Restoration Projects}

Spatial: Hydrodynamic Modeling of POM Transport. Although tidal forcing moved material back and forth between the KF and Seal Slough sites, POM modeling for low-flow conditions showed little transport of mobilized POM occurred out of the KF site, and any mobilized POM remained on the site due a lack of net outflow from the site. In contrast, POM modeling for a peak flood event and three smaller flood events showed 1) floods forced pulses of POM to be transported into the Grays River system from the KF site, with approximately half of it then transported out of the Grays River system; and

2) POM was redistributed throughout the floodplain and channels downstream of the KF site, and was then available for transport during the moderate flow conditions after the peak flood. The study showed the proportion of the mass of POM produced at this particular restoration site that reaches the main-stem river/estuary (PM) was a function of distance in kilometers from the site to the main stem (D); PM = $0.969-0.062 * \mathrm{D}\left(\mathrm{R}^{2}=0.87, \mathrm{n}=3\right.$ ) (Thom et al. In Preparation-a). Overall, the results indicated POM would be mobilized at the study site and, of this mobilized material, approximately $52 \%$ would reach the mainstem Columbia River 7-8 km downstream.

Spatial: Hydrodynamic Modeling of Effects of Multiple Projects. The results of 29 hydrodynamic model simulations, designed according to a statistical model to test effects, identified three types of effect for the Grays River study area: 1) a synergistic effect of multiple breaches with 2) incremental returns of wetted area that diminished once $26 \%$ (11) of the 42 channels on the Grays River floodplain were breached; and 3) an effect of spatial configuration, as measured by the distance from the river mouth, with upstream breaches having just $2 \%$ the effect of downstream breaches on wetted area (Diefenderfer et al. 2012).

Spatial: Detections of Known Interior Columbia ESUs/DPSs. PIT-tagged or genetic-stock identified juvenile salmon and steelhead known to have originated in the interior Columbia River basin, including the Snake River, have been observed in shallow-water tidal freshwater and estuarine ecosystems below Bonneville Dam (Table 3). Species observed included Snake River spring/summer and fall Chinook salmon, Snake River steelhead, and mid/upper Columbia River spring Chinook salmon. These fish were detected at sample locations in off-channel, shallow-water wetland areas away from the main-stem Columbia River.

Temporal. The three historically diked and reconnected sites we studied between rkm 22.5 and 42.6 were Haven Island (breached $\sim 10$ years before sampling), Fort Clatsop (breached $\sim 50$ years before sampling), and Karlson Island (breached $\sim 60$ years before sampling). Complete results for habitatresponse metrics are reported by Diefenderfer et al. (2013). 
Table 3. Within-LCRE detections of PIT-tagged fish and estimates of genetic stock identity (GSI) for juvenile salmon and steelhead known to have originated in the interior Columbia River basin, including the Snake River. The Upper Columbia summer/fall Chinook stock and coho are not included because it is possible these fish originated below Bonneville Dam because of brood stock translocations by hatchery managers.

\begin{tabular}{|c|c|c|c|c|c|}
\hline $\mathrm{Rkm}$ & $\begin{array}{c}\text { Sample } \\
\text { Locations }\end{array}$ & Method & Upriver Fish Stock & $\begin{array}{c}\text { Marked/ } \\
\text { Unmarked }\end{array}$ & Citation \\
\hline 200 & $\begin{array}{c}\text { Col R, Sandy R } \\
\text { delta }\end{array}$ & $\begin{array}{c}\text { Beach } \\
\text { seine, GSI }\end{array}$ & SRF, DRF & $\begin{array}{l}\text { Unmarked, } \\
\text { marked }\end{array}$ & $\begin{array}{l}\text { Sather et al. 2011; } \\
\text { Johnson, G. et al. } \\
\text { In Preparation }\end{array}$ \\
\hline 149 & $\begin{array}{l}\text { Campbell } \\
\text { Slough }\end{array}$ & PIT array & SRF & Marked & $\begin{array}{l}\text { Johnson L., pers. } \\
\text { comm. }\end{array}$ \\
\hline 113 & $\begin{array}{l}\text { Col R, Carroll's } \\
\text { Channel, } \\
\text { Cottonwood } \\
\text { Island }\end{array}$ & PIT array & $\begin{array}{l}\text { Spring, summer, and fall Chinook } \\
\text { salmon from upper Columbia and } \\
\text { Snake River basins }\end{array}$ & $\begin{array}{l}\text { Unmarked, } \\
\text { marked }\end{array}$ & $\begin{array}{c}\text { Skalski and } \\
\text { Townsend } 2011\end{array}$ \\
\hline $\begin{array}{l}110- \\
141\end{array}$ & $\begin{array}{l}\text { Col R, Longview } \\
\text { to St. Helens }\end{array}$ & $\begin{array}{c}\text { Beach } \\
\text { seine, GSI }\end{array}$ & SRF, DRF & Unmarked & Sather et al. 2011 \\
\hline 36 & $\begin{array}{l}\text { Cathlamet Bay, } \\
\text { Russian Island }\end{array}$ & PIT array & $\begin{array}{l}\text { Upper Columbia River spr } \\
\text { Chinook and steelhead, Snake } \\
\text { River spr/sum and fall Chinook, } \\
\text { and Snake River steelhead }\end{array}$ & $\begin{array}{l}\text { Unmarked, } \\
\text { marked }\end{array}$ & $\begin{array}{l}\text { McNatt, pers. } \\
\text { comm. }\end{array}$ \\
\hline $\begin{array}{l}8,10 \\
20,22 \\
79,84\end{array}$ & Various & $\begin{array}{c}\text { Beach } \\
\text { seine, GSI }\end{array}$ & $\begin{array}{c}\text { SRF, DFR, Snake River spring } \\
\text { Chinook salmon, mid/upper Col R } \\
\text { spring Chinook }\end{array}$ & $\begin{array}{l}\text { Unmarked, } \\
\text { marked }\end{array}$ & $\begin{array}{c}\text { Roegner et al. } \\
2012\end{array}$ \\
\hline
\end{tabular}

Each set of results below, for three historically reconnected sites, is ordered starting with the fewest years since breaching. Since breaching, all three sites have transitioned to emergent marshes with little discernible resemblance to the diked pastures of today's landscape, according to data on plant communities collected in $1-\mathrm{m}^{2}$ plots. For the three historically breached sites, researchers found:

- All plants identified were wetland species.

- The total vegetative cover made up of native wetland plants was $68 \%, 72 \%$, and $52 \%$.

- Ratios of numbers of native to non-native wetland plant species were 14:6, 12:5, and 21:7.

- The mean total absolute cover of wetland plants was $60 \%, 120 \%$, and $98 \%$. (Absolute cover, as the sum of percent cover of each plant species in the quadrat, can be $>100 \%$ if multiple canopy layers are present).

- The average number of wetland plant species per square meter of 4.5, 4.2, and 6.4.

- The mean percent total organic carbon in floodplain sediments at previously diked sites was not collected at the Fort Clatsop breach and was 5.16\% at Haven Island and 4.84\% at Karlson Island, which is within the range of reference wetlands (Borde et al. 2011).

- The sediment accretion rates were positive $-2.55 \mathrm{~cm} / \mathrm{yr}, 1.14 \mathrm{~cm} / \mathrm{yr}$, and $1.37 \mathrm{~cm} / \mathrm{yr}$ - and not unusual although Haven Island is nearer the accretion rate of recently reconnected areas of Grays River (Thom et al. In Preparation-b), whereas the majority of reference sites have accretion rates ranging from 0.0 to $1.5 \mathrm{~cm} / \mathrm{yr}$ (Borde et al. 2012a). 
- The percent cover of non-native, invasive plant reed canary grass is $16.3 \%, 19.6 \%$, and $11.5 \%$, which is likely controlled by low elevation and seasonally brackish conditions in this zone (Diefenderfer et al. 2013).

There does not appear to be a physical barrier to fish access to the historically breached sites, as suggested by the following measurements and observations:

- An indicator of fish access potential, the percent time over 1 year that the main channel of each site was inundated to a minimum depth of $50 \mathrm{~cm}$ at the mouth was $100 \%, 99.7 \%$, and $95.4 \%$ for the respective sites.

- The depths (difference between the bank elevation and deepest point on thalweg) at the mouths of the main wetland channel were $2.3 \mathrm{~m}-4.2 \mathrm{~m}$ (mean $=3.4 \mathrm{~m})$.

- The mean width:depth ratio at previously diked sites was $=8.6$.

- Annual patterns in water temperatures are similar to other reference wetlands in the vicinity, which are suitable for juvenile salmon for most of the year. All sites begin to exceed the Washington State Department of Ecology criterion for favorable salmon rearing and migration conditions in May or June of each year, which is $17.5^{\circ} \mathrm{C}$ for highest 7-day running average of the daily maximum (7DADmax).

- Of the three sites in this analysis, Fort Clatsop was not sampled, Haven Island had no salmon present in two hauls on 24 June 2009 and 17 August 2009; in three sampling trips at Karlson Island in 2008 on 28 May, 30 June, and 2 September, researchers captured a total of 83, 20, and 3 Chinook salmon for the 2-replicate hauls and 2 chum salmon in May (Roegner, G.C., NOAA Fisheries, personal communication, 11 January 2013).

\subsubsection{An Additive Model of Net Ecosystem Improvement}

This model is intended to illustrate the maximum potential primary and secondary productivity increase catalyzed by the CEERP, and as detailed below, its assumptions are not conservative.

Primary and Secondary Productivity. We determined mean aboveground biomass values of 600 $1,125 \mathrm{~g}$ dry $/ \mathrm{m}^{2}$ for emergent marshes and 445-909 $\mathrm{g}$ dry $/ \mathrm{m}^{2}$ for recently reconnected marshes (Table 4). Typically, the non-biting midges (Family Chironomidae) and other dipterans were the most abundant prey (Table 4). Prey communities are known to be exceedingly patchy (Winemiller et al. 2010), and this certainly is the case for dipterans in the LCRE (K. MacNeale, NOAA Fisheries, personal communication, 18 June 2013). Prey community variability can be summarized as that occurring across river stretches, habitats, among studies, and within a study. We found that the abundances of the important prey resources from all vegetative cover types varied considerably across river stretches and habitats. For example, chironomids in fallout traps (FOTs) were more abundant between rkm 30 and 86 than between rkm 0 and 29 and were generally more abundant in emergent marshes than in forested marshes. Amongstudy variability in the LCRE was often high as shown by the FOT data for emergent and restored marsh area between rkm 30 and 86 for which the coefficients of variation (CVs) were $64 \%$ and $115 \%$, respectively. Within-study variability from each of the sample types usually was high with CVs typically greater than $50 \%$ but often greater than $100 \%$.

Restored Area. Of the 34 hydrologic reconnection projects documented complete by mid-2012, data on the area affected are available for 19 (total area $6.03 \mathrm{~km}^{2}$ ); an additional 8 projects have recorded data on the length of channel or stream affected (total $38.95 \mathrm{~km}$ ), leaving 7 projects with no spatial measure of effect (Table 5). Until recently, a standard programmatic definition of the tidal wetland 
Table 4. Salmon prey data from studies between 2002 and 2010 and aboveground herbaceous plant biomass data from 1980 and 2011 ( $\mathrm{n}=\#$ data points or \# site-year). Prey were collected in fallout traps (FOTs), emergent traps (ETs), and benthic cores (BCs) in the months of April, May, and June. Peak biomass (live and dead) data were collected in the months of July or August. Prey resources data are means of data from all studies/samples. Standard deviations are in parentheses. All land cover not labeled "restored" is considered a reference wetland type.

\begin{tabular}{|c|c|c|c|c|c|c|c|c|c|c|c|}
\hline \multicolumn{5}{|c|}{ Study Characteristics } & \multicolumn{5}{|c|}{ Prey Resources $\left(\# / \mathrm{m}^{2}\right)$} & \multicolumn{2}{|c|}{ Plant Biomass $\left(\mathrm{g} / \mathrm{m}^{2}\right)$} \\
\hline $\begin{array}{l}\text { River Position } \\
\text { (Rkm) }\end{array}$ & $\begin{array}{c}\text { Plant Community } \\
\text { Land Cover }\end{array}$ & $\begin{array}{c}\text { Prey } \\
\text { Capture } \\
\text { Method }^{(a)} \\
\end{array}$ & Duration & $\begin{array}{c}\text { No. studies } \\
\text { - samples }\end{array}$ & $\begin{array}{l}\text { Chiron- } \\
\text { omidae }\end{array}$ & $\begin{array}{l}\text { Other } \\
\text { Diptera }\end{array}$ & $\begin{array}{l}\text { Hemip- } \\
\text { tera }\end{array}$ & $\begin{array}{l}\text { Arach- } \\
\text { nida }\end{array}$ & $\begin{array}{l}\text { Amphi- } \\
\text { poda }\end{array}$ & $\begin{array}{l}\text { No. studies - } \\
\text { samples }\end{array}$ & $\begin{array}{c}\text { Dry } \\
\text { Weight }\end{array}$ \\
\hline $0-29$ & Emergent marsh & FOT & $48 \mathrm{~h}$ & $1-15$ & $\begin{array}{c}141 \\
\text { (NA) }\end{array}$ & $\begin{array}{c}275 \\
\text { (NA) }\end{array}$ & $\begin{array}{c}61 \\
\text { (NA) }\end{array}$ & $\begin{array}{c}104 \\
(\mathrm{NA})\end{array}$ & - & $16-147$ & $\begin{array}{l}1125 \\
(465)\end{array}$ \\
\hline $0-29$ & Restored & FOT & $48 \mathrm{~h}$ & $1-15$ & $\begin{array}{l}192 \\
\text { (NA) }\end{array}$ & $\begin{array}{c}42 \\
\text { (NA) }\end{array}$ & $\begin{array}{c}7 \\
\text { (NA) }\end{array}$ & $\begin{array}{c}12 \\
\text { (NA) }\end{array}$ & - & $2-14$ & $\begin{array}{c}849 \\
(613)\end{array}$ \\
\hline $30-86$ & Emergent marsh & FOT & $48 \mathrm{~h}$ & $5-75$ & $\begin{array}{l}1113 \\
(713)\end{array}$ & $\begin{array}{c}288 \\
(114)\end{array}$ & $\begin{array}{l}18 \\
(8)\end{array}$ & $\begin{array}{l}19 \\
(6)\end{array}$ & - & $16-131$ & $\begin{array}{c}866 \\
(415)\end{array}$ \\
\hline $30-86$ & Emergent marsh & $\mathrm{BC}$ & instant & $3-45$ & $\begin{array}{l}139 \\
(28)\end{array}$ & $\begin{array}{c}898 \\
(289)\end{array}$ & - & - & $\begin{array}{l}148 \\
(116)\end{array}$ & - & - \\
\hline $30-86$ & Shrub & FOT & $48 \mathrm{~h}$ & $1-15$ & $\begin{array}{c}170 \\
\text { (NA) }\end{array}$ & $\begin{array}{c}77 \\
\text { (NA) }\end{array}$ & $\begin{array}{c}12 \\
(\mathrm{NA})\end{array}$ & $\begin{array}{c}17 \\
\text { (NA) }\end{array}$ & - & - & - \\
\hline $30-86$ & Forested & FOT & $48 \mathrm{~h}$ & $3-45$ & $\begin{array}{c}76 \\
(19)\end{array}$ & $\begin{array}{l}140 \\
(48)\end{array}$ & $\begin{array}{l}16 \\
(10)\end{array}$ & $\begin{array}{l}21 \\
(11)\end{array}$ & - & - & - \\
\hline $30-86$ & Forested & $\mathrm{BC}$ & instant & $1-15$ & $\begin{array}{c}56 \\
(\mathrm{NA})\end{array}$ & $\begin{array}{c}556 \\
\text { (NA) }\end{array}$ & - & - & $\begin{array}{c}583 \\
(\mathrm{NA})\end{array}$ & - & - \\
\hline $30-86$ & Restored & FOT & $48 \mathrm{~h}$ & $2-34$ & $\begin{array}{c}454 \\
(522)\end{array}$ & $\begin{array}{c}284 \\
(205)\end{array}$ & $\begin{array}{l}10 \\
(7)\end{array}$ & $\begin{array}{c}8 \\
(8)\end{array}$ & - & $2-16$ & $\begin{array}{c}909 \\
(387)\end{array}$ \\
\hline $30-86$ & Emergent marsh & ET & $48 \mathrm{~h}$ & $2-69$ & $\begin{array}{l}25 \\
(2)\end{array}$ & $\begin{array}{c}31 \\
(23)\end{array}$ & $\begin{array}{c}2 \\
(1)\end{array}$ & - & - & - & - \\
\hline $30-86$ & Forested & ET & $48 \mathrm{~h}$ & $1-15$ & $\begin{array}{c}20 \\
\text { (NA) }\end{array}$ & $\begin{array}{c}16 \\
\text { (NA) }\end{array}$ & $\begin{array}{c}1 \\
\text { (NA) }\end{array}$ & - & - & - & - \\
\hline $87-136$ & Emergent Marsh & ET & $48 \mathrm{~h}$ & $1-15$ & $\begin{array}{c}9 \\
\text { (NA) }\end{array}$ & $\begin{array}{c}13 \\
(\mathrm{NA})\end{array}$ & $\begin{array}{c}0.4 \\
\text { (NA) }\end{array}$ & - & - & $2-16$ & $\begin{array}{l}600 \\
(36)\end{array}$ \\
\hline $87-136$ & Restored & NA & - & - & - & - & - & - & - & $3-24$ & $\begin{array}{c}445 \\
(196)\end{array}$ \\
\hline
\end{tabular}

(a) $\mathrm{FOT}=$ adults; $\mathrm{BC}=$ pupae; $\mathrm{ET}=$ pupae.

$\mathrm{NA}=$ not applicable because the standard deviation could not be calculated when data from only one study were available. 
Table 5. Cumulative net ecosystem improvement model of the effects of increased restored area on primary and secondary productivity. The "estimated additional area restored" is determined by multiplication of mean project area by number of projects with unreported size. Dipterans and biomass are estimated by multiplication of reference emergent-marsh values in Table 4 by total estimated restored area.

\begin{tabular}{ccccccc}
\hline & $\begin{array}{c}\text { Number of } \\
\text { reported } \\
\text { projects } \\
\text { meeting } \\
\text { criteria }\end{array}$ & $\begin{array}{c}\text { Reported area } \\
\text { restored } \\
\left(\mathrm{km}^{2}\right)\end{array}$ & $\begin{array}{c}\text { No. projects with } \\
\text { no area } \\
\text { data/estimated } \\
\text { additional area } \\
\text { restored }\left(\mathrm{km}^{2}\right)\end{array}$ & $\begin{array}{c}\text { Total } \\
\text { estimated } \\
\text { restored area } \\
\left(\mathrm{km}^{2}\right)\end{array}$ & $\begin{array}{c}\text { Estimated } \\
\text { dipterans in } \\
\text { spring, fallout } \\
\text { traps (\# in } \\
\text { billions/48 } \mathrm{h})\end{array}$ & $\begin{array}{c}\text { Estimated } \\
\text { annual } \\
\text { biomass flux } \\
(\text { metric tons })\end{array}$ \\
\hline $0-29$ & 14 & 1.7 & $8 / 2.5$ & 4.2 & 1.7 & 4780 \\
\hline $30-86$ & 11 & 2.8 & $3 / 1.0$ & 3.8 & 5.3 & 3271 \\
$87-136$ & 2 & 0.8 & $0 / 0$ & 0.8 & $\mathrm{ND}$ & 478 \\
$137-181$ & 2 & 0.3 & $1 / 0.3$ & 0.6 & $\mathrm{ND}$ & $\mathrm{ND}$ \\
$182-235$ & 5 & 0.4 & $3 / 1.0$ & 1.4 & $\mathrm{ND}$ & $\mathrm{ND}$ \\
\hline Total & 34 & 6.0 & $15 / 4.8$ & 10.8 & $7.0^{(\mathrm{a})}$ & $8529^{(\mathrm{b})}$ \\
\hline
\end{tabular}

(a) The total reflects the region from river kilometer 86 to the mouth because of insufficient data further upriver.

(b) The total reflects the region from river kilometer 136 to the mouth because of insufficient data further upriver. $\mathrm{ND}=$ no data.

restoration area affected in the CEERP did not incorporate river stage; thus, areas are those reported to the EP by project sponsors. The minimum and maximum sizes of the reported projects completed are $0.004 \mathrm{~km}^{2}$ and $0.81 \mathrm{~km}^{2}$, respectively. The median size of the 19 projects completed is $0.24 \mathrm{~km}^{2}$; the mean size is $0.32 \mathrm{~km}^{2}(\mathrm{CV}=82 \%)$. If, despite this variation, we assign the mean size value to the remaining 15 projects without available area data, the total estimated area of completed projects would increase to $10.79 \mathrm{~km}^{2}$. In addition, as of the date of this assessment, four projects were in progress, three totaling $.38 \mathrm{~km}^{2}$ and one producing 4 stream kilometers; property for six projects had been acquired and restoration was in the planning stages.

The historical area of the floodplain of the LCRE was $1,468 \mathrm{~km}^{2}$, and calculations of potential restored area using alternative methods ranged from 344 to $403 \mathrm{~km}^{2}$. The reported area restored to date of $\sim 6.0 \mathrm{~km}^{2}$, and the area restored to date estimated by the CNEI model of $\sim 10.8 \mathrm{~km}^{2}$ are $\sim .4 \%$ and $\sim .7 \%$ of the historical floodplain area of $1,468 \mathrm{~km}^{2}$, respectively. Taking this historical floodplain area, and subtracting values for developed area, existing habitat area, and the surface area of the main-stem river from recent land-cover analyses, we calculate that the potential recoverable area is $\sim 344 \mathrm{~km}^{2}$ of which $10.8 \mathrm{~km}^{2}$ would represent $\sim 3.1 \%$. (An independent calculation using EP land-cover analysis estimated the potential restorable area at $403 \mathrm{~km}^{2}$ (K. Marcoe, personal communication, 28 June 2013). In summary, $\sim 3.1 \%$ of the restorable area has been restored under the CEERP, which represents $\sim 0.4 \%$ of the historical floodplain area; the historical area calculation includes the main-stem river and rarely connected floodplain habitats, and for reference, the recent land-cover analysis concluded the main-stem river covers $655 \mathrm{~km}^{2}$.

CNEI Model. We can generate ballpark estimates of future prey presence and biomass flux in restored areas, given our assumptions (detailed in Section 3.1.2) regarding project size estimation, uniform spatial distribution within the project area, and the use of reference emergent-marsh mean abundance values (Table 4) to represent the eventual prey and biomass presence at restoration sites following ecosystem development. While we do not use the biomass and prey data from restored sites in 
these calculations, we note that productivity is substantial even in these early-stage $(<5$ years after hydrologic reconnection) restoring areas (Table 4). To estimate future annual biomass flux from the restored area, we multiplied the biomass flux sampled at emergent-marsh reference sites in a zone (Table 4) by the total estimated restored area in a zone, resulting in a total of 8,529 MT between rkm 0 and 136 (the area for which data were available) (Table 5). Because of known differences in plant communities above rkm 136, we could not extrapolate the results of this analysis of primary and secondary productivity to the region of the LCRE between rkm 137 and rkm 235 .

Given the above-described assumptions, in the following calculations, we summed the Chironomidae, other diptera and hemiptera in emergent-marsh reference sites by zone (Table 4), and multiplied by the total estimated restored area for that zone (Table 5):

- The $4.2 \mathrm{~km}^{2}$ of restoring area between rkm 0 and 29 could support about 1.7 billion adult dipteran insects $/ 48 \mathrm{~h}$ based on data collected in the months of April-June with FOTs (no data for benthic or emerging species) (Table 5).

- The $3.8 \mathrm{~km}^{2}$ of restoring area between rkm 30 and 86 could support about 5.3 billion adult dipteran insects $/ 48 \mathrm{~h}$ based on data collected in the months of April-June with FOTs (Table 5); about 3.9 billion dipterans inhabiting the benthos (instantaneous measurement); and about 213 million emerging dipteran insects/48 $\mathrm{h}$.

- We have emergent trap data available for the $0.8 \mathrm{~km}^{2}$ of restoring area between rkm 87 and 136 , which indicate that about 18 million dipteran insects $/ 48 \mathrm{~h}$ could emerge in this restoring area.

\subsubsection{Estuary-Wide Qualitative Meta-Analysis of Restoration Project Performance}

From seven restoration projects in the LCRE where effectiveness was monitored, we identified paired restoration and reference site data relevant to four habitat-based and one fish-based ancillary hypothesis (Table 6). The resulting qualitative meta-analysis involved 24 instances where, for purposes of this evidence-based evaluation, we compared results for a given monitored indicator at the restoration site to data from the associated reference site (not a control site) to address the hypothesis that post-restoration condition is on a trajectory toward the condition at the reference site. Of the 24 data points, 13 indicated support, 6 indicated lack of support, and 5 were inconclusive relative to the respective ancillary hypothesis. Generally, results across the seven restoration sites were mixed for four of five monitored indicators, the exception being the sediment accretion ancillary hypothesis, which was supported in the instances it was evaluated. All "lack of support" results were from restoration actions where a new tide gate was installed on a relatively small slough (not a tidal river). "Inconclusive" results for water level and temperature at Julia Butler Hansen National Wildlife Refuge (NWR) were caused by uncertainty about how a muted tidal cycle affects ecological processes. Furthermore, the trend in trajectory of vegetation at restoration and reference sites for KF is inconclusive in this early-stage assessment, because of the relatively long response time of this variable and the lack of information regarding the ecological relationship between juvenile salmon and prevalent non-native vegetation species (e.g., reed canary grass [Phalaris arundinacea]). At two sites (Crims Island and KF), positive trends in the presence of juvenile salmon were associated with improved water levels. 
Table 6. Qualitative meta-analysis based on comparisons between paired restoration and reference sites for five response metrics. Color codes indicate our interpretation of results relative to the ancillary hypotheses for this evidence-based evaluation.

\begin{tabular}{|c|c|c|c|c|c|c|}
\hline $\begin{array}{l}\text { Restoration } \\
\text { Project }\end{array}$ & $\begin{array}{l}\text { Restoration } \\
\text { Action }\end{array}$ & Water Level & $\begin{array}{l}\text { Sediment } \\
\text { Accretion }\end{array}$ & $\begin{array}{c}\text { Water } \\
\text { Temperature }\end{array}$ & $\begin{array}{l}\text { Vegetation } \\
\text { Similarity }\end{array}$ & $\begin{array}{c}\text { Salmon } \\
\text { Presence }\end{array}$ \\
\hline Crims Island & $\begin{array}{l}\text { Channel } \\
\text { Excavation, } \\
\text { Grading }\end{array}$ & $\begin{array}{l}\text { Haskell and } \\
\text { Tiffan } 2011\end{array}$ & $\begin{array}{l}\text { Thom et al. } \\
2012^{\text {(a) }}\end{array}$ & & $\begin{array}{l}\text { Thom et al. } \\
2012\end{array}$ & $\begin{array}{l}\text { Haskell and } \\
\text { Tiffan } 2011\end{array}$ \\
\hline Johnson Farm & Dike Breach & & & & & Eaton $2010^{(b)}$ \\
\hline Kandoll Farm & $\begin{array}{l}\text { Dike Breach, } \\
\text { Culvert } \\
\text { Installation }\end{array}$ & $\begin{array}{l}\text { Roegner et } \\
\text { al. } 2010\end{array}$ & $\begin{array}{l}\text { Thom et al. } \\
2012^{\text {(a) }}\end{array}$ & $\begin{array}{l}\text { Roegner et al. } \\
\text { 2010, Thom et al. } \\
2012\end{array}$ & $\begin{array}{l}\text { Thom et al. } \\
2012^{(\mathrm{e})}\end{array}$ & $\begin{array}{l}\text { Roegner et } \\
\text { al. } 2010^{(\mathrm{f})}\end{array}$ \\
\hline South Slough & $\begin{array}{l}\text { Dike Breach, } \\
\text { Culvert } \\
\text { Removal }\end{array}$ & $\begin{array}{l}\text { CREST } \\
2012\end{array}$ & & CREST 2012 & & CREST 2012 \\
\hline $\begin{array}{l}\text { Julia Butler } \\
\text { Hansen NWR }\end{array}$ & $\begin{array}{l}\text { Tide-Gate } \\
\text { Replacement }\end{array}$ & $\begin{array}{l}\text { Johnson J et } \\
\text { al. 2009, } \\
2011^{(\mathrm{c})}\end{array}$ & & $\begin{array}{l}\text { Johnson J et al. } \\
2009,2011\end{array}$ & & $\begin{array}{l}\text { Johnson J et } \\
\text { al. 2009, } \\
2011^{(\mathrm{d})}\end{array}$ \\
\hline $\begin{array}{l}\text { Tenasillahe } \\
\text { Island }\end{array}$ & $\begin{array}{l}\text { Tide-Gate } \\
\text { Replacement }\end{array}$ & $\begin{array}{l}\text { Johnson J et } \\
\text { al. } 2008\end{array}$ & & $\begin{array}{l}\text { Johnson J et al. } \\
2008\end{array}$ & & $\begin{array}{l}\text { Johnson J et } \\
\text { al. } 2008\end{array}$ \\
\hline Vera Slough & $\begin{array}{l}\text { Tide-Gate } \\
\text { Replacement }\end{array}$ & $\begin{array}{l}\text { Thom et al. } \\
2012^{\text {(c) }}\end{array}$ & $\begin{array}{l}\text { Thom et al. } \\
\text { 2012, In } \\
\text { Prep.--b } \\
\text { (a) }\end{array}$ & Thom et al. 2012 & $\begin{array}{l}\text { Thom et al. } \\
2012\end{array}$ & $\begin{array}{l}\text { Thom et al. } \\
2012^{(\mathrm{g})}\end{array}$ \\
\hline
\end{tabular}

Key: green $=$ support; red $=$ lack of support; yellow $=$ inconclusive; dark gray $=$ insufficient data; white $=$ not evaluated.

(a) Compared to the reference site, we observed a relatively high sediment accretion rate (as expected).

(b) Juvenile chum, coho, and Chinook salmon were found in both the restoration site and the reference site, although migration patterns varied between the two sites because of differences in location relative to the mainstem Grays River.

(c) Water levels were improved although still muted behind the tide gates at the restoration site; there is uncertainty about how a muted tidal cycle affects ecological processes.

(d) Opportunity to access habitats increased after the new tide gates were installed.

(e) The restoration and reference sites at Kandoll Farm have substantially different elevations, which will affect the comparison of vegetation communities.

(f) A location outside of Kandoll Farm on Seal Slough was used as a reference site for fish sampling.

(g) Few juvenile salmon were captured at either the restoration or reference sites at Vera Slough.

\subsubsection{Ecological Relationships}

At the outset of this study in 2004, substantial uncertainty regarding fundamental ecological relationships in the LCRE existed, hindering the development of restoration projects because of the difficulty of predicting site-scale responses to restoration actions. Here we briefly summarize 12 particularly relevant relationships that research has addressed, the findings of which inform the conceptual model and this evidence-based assessment. In the relationships listed below, the response variable may also be dependent on independent variables in addition to those listed, i.e., we are not implying that the response variable is solely a function of the independent variables that are included. Generally, data indicate the following: 
- Most estuarine food webs supporting subyearling Chinook salmon are a function of autochthonous marsh production (Maier and Simenstad 2009).

- Juvenile salmon presence at wetland restoration sites is a function of water temperature, whereby peak abundances are at temperatures below $19^{\circ} \mathrm{C}$ although fish can be present even at $23^{\circ} \mathrm{C}$ (e.g., Roegner et al. 2010).

- The opportunity for juvenile salmon to access a restoring wetland is a function (positive relationship) of physical wetted area and biological migration timing (Roegner et al. In Preparation).

- The cross-sectional area of a channel at its outlet is a function of the contributing catchment area and of the total length of channels upstream (Diefenderfer et al. 2008).

- The number of pools present in forested wetlands is a function of the number of log jams (Diefenderfer and Montgomery 2009).

- Plant community composition is a function of salinity, land elevation, and inundation (Diefenderfer et al. 2013; Borde et al. 2012a, b, In Preparation; Sager et al. 2013).).

- LCRE-wide, system zonation is a function of topography, salinity intrusion, the balance of tidal and fluvial forces, and vegetation (Borde et al. 2012a, b; Jay et al. In Revision, In Review; Sager et al. 2013).

- Sediment accretion/erosion rate is a function (negative relationship) of land elevation (Thom et al. 2012).

- Stock-specific density of juvenile salmon present in restoring wetland habitats is a function (negative relationship) of the distance of the natal stream from the wetland; i.e., there is proportionally greater representation from local stocks than more distant stocks in LCRE wetlands (Roegner et al. 2010; Sather et al. 2011).

- The density of juvenile salmon in shallow-water habitats is a function (negative relationship) of fish size (Sather et al. 2011; Roegner et al. 2010, 2012).

- Regardless of size, residence time of juvenile salmon in off-channel areas is a function (negative relationship) of the propensity to be actively migrating to the ocean (Johnson et al. In Preparation).

- The accessibility of juvenile salmon to reconnected wetlands is a function (positive relationship) of the degree to which natural hydrologic processes are restored (Greene et al. 2012).

- The size of subyearling Chinook and chum salmon in the LCRE is a function (positive relationship) of Julian date and distance from Bonneville Dam (Roegner et al. 2012; Sather et al. 2011).

\subsubsection{Offsite Benefits to Juvenile Salmon}

Stomach fullness and diet data for fish sampled in the smolt bypass system at John Day Dam (rkm 349) show that $12 \%$ of juvenile steelhead, $11 \%$ of yearling Chinook salmon, and $27 \%$ of subyearling Chinook salmon had been actively feeding (Table 7, Figure 6). At Bonneville Dam (rkm 235), those numbers drop to 5-7\%. In contrast, near the mouth of the river (rkm 15), 68\% of juvenile steelhead, $56 \%$ of yearling Chinook salmon, and $52 \%$ of subyearling Chinook salmon were actively feeding, indicating the fish actively foraged while transiting the LCRE.

Stomach content weights for fish sampled at rkm 15 were typically $0.2-0.8 \%$ of body weight, and typically contained 1/3-1/2 Americorophium amphipod crustaceans and 1/3-1/2 insects (primarily dipterans) by wet weight (Table 7). The percentage of insects was highest in the stomach contents of juvenile steelhead (54\%). 


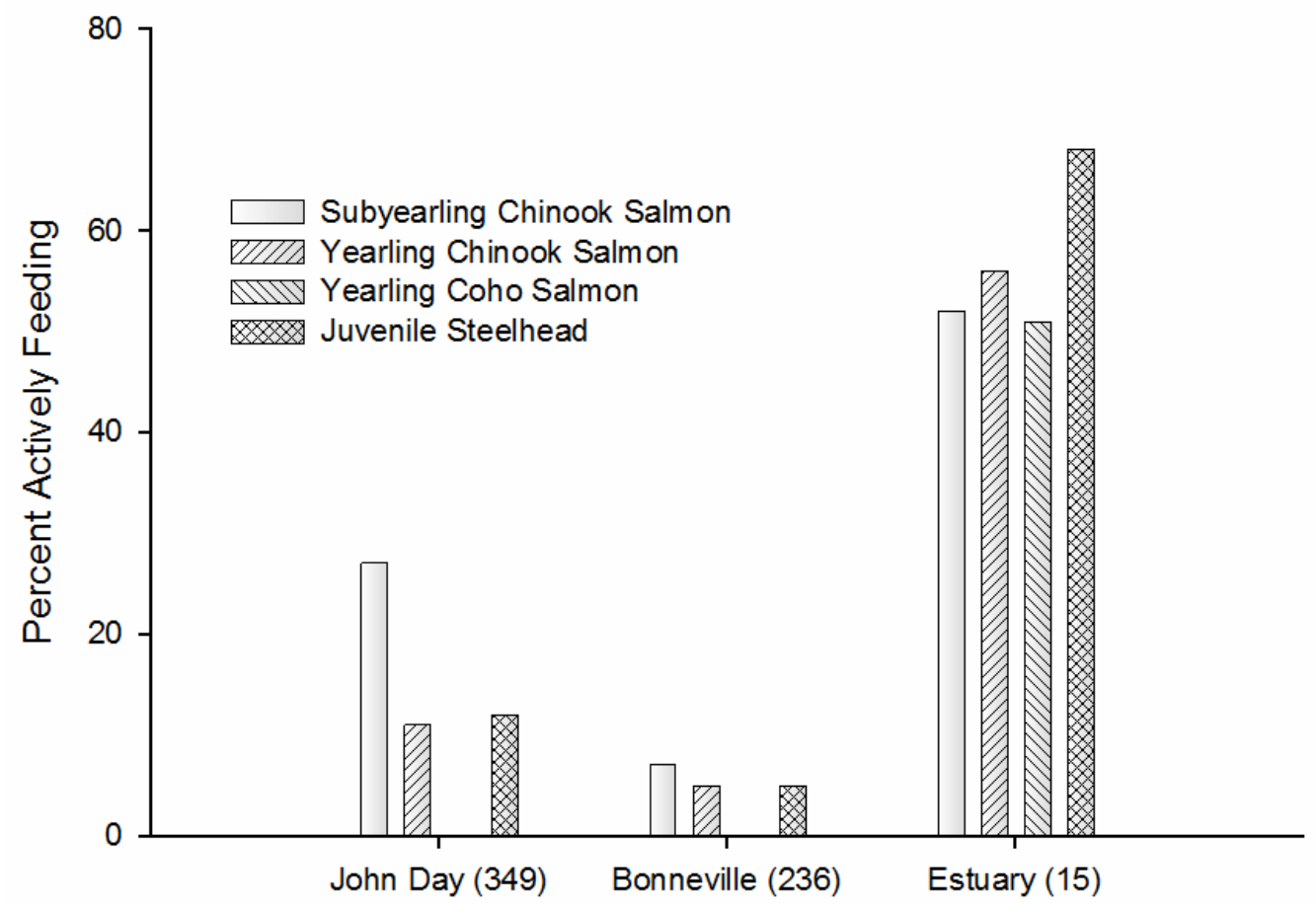

Figure 6. Percentage of juvenile salmon actively feeding in the Columbia River measured near John Day Dam, Bonneville Lock and Dam, and river kilometer 15 in the estuary. River kilometer is in parentheses. No data were available for yearling coho salmon at the dams.

Table 7. Percentage of juvenile salmon actively feeding, average stomach fullness, and percentage wet weight of identifiable prey made up of Americorophium and insects. Active feeding is defined as $>24 \%$ stomach fullness of identifiable prey taxa including Americorophium amphipod crustaceans, insects (primarily dipterans), crustaceans, and fish. Active feeding data are for 2010-2012 near John Day (rkm 349) and Bonneville (rkm 236) dams, and 2007-2011 near the mouth of the Columbia River (rkm 15). At the Columbia River mouth, the average stomach fullness is expressed as percent body weight.

\begin{tabular}{|c|c|c|c|c|c|c|}
\hline & \multirow[b]{2}{*}{$\begin{array}{l}\text { John Day } \\
\\
\text { \% Fish } \\
\text { Actively } \\
\text { Feeding } \\
\text { (n) }\end{array}$} & \multirow[b]{2}{*}{$\begin{array}{c}\text { Bonneville } \\
\\
\text { \% Fish } \\
\text { Actively } \\
\text { Feeding } \\
\text { (n) }\end{array}$} & \multicolumn{4}{|c|}{ Columbia River Mouth } \\
\hline & & & $\begin{array}{l}\% \text { Fish } \\
\text { Actively } \\
\text { Feeding } \\
\text { (n) }\end{array}$ & $\begin{array}{l}\text { Average } \\
\text { Stomach } \\
\text { Fullness } \\
\text { (\% body } \\
\text { weight) }\end{array}$ & $\begin{array}{c}\% \text { Wet Weight Stomach } \\
\text { Contents } \\
\text { Americorophium } \\
\text { (standard deviation) }\end{array}$ & $\begin{array}{l}\% \text { Wet Weight } \\
\text { Stomach } \\
\text { Contents Insects } \\
\text { (standard } \\
\text { deviation) }\end{array}$ \\
\hline $\begin{array}{l}\text { Subyearling } \\
\text { Chinook } \\
\text { Salmon }\end{array}$ & $\begin{array}{c}27 \\
(441)\end{array}$ & $\begin{array}{c}7 \\
(292)\end{array}$ & $\begin{array}{c}52 \\
(193)\end{array}$ & $\begin{array}{c}0.63 \\
(0.83)\end{array}$ & $\begin{array}{c}36 \\
(44)\end{array}$ & $\begin{array}{c}34 \\
(42)\end{array}$ \\
\hline $\begin{array}{l}\text { Yearling } \\
\text { Chinook } \\
\text { Salmon }\end{array}$ & $\begin{array}{c}11 \\
(626)\end{array}$ & $\begin{array}{c}5 \\
(456)\end{array}$ & $\begin{array}{c}56 \\
(107)\end{array}$ & $\begin{array}{c}0.83 \\
(0.97)\end{array}$ & $\begin{array}{c}47 \\
(42)\end{array}$ & $\begin{array}{c}28 \\
(38)\end{array}$ \\
\hline Yearling Coho & ND & ND & $\begin{array}{c}51 \\
(171)\end{array}$ & $\begin{array}{c}0.68 \\
(0.72)\end{array}$ & $\begin{array}{c}48 \\
(43)\end{array}$ & $\begin{array}{c}32 \\
(41)\end{array}$ \\
\hline $\begin{array}{l}\text { Juvenile } \\
\text { Steelhead }\end{array}$ & $\begin{array}{c}12 \\
(600)\end{array}$ & $\begin{array}{c}5 \\
(406)\end{array}$ & $\begin{array}{c}68 \\
(109)\end{array}$ & $\begin{array}{c}0.19 \\
(0.37)\end{array}$ & $\begin{array}{c}40 \\
(44)\end{array}$ & $\begin{array}{c}54 \\
(45)\end{array}$ \\
\hline
\end{tabular}


According to genetic-stock analysis and tag data (coded-wire tag, PIT tag), the origins of juvenile salmon captured near rkm 15 for this research included the Willamette; lower, mid-, and upper Columbia; and Snake River basins (Weitkamp et al. 2012, unpublished data).

\subsection{Analysis of Literature from Analogous Ecosystems}

The selection process identified 15 papers that met the criteria for relevancy-original salmon data, hydrologic reconnection, and a tidal study area - and were not redundant with the others. The final set included studies on only eight world rivers: the Skjern in Denmark, the Sacramento in California, and in the Pacific Northwest the Chehalis, Duwamish, Fraser, Columbia (Grays), Puyallup, and Snohomish. Thus, on average, approximately two papers were published for each river system that contained data that were not redundant to other data (typically these data represented different indicator categories). We scored these to evaluate the hypothesis that fish-based indicators of ecosystem processes and functions show positive effects from restoration.

The strength of association and consistency of association criteria are met if results show a $>20$ study weight supporting and a $<20$ study weight not supporting the indicator category; the consistency of association criterion is not met if there is $\geq 20$ study weight supporting and $\geq 20$ study weight not supporting the indicator category (Norris et al. 2012). Therefore, the conclusion of the causal criteria analysis of literature was strong and consistent support for the hypothesis based on three indicator categories - presence, prey, and diet — two of which had overwhelming supporting evidence (approximately twice the minimum requirement) (Table 8a). Insufficient evidence was available in these studies to evaluate the remaining four categories (survival, stomach fullness, fish growth and residence time). However, evidence reported by five studies supported growth of juvenile salmon, and evidence against growth was found at just one of three sites in one study. Evidence reported by four studies supported residence time, and no evidence against residence time was reported. Therefore, evidence for both growth and residence time is highly consistent based on the scoring method. Only three studies evaluated fullness and two studies evaluated survival, and evidence was inconsistent.

In the CEERP restoration reports, insufficient evidence was available to evaluate six of the fish indicator categories and evidence for the seventh, salmon presence, was inconsistent as measured by abundance, density, or CPUE (Table 8b). While the data were insufficient for the purpose of this scoring approach, there were indications of positive responses in residence, prey, and diet at Crims Island (Haskell and Tiffan 2011), diet at the Grays River (Roegner et al. 2010), and growth at Tenasillahe (Johnson, J. et al. 2008). On this basis, there were no findings from the LCRE that were inconsistent with the global review. 
Table 8. Causal criteria scoring of the literature: (a) analogous cases, tidal rivers, and (b) LCRE (tidal reconnection projects since 2004).

\begin{tabular}{|c|c|c|c|c|c|c|c|c|c|c|c|c|c|c|c|c|c|c|c|c|}
\hline \multirow[b]{2}{*}{ River } & \multirow[b]{2}{*}{ Study } & \multirow{2}{*}{$\begin{array}{c}\text { \# Ref. or } \\
\text { Control } \\
\text { Sites }\end{array}$} & \multirow{2}{*}{$\begin{array}{l}\# \\
\text { Rest. } \\
\text { Sites }\end{array}$} & \multirow{2}{*}{$\begin{array}{l}\text { Total Rep. } \\
\text { Weight }{ }^{(\mathrm{a})}\end{array}$} & \multirow{2}{*}{$\begin{array}{c}\text { Study } \\
\text { Design } \\
\text { Type } \\
\text { Weight }^{(b)} \\
\end{array}$} & \multirow{2}{*}{$\begin{array}{c}\text { Total } \\
\text { Study } \\
\text { Weight } \\
\text { (e) }\end{array}$} & \multicolumn{2}{|c|}{$\begin{array}{l}\text { Abundance/ } \\
\text { Density/ } \\
\text { CPUE }\end{array}$} & \multicolumn{2}{|c|}{$\begin{array}{l}\text { Residence } \\
\text { Time }\end{array}$} & \multicolumn{2}{|c|}{ Survival } & \multicolumn{2}{|c|}{$\begin{array}{l}\text { Prey Taxa } \\
\text { Composition/ } \\
\text { Abundance }\end{array}$} & \multicolumn{2}{|c|}{$\begin{array}{c}\text { Diet } \\
\text { Composition } \\
\text { (feeding) }\end{array}$} & \multicolumn{2}{|c|}{$\begin{array}{l}\text { Stomach } \\
\text { Fullness }\end{array}$} & \multicolumn{2}{|c|}{$\begin{array}{c}\text { Growth/ } \\
\text { Bioenergetics }\end{array}$} \\
\hline & & & & & & & Yes & No & Yes & No & Yes & No & Yes & No & Yes & No & Yes & No & Yes & No \\
\hline \multicolumn{21}{|c|}{ (a) Analogous Cases: Tidal Rivers } \\
\hline Chehalis & $\begin{array}{c}\text { Miller \& } \\
\text { Simenstad (1997) }\end{array}$ & 1 & 1 & 2 & 2 & 4 & & & 1 & & & & & & 1 & & & 1 & 1 & \\
\hline Duwamish & $\begin{array}{l}\text { Cordell et al. } \\
\text { (2011) }\end{array}$ & 3 & 3 & 6 & 2 & 8 & 0.7 & 0.3 & & & & & & & 1 & & 1 & & 0.7 & 0.3 \\
\hline Duwamish & $\begin{array}{l}\text { Cordell et al. } \\
(2001)^{(c)}\end{array}$ & $\begin{array}{l}2 \text { or } \\
\text { more }\end{array}$ & 4 & 6 & 4 & 10 & & & & & & & 1 & & & & & & & \\
\hline Fraser & $\begin{array}{c}\text { Levings \& } \\
\text { Nishimura (1997) } \\
\text { (d) }\end{array}$ & 2 & 2 & 5 & 2 & 7 & & & 1 & & & & 0.5 & 0.5 & 1 & & & & & \\
\hline Fraser & $\begin{array}{l}\text { Scott and Susanto } \\
\text { (1993) }\end{array}$ & 2 & 2 & 5 & 2 & 7 & 1 & & & & & & & & & & & & & \\
\hline $\begin{array}{c}\text { Grays/ } \\
\text { Columbia }\end{array}$ & $\begin{array}{l}\text { Roegner et al. } \\
\text { (2010) }\end{array}$ & 0 & 2 & 2 & 1 & 3 & 1 & & & & & & & & 1 & & & & & \\
\hline Puyallup & $\begin{array}{l}\text { Shreffler et al. } \\
\text { (1990) }\end{array}$ & 0 & 1 & 0 & 1 & 1 & & & 1 & & & & & & & & & & 1 & \\
\hline Puyallup & $\begin{array}{l}\text { Shreffler et al. } \\
\text { (1992) }\end{array}$ & 0 & 1 & 0 & 1 & 1 & 1 & & & & & & 1 & & 1 & & & & & \\
\hline Sacramento & $\begin{array}{l}\text { Feyrer et al. } \\
\quad(2006)\end{array}$ & 0 & 1 & 0 & 1 & 1 & 1 & & & & & & & & & & & & & \\
\hline Sacramento & $\begin{array}{l}\text { Sommer et al. } \\
\text { (2001) }\end{array}$ & 1 & 1 & 2 & 2 & 4 & & & & & 1 & & 1 & & 1 & & & & 1 & \\
\hline Sacramento & $\begin{array}{l}\text { Sommer et al. } \\
\text { (2005) }\end{array}$ & 0 & 1 & 0 & 1 & 1 & 1 & & 1 & & & & & & & & & & 1 & \\
\hline Salmon & $\begin{array}{l}\text { Bottom et al. } \\
(2005 \mathrm{~b})\end{array}$ & 1 & 3 & 5 & 2 & 7 & 1 & & & & & & & & & & & & & \\
\hline Salmon & Gray et al. (2002) & 1 & 3 & 5 & 2 & 7 & 1 & & & & & & 1 & & 1 & & 1 & & & \\
\hline Skjern & Koed et al. (2006) & 0 & 1 & 0 & 2 & 2 & & & & & & 1 & & & & & & & & \\
\hline Snohomish & $\begin{array}{l}\text { Tanner et al. } \\
\quad(2001)\end{array}$ & 1 & 1 & 2 & 2 & 4 & 1 & & & & & & 1 & & 1 & & & & & \\
\hline & & & & & & ore Total & 8.7 & 0.3 & 4.0 & 0.0 & 1.0 & 1.0 & 5.5 & 0.5 & 8.0 & 0.0 & 2.0 & 1.0 & 4.7 & 0.3 \\
\hline & & & & Study-V & Veighted To & al Score ${ }^{(\mathrm{f})}$ & 36.3 & 2.6 & 13.0 & 0.0 & 4.0 & 2.0 & 29.5 & 3.5 & 38.0 & 0.0 & 15.0 & 4.0 & 15.3 & 2.6 \\
\hline & & & & & & clusion $^{(\mathrm{g})}$ & $\begin{array}{l}\text { Sup } \\
\text { (str }\end{array}$ & & $\begin{array}{r}\text { Insuff } \\
\text { evid }\end{array}$ & $\begin{array}{l}\text { cient } \\
\text { hce }\end{array}$ & $\begin{array}{r}\text { Insuff } \\
\text { evid }\end{array}$ & $\begin{array}{l}\text { ient } \\
\text { ice }\end{array}$ & Sup & & $\begin{array}{l}\text { Sup } \\
\text { (stro }\end{array}$ & & $\begin{array}{r}\text { Insuff } \\
\text { evid }\end{array}$ & $\begin{array}{l}\text { ient } \\
\text { tce }\end{array}$ & $\begin{array}{r}\text { Insuf } \\
\text { evid }\end{array}$ & \\
\hline
\end{tabular}


Table 8. (contd)

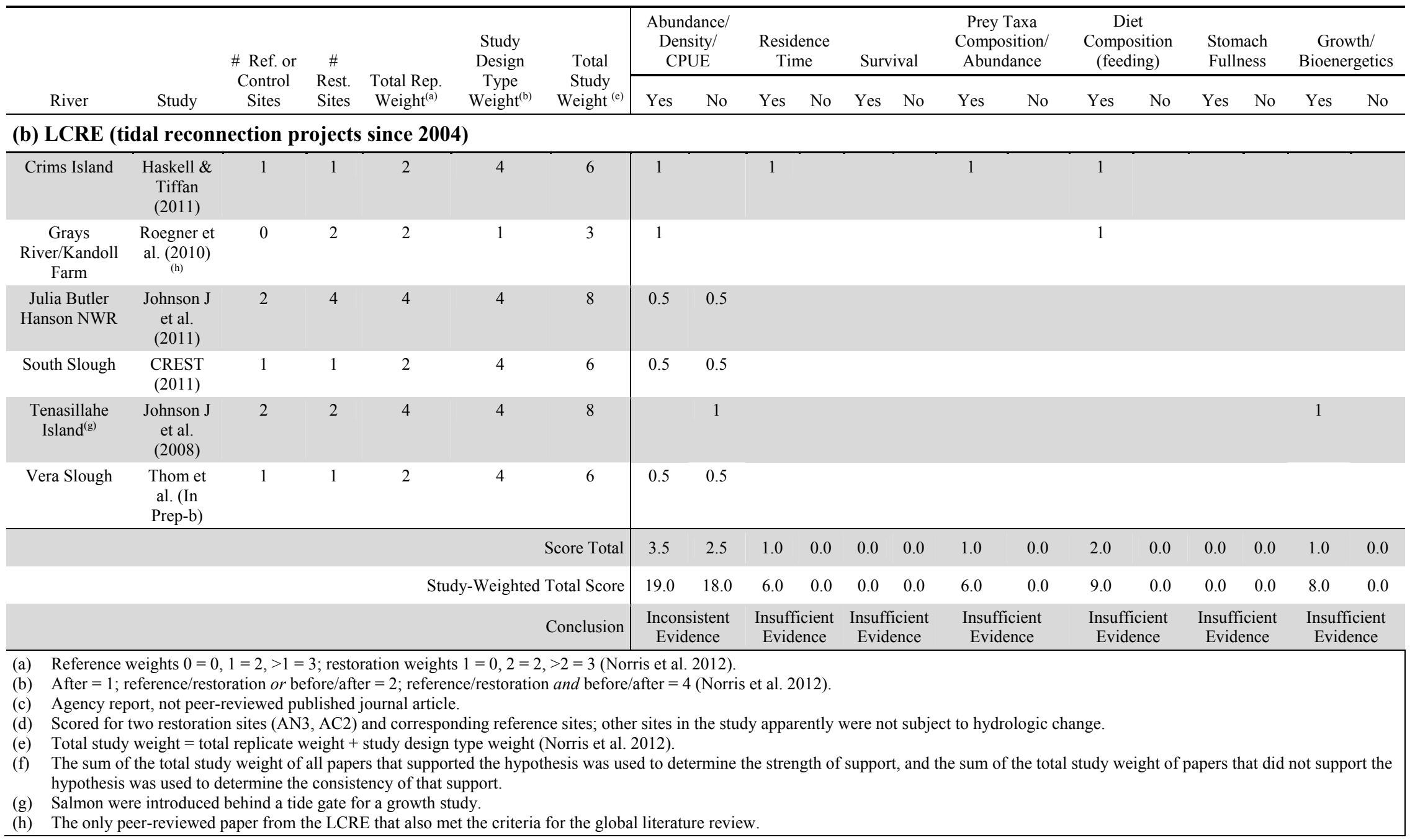




\subsection{Landscape Assessment: Contributing Watersheds}

Land-cover change trends were variable among the contributing watersheds to the eight reaches of the LCRE and between the two periods analyzed, and included both losses and gains. The majority of forest change and urbanization occurred in the contributing watersheds, not the floodplain. Wetland area fluctuated very little, likely within the margin of remote-sensing classification error, and is not reported.

Total urbanization (or impervious surface) in the contributing watersheds was $48.4 \mathrm{~km}^{2}$, a $4.6 \%$ increase over 10 years, occurring primarily in reach $F\left(12.6 \mathrm{~km}^{2}\right)$ and reach $\mathrm{G}\left(22.4 \mathrm{~km}^{2}\right)$ where the cities of Portland, Oregon, and Vancouver and Longview, Washington, are located. On the floodplain, total measured urbanization was $8.3 \mathrm{~km}^{2}$ or a $2.5 \%$ increase. More than $60 \%$ of the land area of contributing watersheds of the LCRE landscape (excluding the floodplain) was forested. The total area in evergreen, mixed, or deciduous forest or forested wetland was $>8,000 \mathrm{~km}^{2}$. We report both net change in forest cover (the sum of forest gained and lost) and cumulative forest lost (the sum of all forest lost) because of the presumed differences in ecological effects. The net change in forest cover in the 10 years from 1996 to 2006 was $-189.0 \mathrm{~km}^{2}$ in the contributing watersheds, a $2.3 \%$ net decrease, much of which is accounted for by reaches $F\left(35.8 \mathrm{~km}^{2}\right)$ and $\mathrm{G}\left(35.5 \mathrm{~km}^{2}\right)$ and lower river reaches $\mathrm{A}\left(24.3 \mathrm{~km}^{2}\right), \mathrm{B}\left(74.6 \mathrm{~km}^{2}\right)$, and $\mathrm{C}\left(15.2 \mathrm{~km}^{2}\right)$. The cumulative forest cover loss from 1996 to 2006 in the contributing watersheds was $-642.7 \mathrm{~km}^{2}$; of this, $-361.6 \mathrm{~km}^{2}$ occurred during the first 6 years of the CEERP (2001-2006). On the floodplain, the net change in forest cover from 1996 to 2006 was $-13.3 \mathrm{~km}^{2}$ and cumulative forest cover loss was $-17.7 \mathrm{~km}^{2}$.

\subsection{Summary}

Each of the 10 reported analyses, with the exception of land-cover change, involved one or more of the indicators of fish or habitat response that we identified in this evidence-based approach (Figure 3). The number of indicators treated by each analysis was constrained by either the type of analysis, the availability of data, or both. However, it is important to revisit each of the 10 analyses that contributed to the lines of evidence, and summarize the general effect observed on each relevant indicator, i.e., whether it was positive, negative or ambiguous (Table 9). There were very little or no data collected within CEERP restoration sites on response metrics for juvenile salmon, including residence time, growth, diet, prey, fullness, and survival. Even considering all of the analyses taken together, data were lacking to evaluate salmon growth and survival. Evidence supported positive responses by all other indicators, except in the case of tide-gate replacement type restoration actions. We assessed these results relative to the framework for the evidence-based assessment; i.e., if an indicator was expected to be evaluated by a particular analysis and was not, then it had "insufficient data," whereas if it was not meant to be evaluated it was "not applicable." 
Table 9. Summary of the results of 10 analyses of habitat-based and fish-based monitored indicators. Except for the global literature analysis, the analyses are of data collected in the LCRE.

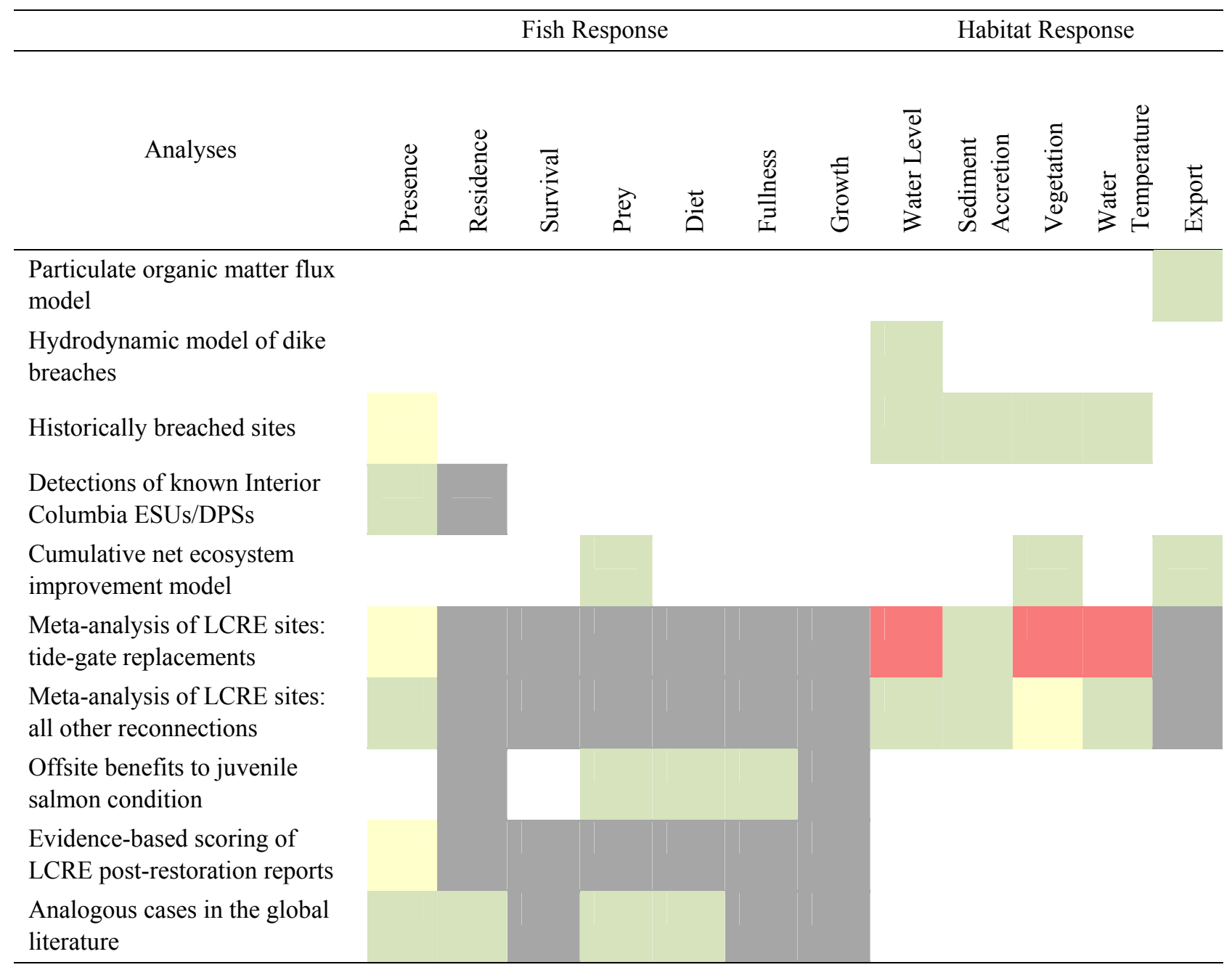

Key: green = support; red $=$ lack of support; yellow $=$ inconclusive; dark gray $=$ insufficient or no data; white $=$ not applicable, or not collected under the sampling design, for this evidence-based evaluation. 


\subsection{Synthesis and Evaluation}

In ecology, there are fast-response and slow-response variables (Carpenter and Turner 2001), as well as variables that indicate trends at larger and smaller scales (Gardner 1998). One of the problems of ecosystem management is to judge which variables are the most suitable for a given question. We have analyzed a large set of indicators from the LCRE and analogous ecosystems, with temporal ranges from $\sim 4$ to 60 years and potential spatial effect areas from $<1 \mathrm{~m}$ to $>1,000 \mathrm{~km}^{2}$. In our evidence-based assessment approach (Diefenderfer et al. 2011), the review of indicators reported in the global literature or analogous cases is augmented by six lines of evidence providing different spatial and temporal perspectives from the study region (Table 1).

In evaluating these lines of evidence against the causal criteria (Table 2), it is important to keep in mind that the study area is spatially complex and temporally dynamic and that this is an early-stage assessment. Within 5 years of tidal wetland restoration implementation in the Pacific Northwest, the conditions of slow-response variables such as vegetation cannot be expected to begin to trend toward those at reference sites, although they may undergo substantial changes from initial conditions (cf. Frenkel and Morlan 1990; Simenstad and Thom 1996; Cornu and Sadro 2002; Crooks et al. 2002; Thom et al. 2002). The response of such variables is related to initiation of other ecosystem processes such as water-level dynamics and sediment accretion. Fast-response variables may include water levels, water temperature, and the presence of juvenile salmon (Roegner et al. 2010) as well as sediment accretion rates (Diefenderfer et al. 2008). Given the stage of this analysis, it is particularly important to consider the temporal and spatial contexts provided by the lines of evidence given here in addition to site-scale restoration monitoring. We have attempted to use the best available indicators and data to answer the question of whether habitat restoration projects in the LCRE are having or will have a cumulative beneficial effect on juvenile salmon; however, the restoration effort is in its early stages.

This synthesis is organized by 11 criteria which, to paraphrase Hill (1965), are aspects of an association that should be considered before concluding that the most likely interpretation of the association is causation. While the use of these criteria as a sort of checklist has been advocated, in the origins of the approach they are rather a guide for interpretation of the accumulated evidence, and this is the sense in which we use them here. "The criteria dating back to the 1964 Surgeon General's report remain useful as guidelines for evaluating evidence (USDHEW 1964), but they were not intended to be applied strictly or as a 'checklist' that needed to be met before the designation of 'causal' could be applied to an association" (USDHEW 2006). For each criterion, our two secondary hypotheses are addressed to the extent information is available; recall: 1) habitat-based indicators of ecosystem controlling factors, processes, and structures show positive effects from restoration actions; and 2) fishbased indicators of ecosystem processes and functions show positive effects from restoration actions and

habitats undergoing restoration. Here, we review the support for and against these two hypotheses, for each criterion. Note: the strength and consistency criteria are combined below, as are temporality and specificity. 


\subsection{Causal Criteria Synthesis}

\subsubsection{Strength and Consistency of Association}

We agree with Hill (1965) that the most important criteria are the strength and consistency of the association, which are combined in our interpretation. We addressed these criteria through three lines of evidence: scoring evidence available in the literature, examining historically reconnected sites in the LCRE, and conducting meta-analysis of early-stage restoration sites in the LCRE. Evidence from other ecosystems as well as historically reconnected sites in the LCRE provides spatial and temporal context for the present-day restoration sites. Evidence from restoration in the analogous tidal rivers is particularly important because activities in the LCRE are in their early stages.

Collectively, these three lines of evidence provide a higher number of samples following restoration or natural breaching than any one alone. The number of studies from restoration sites in the LCRE is no more than seven for any ancillary hypothesis. The number of historically breached sites reported in the LCRE is only three, and two of these were sampled for salmon. The number of studies from the global literature is higher but still no more than 12 for any ancillary hypothesis. Taken together, e.g., for evaluation of salmon presence (including density, abundance, and CPUE measures), there is a total of $\mathrm{n}=17$ including 2 historically breached sites in the LCRE, 6 recently restored sites in the LCRE, and 9 studies in the global literature.

The evidence from the global literature on restoration in tidal areas where salmon exist showed scant evidence of mortality, and strong and consistent support for benefits to salmon as measured by three salmon indicators: presence, prey, and diet (Table 8). Insufficient evidence existed to evaluate other salmon indicators in analogous systems, although virtually all evidence reported supported growth of juvenile salmon and all evidence reported supported residence time.

Observations of historically reconnected sites indicated that all had become emergent marshes. Potential fish access was high as indicated by the fact that the percentage of time over 1 year that the main channel of each site was inundated to a minimum depth of $50 \mathrm{~cm}$ at the mouth was $>95 \%$. Beach seining captured juvenile salmon at one of the two sites sampled. It should be noted that the site where salmon were not captured was sampled only once in June and once in August, months in which salmon density in the LCRE is much lower than the late winter and spring (Sagar et al. 2013), so uncertainty remains regarding salmon presence in historically reconnected sites. It is also important to acknowledge that historical conditions may not be adequate to predict those in the future because of trends in relative sealevel rise on the Pacific Northwest coast (NRC 2012).

We evaluated the data from early-stage LCRE restoration sites (Table 6) relative to five of the six ancillary hypotheses: water level, water temperature, sediment accretion rate, vegetation similarity, and salmon presence (Figure 3). This evaluation indicated that it is important to distinguish tide gate from dike breach and other reconnection actions; tide-gate installations were responsible for all six cases of lack of support for the hypothesis as well as three of five inconclusive cases. Fish response measured by their entrance and use of restored habitats was mixed; salmon presence has been documented at some restoration sites and not others; in most cases, sampling intensity was not high enough to determine whether this variability is seasonal, but in some cases it has been hypothesized that the landscape position of sites relative to migration routes is a factor (Thom et al. 2012). Excluding tide gates on relatively small sloughs from the assessment, the environmental indicators of water level and temperature, sediment 
accretion rate, vegetation similarity, and salmon presence generally responded positively to hydrologic reconnection in the LCRE. At the more recent restoration sites (excluding those with tide gates), fastresponse variables such as water levels, water temperatures, and sediment accretion rates are trending toward reference site conditions.

Plant cover is trending away from before conditions but not yet toward reference site conditions. This would be expected at this stage of a diked marsh restoration in the Pacific Northwest because the elevation of a site strongly affects site water levels and thus influences the plant community dynamics during reestablishment at a site. Land behind dikes typically subsides in elevation because of factors including compaction, altered organic matter inputs and rates, evaporation from soils, mineralization of organic matter, and grading (Thom 1992). Thus, following the dramatic alteration of hydrologic processes by restoration actions at a historically subsided site, more frequent inundation occurs, and inundation is a controlling factor on the establishment of wetland vegetation.

Three intensive studies of restoration sites in the LCRE, by the USGS, U.S. Fish and Wildlife Service, and NOAA, found indications of positive responses by salmon: in residence, prey, and diet at Crims Island (Haskell and Tiffan 2011); diet at the Grays River (Roegner et al. 2010); and growth at Tenasillahe (Johnson, J. et al. 2008). Thus, there were no findings from salmon sampling in the LCRE that were inconsistent with the global review although the data on salmon at restoration sites in the LCRE were insufficient for the purpose of the scoring approach used herein because so few sites have been sampled.

In conclusion, evidence from the review and scoring of the literature concerning analogous ecosystems, examination of historically reconnected sites in the LCRE, and meta-analysis of early-stage restoration sites in the LCRE supports the strength and consistency of associations between hydrologic reconnection to the main-stem river, and indicators of ecosystem restoration response and juvenile salmon response. At early-stage reconnected sites in the LCRE, fast-response environmental indicators including water levels, water temperatures, and sediment accretion rates are trending toward conditions at reference sites and slow-response indicators (vegetation) are trending away from pre-restoration conditions.

\subsubsection{Biological Plausibility}

The plausibility criterion is addressed most fundamentally by the conceptual model (Figure 2), which illustrates the cause-and-effect relationships postulated in the literature. Further evidence of the mechanisms was provided by examination of the sixth ancillary hypothesis, export to the main-stem river (Figure 3). This examination entailed three lines of evidence and is supported by a large number of samples. First, cumulative net ecosystem improvement was calculated using the additive model of salmon prey ( $\mathrm{n}=358$ samples including fallout traps, emergent traps, and benthic cores) and aboveground herbaceous biomass $(n=348$ samples $)$ (Table 4). Second, a particulate organic transport model showed movement of matter from restoration sites on the floodplain to other restoration sites and the main-stem river (Thom et al. 2012). These studies are concentrated in certain locales and can be presumed not to represent the high spatial variability of vegetation and prey resources in the LCRE. Third, offsite benefits to migrating salmon were assessed by the consumption of marsh-produced prey resources by juvenile salmon in the LCRE $(n=2,821$ near the outlet of the hydrosystem immediately upstream of the LCRE, and $n=580$ near mouth of Columbia) (Table 7). Again, these large sample sizes include considerable variation between marked and unmarked fish of multiple species, stocks, age/size classes, and environmental histories. 
The additive model of CNEI shows that wetland restoration fuels primary productivity, in turn producing secondary productivity in the form of salmon prey, but it is limited by the narrow range of wetland types in which data have been collected relative to the variation in the LCRE ecosystem, the number of samples that have been extrapolated over much larger areas, and the incomplete representation of zones (Borde et al. 2012a, b; Jay et al. In Review). Data from four recently reconnected sites indicates primary productivity (herbaceous plants) and secondary productivity (salmon prey) is occurring (Table 4). Studies of restoration sites in the LCRE have reported positive response in juvenile salmon diet, growth, and residence (Johnson, J. et al. 2008; Roegner et al. 2010; Haskell and Tiffan 2011). Evidence from a particulate organic matter transport model shows that organic matter produced at restoration sites on a tributary of the lower Columbia River can be exported at least $7 \mathrm{~km}$ to the main-stem river (Thom et al. 2012); this is important because many restored sites are not located on the main-stem river, and although actively migrating fish may not visit them they still influence the food web. However, fluxes from other tributary rivers have not to our knowledge been examined, nor has a model been constructed for typical tidal sloughs in the LCRE. The model also shows that organic matter can be exported to nearby restoration sites, which is a first step toward addressing an information gap in the region concerning the potential for synergistic effects between restoration sites (Diefenderfer et al. 2011). The stomachs of fish near the mouth of the estuary are substantially fuller than those of fish exiting the hydropower system at the lowest major dam, and stomach contents contain substantial quantities of marsh-produced dipteran insects (Table 4), providing local confirmation of widespread evidence in the literature that tidal freshwater and estuarine habitats provide forage for juvenile salmon, even to fish that did not actually reside in marshes.

In conclusion, the lines of evidence we have analyzed in this assessment, including the increasing body of evidence on ecological relationships in the LCRE developed since the outset of this study in 2004 (Section 4.1.4), support the indirect and direct ecological relationships between tidal wetlands and salmon, which are detailed in the ecosystem conceptual model.

\subsubsection{Biological Gradient}

We observed in the meta-analysis and hydrological modeling (Coleman et al. In Review; Thom et al. In Preparation-a) that the biological gradient aspect of the association may offer a reasonable model for the apparent range of effects resulting from modifications to hydrologic connectivity. Connectivity to the main-stem river is affected on a gradient by tide-gate operations, culvert installation, dike breaches, and dike removal. We have constructed a preliminary model of the range of effects of tide-gate operations scenarios for one restoration site, using the sum exceedance value (Borde et al. 2012a, 2012b; In Preparation), and may be able to develop a more generalizable model. Hydrologic connectivity can be presumed to indicate the potential for fluxes of biota including plankton, invertebrates, and juvenile salmon (Welcomme 1979; Junk et al. 1989; Naiman and Decamps 1997; Nakano and Murakami 2001). The exposure of salmon to the reconnected habitat is thus mediated by hydrologic connectivity, and accessibility of reconnected wetlands for juvenile salmon is a function (positive relationship) of the degree to which natural hydrologic processes are restored (Greene et al. 2012). In the Pacific Northwest, the exchange of sediment, wood, and other organic matter has an important influence on aquatic habitat complexity and trophic diversity (Swanson et al. 1982; Bisson et al. 1992). Thus connectivity is also linked to the sustainability of restored habitats. 
In this type of ecological restoration application, which does not involve remediation, the doseresponse conceptualization of this causal criterion relative to stressors is not likely to be applicable. Previous research in the region has revealed few toxic stressors associated with the types of rural grazing areas that are typically being reconnected, so the chance of such exposures originating from hydrologic reconnection is low (Diefenderfer and Ward 2002). Toxins from industrial, urban, and upriver agricultural sources are, however, a factor in the Columbia River that affects juvenile salmon condition (Johnson L et al. 2007; Morace 2012).

In conclusion, the level of response is associated with a gradient in the hypothesized cause, as supported by data indicating that hydrologic connectivity, biological fluxes, and salmon-habitat access are modified on a hydrologic gradient typified by tide gates, dike breaches, and dike removals.

\subsubsection{Experimentation}

While experimentation is rare in restoration ecology, we take the view that it is important, particularly for large programs such as the CEERP that have the opportunity to benefit from experimental results through adaptive management. Although some effectiveness monitoring has occurred in the program using a BARR design, strictly viewed, this is a sampling design not an experimental design. We proposed several statistical sampling designs that would help to ascertain cumulative effects (Diefenderfer et al. 2011), which we have not been able to implement on the ground because of practical constraints. We did implement one of the proposed designs, by generating data from a hydrological model to experimentally test effects of the density ("space crowding") and pattern of dike breaches on wetted area, and showed both synergistic effects and diminishing returns (Diefenderfer et al. 2012). We have retained the causal criterion, experimentation, in the framework for the CEERP assessment as a "placeholder" for recommended future research. We view this as having particular applicability to some remaining uncertainties regarding management of the LCRE ecosystem. For instance, there is a need for more information about the effect of tide-gate management scenarios on vegetation, ecosystem processes, and salmon benefits; and more information about the salmon-habitat functions of invasive monocultural reed canary grass. If such experiments occur in the future, the criterion predictive performance, or the ability of the cause-and-effect hypothesis to correctly predict outcomes, should be considered for incorporation in future evaluations of experimental results.

\subsubsection{Specificity of Association and Temporality}

With hydrologic reconnection, both the specificity of association and its temporality are clear. As we argued in Diefenderfer et al. (2011), the difference between a control (diked pasture) and restoration (hydrologic reconnection) is great, and the evidence reviewed in the meta-analysis confirmed that at specific sites where dikes are breached and tide gates are upgraded, the hydrology responds immediately, closely followed by sediment deposition behind the dike (Diefenderfer et al. 2008; Thom et al. 2012). Evidence from the LCRE site-scale ecological relationships and global literature also indicate fish presence following reconnection, although migration characteristics in the LCRE for juvenile salmon originating in interior basin streams are affected by river discharge, level of smoltification, and stock of origin (Dawley et al. 1986).

However, for indicators that take longer to respond, such as vegetation, specificity is harder to detect in the available data. Moreover, spatial and temporal variability in the estuary are significant (Borde et al. $2012 \mathrm{a}, \mathrm{b})$ and the quantification of these patterns and dynamics is incomplete. It should be noted that the 
effects of hydrologic reconnection are not necessarily limited to the sites at which restoration occurs, as shown by the offsite benefits analysis. In conclusion, information from the meta-analysis and ecological relationships supports the specificity of association and temporality between hydrologic reconnections and responses of habitat- and fish-based monitored indicators.

\subsubsection{Analogy}

As described in the results of the global literature review, by analogy to other similar ecosystems with native salmon, there is strong support for the secondary hypothesis of fish response based on three indicator categories: salmon presence, prey, and diet. There is no conclusive evidence against it based on these or four additional categories reviewed: survival, stomach fullness, fish growth and residence time. The analogous cases of other tidal river systems also illuminated more complex factors. Neither the conversion of other habitat types to marshes, nor large relatively isolated engineered projects, are particularly good analogs for the types of restoration occurring in the LCRE. While they were included in the causal criteria analysis, care must be used in interpretation of results.

Driven by the extensive loss of emergent marshes, restoration actions in 1970-2000 emphasized emergent marsh as opposed to other tidal habitats located at lower and higher elevations (e.g., Simenstad and Thom 1996). Evidence of this is seen in that at the lower end of the elevation gradient, a program in the Fraser River estuary attempted to convert sandflats and mudflats to marsh for juvenile salmon habitat by planting marsh vegetation (Levings and Nishimura 1997). At the upper end of the gradient, on the Chehalis River estuary, forested and shrub wetland habitat was converted to marsh by excavation and grading (Miller and Simenstad 1997). However, that project and others (e.g., Simenstad and Thom 1996) recognized that enhanced access by fish to the surrounding ecotone was an aspect important to consider in the project design. Today, research in the LCRE and elsewhere has confirmed the need for expanding the mix of habitats considered for restoration to include unvegetated flats and forested and shrub wetlands as juvenile salmon habitat (Diefenderfer and Montgomery 2009; Bottom et al. 2011; Diefenderfer et al. unpublished data). For instance, this review supports a change in the marsh-specific focus of estuarine restoration for juvenile salmon.

This review also revealed some of the limitations that constrain project types in some regions; e.g., the largest restoration programs identified in the review are both highly engineered for flood control: the 24,000-ha Yolo Bypass on the Sacramento River in California was engineered in the 1930s (Sommer et al. 2001a) and the 2,200-ha Skjern River estuary restoration project is entirely located behind floodgates on the North Sea, which are opened at low tide and closed at high tide (Pedersen et al. 2007). It should be noted that the size of the restoration sites examined ranged from the above-mentioned Yolo Bypass to small pocket wetlands; it would have been possible to count all of the various sites sampled and reported on within a large area like the Yolo Bypass separately, and the result would have been far greater evidence in support of the hypothesis, but our goal was to remain as conservative as possible in this analysis.

In conclusion, the causal criterion for analogy is supported because a comparison to other systems revealed no conflicts in the relationships between hydrologic reconnection and responses of habitat- or fish-based monitored indicators. 


\subsubsection{Coherence}

According to Hill (1965), "the cause-and-effect interpretation of our data should not seriously conflict with the generally known facts of the natural history and biology." Thus, we review the logic underpinning our primary hypothesis, which comprises two steps, relative to the findings: first, does hydrologic reconnection restore the ecosystem and second, does the ecosystem have important functions for salmon?

The short- and long-term direct and indirect effects of hydrologic connection type restoration measures are generally well-established in the literature as we documented in our 2004 review at the outset of this study (see Diefenderfer et al. 2011, Table 1). There is, however, considerable variability in responses to dike breaches and tide gates as we observed in the meta-analysis (Table 6). While our analysis has necessarily focused on the effects of restoration, we consider the function and importance of tidal wetland habitats and ecosystem processes in the early life stages of salmon in general to be wellestablished in the literature; e.g., residence times (Levy and Northcote 1982; Healey 1982a; Hering et al. 2010), successful foraging (Levings 1982; Gray et al. 2002; Shreffler et al. 1992), and growth (Healey 1982a, b; MacFarlane and Norton 2002.)

It is important to understand which stocks are affected, because of the large number of stocks and life history strategies present in the Columbia basin. Juvenile salmon migrating downstream as fry from natal streams west of the Cascade Mountains are known to feed in shallow-water LCRE habitats (e.g., Roegner et al. 2010; Sather et al. 2011). For larger subyearling or yearling migrants, our analysis found that the stomach contents of these fish indicate that they are feeding actively in the LCRE (Table 7). Furthermore, everywhere that PIT-tag detection arrays have been installed in the LCRE, juvenile salmon of upriver origin have been detected (Table 3).

In short, we see no conflict with the state of the science in concluding that hydrologic reconnection of tidal floodplain habitats with a main-stem river has a beneficial effect on juvenile salmon and steelhead. Therefore, the coherence criterion is supported.

\subsubsection{Complete Exposure Pathway}

Restoring hydrologic connectivity in the LCRE is fundamental to "complete exposure pathways," i.e., enabling restoration to affect juvenile salmon either directly (onsite) or indirectly (offsite). The evidence from the meta-analysis shows that for dike breach and culvert replacement projects the exposure pathway can be completed through direct access to restoration sites by juvenile salmon (Haskell and Tiffan 2011; Roegner et al. 2010). The evidence from particulate organic matter modeling (Thom et al. 2012), biomass and prey collection (Table 4), and salmon feeding in the main-stem LCRE (Table 7; Maier and Simenstad 2009) also shows that the pathway can be completed through export to the main-stem river. Additional data linking reconnected wetlands in the LCRE to realized functional benefits to juvenile salmon are needed to unequivocally demonstrate complete exposure pathways. In conclusion, the evidence supports the causal criterion for complete exposure pathway.

\subsubsection{Predictive Performance}

In the context of ecosystem restoration and the adaptive management of ecosystems, the causal criterion "predictive performance" can be interpreted to mean how accurately and precisely we can predict outcomes of restoration. However, the ability to correctly predict restoration outcomes cannot be 
evaluated with the action-effectiveness monitoring data that have been collected to date under the CEERP (Table 6, Table 8b). This situation, while especially true for fish-based monitored indicators of realized ecosystem functions, such as growth and residence time, is not surprising given the early stage of the CEERP restoration and monitoring program. The collection of data on fish-based monitored indicators to measure effects of restoration will be especially important to predict and manage outcomes.

\subsubsection{Summary of Causal Criteria Synthesis}

In summary, the evidence evaluated supports eight of the causal criteria (Table 10). Two criteria were not evaluated because they have not been implemented in the CEERP.

Table 10. Summary of the causal criteria synthesis of the lines of evidence results.

\begin{tabular}{|c|c|c|c|}
\hline Causal Criterion & Short Definition & Conclusion & Comment \\
\hline $\begin{array}{l}\text { Strength and } \\
\text { Consistency of } \\
\text { Association }^{(a)}\end{array}$ & $\begin{array}{l}\text { The magnitude of the effect of an } \\
\text { exposure relative to non-exposure } \\
\text { and its repeated observation in } \\
\text { varied times and circumstances by } \\
\text { multiple observers }\end{array}$ & Supported $^{(b)}$ & $\begin{array}{l}\text { At early-stage sites, fast-response environmental } \\
\text { indicators are trending toward conditions at } \\
\text { reference sites, and on longer time scales, } \\
\text { evidence from analogous ecosystems and } \\
\text { historically reconnected sites indicates marsh and } \\
\text { salmon response to reconnection. }\end{array}$ \\
\hline $\begin{array}{l}\text { Biological } \\
\text { Plausibility }\end{array}$ & $\begin{array}{l}\text { Knowledge of the mechanism (not } \\
\text { a necessary condition of causation } \\
\text { because it depends on the state of } \\
\text { the science) }\end{array}$ & Supported & $\begin{array}{l}\text { The indirect and direct ecological relationships } \\
\text { between tidal wetlands and salmon outlined in } \\
\text { the ecosystem conceptual model are reasonable } \\
\text { based on the body of evidence from the LCRE } \\
\text { and analogous ecosystems. }\end{array}$ \\
\hline $\begin{array}{l}\text { Biological } \\
\text { Gradient }\end{array}$ & $\begin{array}{l}\text { The level of response is associated } \\
\text { with a gradient in the } \\
\text { hypothesized cause }\end{array}$ & Supported & $\begin{array}{l}\text { Hydrologic connectivity, biological fluxes, and } \\
\text { salmon-habitat access are modified on a gradient } \\
\text { by tide gates, dike breaches, dike removal, etc. }\end{array}$ \\
\hline Experimentation & $\begin{array}{l}\text { Manipulation of the hypothesized } \\
\text { cause }\end{array}$ & $\begin{array}{l}\text { Not } \\
\text { evaluated }\end{array}$ & Experimentation has not occurred. \\
\hline $\begin{array}{l}\text { Specificity of } \\
\text { Association and } \\
\text { Temporality }\end{array}$ & $\begin{array}{l}\text { Limitation of the association to } \\
\text { particular sites and effects; the } \\
\text { effect is shown to follow the } \\
\text { hypothesized cause. }\end{array}$ & Supported & $\begin{array}{l}\text { With hydrologic reconnection, both the } \\
\text { specificity of association and its temporality are } \\
\text { clear. }\end{array}$ \\
\hline Analogy & Comparison to similar systems & Supported & $\begin{array}{l}\text { By analogy to other similar ecosystems, results } \\
\text { of the global literature review showed strong } \\
\text { support for the salmon-response hypothesis } \\
\text { based on four indicator categories: salmon } \\
\text { presence, residence, prey, and diet. }\end{array}$ \\
\hline Coherence & $\begin{array}{l}\text { Lack of serious conflict between } \\
\text { the cause-and-effect interpretation } \\
\text { and known facts about the case } \\
\text { under consideration }\end{array}$ & Supported & $\begin{array}{l}\text { We found no conflict with the state of the science } \\
\text { in concluding that hydrologic reconnection of } \\
\text { tidal floodplain habitats with a main-stem river } \\
\text { has a beneficial effect on juvenile salmonids. }\end{array}$ \\
\hline $\begin{array}{l}\text { Complete } \\
\text { Exposure } \\
\text { Pathway }\end{array}$ & $\begin{array}{l}\text { Ability of the cause to physically } \\
\text { reach the biological or ecological } \\
\text { receptor }\end{array}$ & Supported & $\begin{array}{l}\text { The evidence and known ecosystem processes } \\
\text { and functions indicate viable exposure pathways } \\
\text { via hydrologic connectivity to realize benefits to } \\
\text { juvenile salmon from habitat restoration. }\end{array}$ \\
\hline $\begin{array}{l}\text { Predictive } \\
\text { Performance }\end{array}$ & $\begin{array}{l}\text { Ability to accurately and precisely } \\
\text { predict restoration outcomes }\end{array}$ & $\begin{array}{l}\text { Not } \\
\text { evaluated }\end{array}$ & $\begin{array}{l}\text { The ability to correctly predict restoration } \\
\text { outcomes cannot be evaluated with existing } \\
\text { action-effectiveness monitoring data. }\end{array}$ \\
\hline
\end{tabular}

(a) Two causal criteria are included in these rows.

(b) "Supported" means the analyses for the line(s) of evidence substantiate or corroborate the causal criterion. 


\subsection{Cumulative Effects Evaluation}

Through the analyses completed for the lines of evidence, we examined eight cumulative effects categories described by the CEQ (1997) (Table 1). The results indicate the occurrence of cumulative effects in all categories (in bold below). While this cumulative effects evaluation focused on five lines of evidence regarding the effects of tidal wetland restoration projects on the floodplain, we also assessed potential cumulative impacts from land-use change in contributing watersheds in a sixth line of evidence, landscape condition. Cumulative effects assessment was not a criterion for the literature we scored for this evaluation (Table 1), though we summarized potential cumulative effects in a previous literature review (see Table 1 in Diefenderfer et al. 2011).

Cross-boundary effects are demonstrated by fluxes of prey, neuston, organic matter, and nutrients between restoration sites and between restoration sites and the main-stem river (Table 1; Thom et al. 2012). They are also shown by the stomach contents of actively migrating juvenile salmon captured near the mouth of the LCRE, which indicate offsite usage of prey produced in LCRE marshes (Table 7). These contributions of floodplain wetlands to the food web experienced by migrating salmon in the mainstem river (Maier and Simenstad 2009) are also indirect effects.

Time lags are suggested by the contrast between effectiveness monitoring results at historically breached sites and early-stage restoration sites. Early-stage restoration sites are changing rapidly and some have a high cover of non-native, invasive reed canary grass, typical of most reference sites in the LCRE (Borde et al. 2012a, b; Thom et al. 2012, 2013). At historically breached sites, all plant species are wetland plants, the total vegetative cover at the sites made up of native plants is $>50 \%$, and plant communities are diverse and dense; moreover, reed canary grass cover is $<20 \%$ at these sites, the ratio of number of native to non-native species is $>2.3$, the average number of species $/ \mathrm{m}^{2}$ is $>4.2$, and the average total absolute cover is 93\% (Diefenderfer et al. 2010, In Preparation).

Synergistic and nonlinear hydrologic effects have been documented showing that the wetted area produced by dike breaches responds strongly to a small number of breaches and, once the floodplain is inundated, falls off rapidly representing an instance of "diminishing returns" (Diefenderfer et al. 2012). The CEQ calls the source of this effect space crowding; i.e., the effect of multiple actions co-located in space. Through this research, we tested one of the statistical responses that we predicted for cumulative effects of ecological restoration - the effect of clustering restoration projects on cumulative response (see Diefenderfer et al. 2011, Figure 5a). While this finding serves as an important predictor of the outcome of hydrologic reconnection restoration and therefore has design value, the implications of this physical response for primary and secondary productivity and other indicators of the physical environment remain to be investigated.

The scale of the estuary-wide meta-analysis (Table 6) and the additive model of cumulative net ecosystem improvement (Table 4, Table 5) is the LCRE floodplain, a landscape. Although data are not yet available to represent all zones of the floodplain, both of these methods showed net positive cumulative effects. However, to augment the landscape-scale evaluation of effects, we also examined fragmentation, an indicator of cumulative effects (CEQ 1997) at the catchment scale. The findings are consistent with the general progression of forest land conversion and urbanization in the Pacific Northwest and other regions of the world (Gosselink et al. 1990; Boyle et al. 1997; Lindenmayer and Franklin 2002; Wimberly and Ohmann 2004). Urbanization and reduction of forest cover are particularly important to salmon because of the effects of impervious surfaces on toxics and sedimentation in 
waterways (Lee et al. 2003; Byrd et al. 2007; Johnson L et al. 2007; Morace 2012). The effect of deforestation on sedimentary processes is, however, also likely to provide a source of sediment for accretion needed during the restoration of previously subsided marshes and swamps of the LCRE. This trend of recent past cumulative impacts on the LCRE from State and private non-federal activities in contributing watersheds indicates the likelihood of future declines in the LCRE as a result of changes in landscape processes.

Analyses of data supporting five lines of evidence also indicated compounding cumulative effects from multiple sources and pathways. The cross-boundary and indirect effects described previously are compounding in the sense that the food web in the lower 235 kilometers of the main-stem Columbia River is influenced by the tidal wetlands on the floodplain. The CNEI model and estuary-wide metaanalysis are also measures of compounding effects.

In summary, the ten analyses of data reported herein (Table 9) all support one or more of the eight effects categories. Net positive cumulative effects were demonstrated at the restoration site and floodplain scales, while net negative effects unassociated with the CEERP were measured at the catchment scale, and we did not attempt to quantitatively compare the magnitude of these on balance. Several data sets (e.g., dike breaches versus wetted area, flood-driven export of organic matter, salmon presence in wetlands, rapid early accretion rates) illustrated nonlinear, synergistic, and/or pulsed characteristics of hydrologic reconnection. This suggests that the cumulative effects of restoration are complex in space and time, and prediction of the trajectories of development of restoring systems and their benefits to juvenile salmon must consider a mix of linear and nonlinear aspects. 


\subsection{Discussion}

The findings of this study were synthesized and evaluated in Section 5.0 and the analyses indicate that evidence evaluated supports eight of the causal criteria (Table 10). The results of the lines of evidence we evaluated support a coherent and plausible picture. Habitat-response metrics at restoration sites indicate that physical processes have been affected; i.e., water levels return to reference conditions relatively quickly and regular flooding carries with it sediments that are deposited onto the subsided restoration areas producing relatively high rates of accretion on the land surface. Barring human intervention, this accretion is needed to raise the land to levels that will support native wetland vegetation, a slower response variable. Water temperatures are affected relatively quickly by hydrologic reconnection although it is too early to tell whether further changes will occur as riparian vegetation changes. Strong evidence is provided by the fact that historically breached sites have become marshes. Further, the cumulative effects of marsh restoration fuel primary productivity that, because of reconnection, is now available to the main-stem river ecosystem. This has the potential to fuel secondary productivity, and we see that the stomachs of fish near the mouth of the estuary are fuller than those of fish exiting the hydropower system. Restoration of analogous systems reported in the literature provides strong evidence that hydrologic reconnection leads to salmon benefits.

Both inductive and deductive reasoning play a role in our interpretation of the lines of evidence. The observation that a much larger percentage of marked and unmarked fish captured near the mouth of the Columbia have recently fed than have done so near the terminus of the hydrosystem at Bonneville and John Day dams (in samples that include actively migrating fish) suggests, by deductive reasoning from a general principle to specific examples, that any particular individual salmon belonging to a listed Evolutionarily Significant Unit is likely to exhibit similar characteristics. This same observation suggests that juvenile salmon grow during residence in the LCRE, a finding that is corroborated by the review of global literature (Table 8), and we accept this because it is biologically plausible that food consumption leads to growth. The observation that fish from interior basin stocks are detected on PIT arrays deployed in shallow-water areas of the LCRE suggests by inductive reasoning, from specific examples to a general proposition, that at least some fish from interior basin stocks reside for a time in off-channel, shallow tidal freshwater and estuarine areas. For vegetated habitat, inductive reasoning from the particular cases in the meta-analysis suggests that as a general principle, it is too early in the restorative process to expect that marshes would exhibit typical wetland vegetation. This principle is given credence by our understanding of the rates of recovery at other marsh restoration sites in the Pacific Northwest near the Columbia River mouth (e.g., Frenkel and Morlan 1990; Thom et al. 2002).

In this section, we discuss juvenile salmon and ecosystem restoration in the LCRE and the limitations of the study. The section closes with recommendations and conclusions.

\subsection{Juvenile Salmon and Ecosystem Restoration in the LCRE}

Juvenile salmon from throughout the Columbia River basin experience an LCRE environment that is large, complex, and variable. It is affected from upstream by dam operations, runoff conditions, hatchery practices, and other factors and from downstream by ocean and subwatershed conditions. This discussion, while including fundamental aspects of juvenile salmon ecology in tidal freshwater and estuaries, primarily concerns the contribution the LCRE ecosystem restoration makes to improve chances for juvenile fish to survive the critical ocean-entry stage and ultimately return to the Columbia River basin 
as reproductive adults to complete the life cycle. No studies have linked restoration of LCRE ecosystems to adult salmon returns. Although assessing restoration benefits by measuring differential juvenile fish survival rates between restored and non-restored areas in the LCRE is impractical and unrealistic with currently available methods (Diefenderfer et al. 2010), fish response to ecosystem restoration, in terms of monitored indicators other than presence, remains to be quantified in studies with statistically rigorous sampling designs. Overall, however, the LCRE literature indicates that ecosystem restoration could contribute to increased early life history diversity (Bottom et al. 2005a) and that restoration could foster increased juvenile salmon growth (Haskell and Tiffan 2011). Here we encapsulate and discuss the effects of ecosystem restoration in the LCRE on juvenile salmon, specifying ESA-listed fish when possible.

As described above, the primary restoration strategy in the LCRE involves reestablishing hydrologic connections between shallow-water areas and the main-stem Columbia (BPA/USACE 2012). Restoring hydrologic connections can increase access for juvenile salmon to rearing and refuge areas (Roegner et al. 2010). Hydrologic reconnections can also improve habitat capacity (Thom et al. 2012), as can other restoration actions, such as riparian improvements, habitat creation, and invasive species removal coupled with native species plantings. Increased access and habitat capacity in the LCRE presumably contribute to improving survival rates during the early ocean stage. The discussion that follows is organized around these tenets.

\subsubsection{Access}

Access refers to contact with biologically beneficial conditions. This can be the opportunity for fish to move into places of refuge from predators and warm water, or to find available prey for feeding whether onsite in the restored area (directly) or offsite (indirectly). Hydrologic reconnections essentially restore access for fish to move into a site to find prey produced there (Table 4) and for the flux of prey from the site to the main-stem river, where our data show that offsite access occurs (Table 7).

Marked and unmarked juvenile salmon are known to move into restoring wetlands and shallow-water habitats at various life stages (Bottom et al. 2005a, b; Roegner et al. 2010, 2012; Sather et al. 2009, 2011). Salmon fry are more common in these habitats than subyearlings or yearlings. Life history strategies expressed in the LCRE by upriver salmon populations include 1) active migration by yearlings, mostly during the spring, accompanied by feeding in the main stem and characterized by short LCRE residence times (McMichael et al. 2011); 2) a similar migration pattern for subyearlings during summer (McMichael et al. 2011); and 3) active migration as subyearlings or fry into the LCRE during fall, with overwintering in tidal freshwater and relatively long residence times, before emigrating early the following spring (Johnson et al. In Preparation).

Yearling and subyearling migrants do not use the main-stem LCRE exclusively. Johnson et al. (In Preparation) observed that 4 to $9 \%$ of run-of-river, hatchery yearling and subyearling Chinook salmon and steelhead tagged with acoustic transmitters and released at various locations above Bonneville Dam used off-channel, shallow-water routes at the Sandy River delta and vicinity ( $\sim$ rkm 200$)$. In an acoustic telemetry study with a receiver array at $\mathrm{rkm} 37,13 \%$ of yearling, $12 \%$ of subyearling Chinook salmon, and $18 \%$ of steelhead migrated in off-channel routes (Harnish et al. 2012). Our compilation of PIT and genetic-stock identification data (Table 3) shows juvenile salmon, including yearling migrants from interior basin stocks, present in shallow-water LCRE habitats. It is reasonable to expect they would use restored areas similarly, as Roegner et al. (2010) showed. Residence times and migration routes, and 
therefore access to restored areas, vary depending on propensity for active downstream migration, which is related to smoltification level and other factors (Beckman and Dickhoff 1998).

Based on the effects of tide gates on small sloughs reviewed in this research, we view tide gates as less effective than dike breaches for direct access by salmon to rearing habitats. This review did not include any tide gates on tributaries to the LCRE so our findings do not extend to rivers (e.g., Chinook River estuary). Furthermore, we recognize that tide gates may make improvements possible at sites with multiple-use factors such as other threatened and endangered species (e.g., the Columbia white-tailed deer at Julia Butler Hansen NWR) or infrastructure (e.g., the Astoria International Airport at Vera Slough). Overall, the evidence generally indicates downstream migrants from upriver stocks can access biological benefits from restored areas onsite and offsite.

\subsubsection{Capacity}

Ecosystem restoration increases habitat capacity, most importantly for juvenile salmon in the form of prey availability through the linkages among hydrology, vegetation structure, and prey production (Thom et al. 2013). Like access, improved capacity has direct and indirect effects on juvenile salmon. Our analysis of the global literature indicated that juvenile salmon consume prey from restored areas onsite and offsite (Cordell et al. 2011). Shallow-water areas produce prey (Table 4) and provide bioenergetic benefits to juvenile salmon (Storch and Sather In Review; Storch and Sather 2011; Roegner et al. 2010). Our stomach fullness data indicate that more salmon are actively feeding at rkm 15 near the mouth of the Columbia than at Bonneville and John Day dams; i.e., salmon are directly benefitting from their time in the LCRE (Table 7). The decline in stomach fullness between John Day and Bonneville dams indicates a lack of foraging or foraging potential in this portion of the hydrosystem immediately above the LCRE, and it highlights the need for a functioning LCRE that provides habitat access and capacity so that migrating fish are prepared for ocean entry. The dipteran insects consumed by salmon in the lower river and estuary (Table 7) can be presumed to have been produced in floodplain wetlands (Maier and Simenstad 2009), but fluxed to the main-stem river and most frequently consumed in the main-stem river given the often short transit times of these migrating fish, which indicates the benefits of restoring habitat capacity.

Prey frequency and stomach fullness can be examined across species at restoration and reference sites, and used to develop energetic balances. These measures are useful for describing the inter- and intra-year and species variations (Roegner et al. 2012). For example, the stomach fullness data (Table 7) are similar to the finding of Dawley et al. (1986) where average stomach fullness was greatest in coho and Chinook salmon, and lowest values tended to be associated with steelhead. Similarly, Daly et al. (2012) found that as Chinook salmon increased in size, their foraging switched from small prey items to larger items, including a higher rate of piscivory. The stomach fullness data from the Fraser River estuary, British Columbia (Healey 1979); Grays Harbor, Washington (Miller and Simenstad 1997); and Snohomish River estuary, Washington (Cordell et al. 2001a) provide values for chum, coho, and subyearling Chinook salmon of stomach fullness ranging from $0.6 \%$ to $5.6 \%$ of body weight, suggesting greater feeding opportunities in these systems compared to the LCRE. Despite the difference in stomach fullness, however, diet composition was similar with large contributions from insects and Americorophium amphipods in all systems. Habitat capacity from LCRE restoration improves growth potential of juvenile salmon, which presumably benefits them when they migrate into the ocean. 


\subsubsection{Early Ocean Stage}

During the first few months after ocean entry, juvenile salmon continue to undergo physiological changes that can affect their foraging and behavior as post-smolts (Stefansson et al. 2011). In addition, juvenile salmon can experience intense growth-mediated mortality due to predation (Healey 1982b; Mangel 1994; Freidland et al. 2000; Strand et al. 2011). Predator density has been postulated as a primary factor in this mortality; however, if early marine survival of post-smolts was predator-density dependent, the continued reappearance of tightly coupled growth-survival correlations would not be as prevalent. Another important driver of post-smolt success is available energy during the first winter when food abundance can be low (Trudel et al. 2002, 2011; Jacobson et al. 2012). Thus, growth within the estuary and size at ocean entry could be influential indicators of early marine survival (Koenings et al. 1993; Cordell et al. 2011; Strand et al. 2011). Hanson et al. (2012) found that during April-June 2010 juvenile Chinook salmon in off-channel areas of the LCRE had better body condition than those in the main channel, although they were unable to measure growth.

Marine survival represented as adult returns is dependent upon post-smolt survival during early marine life (Stefansson et al. 2003; Ruggerone et al 2009; Tomaro et al. 2012). This in turn may be dependent on growth in the LCRE. Studies of scale and otolith patterns indicate that Chinook salmon growth at sea is dependent on prior growth in freshwater habitats, thereby emphasizing the need for "quality" LCRE habitats (Beamish et al. 2004; Farley et al. 2007; Ruggerone et al. 2009). In contrast, other studies have shown that survival is largely dependent on early ocean growth, not size at ocean entry (MacFarlane 2010; Tomaro et al. 2012). Overall, we infer from the available data that LCRE ecosystem restoration supports increased juvenile salmon growth and enhanced fitness (condition) thereby suggesting increased survival rates during the early ocean stage.

\subsection{Limitations of the Study}

Few LCRE studies have been published with the same spatial scale as this one, the $1,468-\mathrm{km}^{2}$ historical floodplain. Most prior major studies in the region, e.g., the Columbia River Estuary Data Development Program (Small 1990), focused on portions of the LCRE defined by factors such as the extent of salt intrusion, the coastal zone, plant community type, etc. (Christy and Putera 1992; Kunze 1994; Bottom et al. 2011). On the other hand, Bottom et al. (2005a) synthesized hydrologic and ecologic aspects of the role of the LCRE for juvenile salmon and applied this information in recommendations for management of future ecosystem restoration. However, there are no comprehensive studies of the effects of ecosystem restoration on juvenile salmon in the LCRE to which our results can be compared.

The dynamics of the study area range widely from fluvially dominated below Bonneville Lock and Dam to tidally dominated near the river mouth, and the structure of tidal wetland habitats similarly comprises many zones (Borde et al. 2012a, b; Jay et al. In Revision, In Review). The ramifications of these factors relative to available data indicate an important weakness for estuary-wide inferences or estimates: the assumption of random sampling across the entire study area has not been met by any study

that we are aware of. As a result, values such as the estimates of prey and biomass produced by our additive model of CNEI should be viewed as approximations. 
Our examination of concurrent cumulative impacts (Section 4.3) was limited to the landscape scale (Ke et al. 2013). The land conversion and forest management activities we documented would be expected to affect salmon habitats on the floodplain through sedimentation and altered hydrodynamics, but because we did not examine forest age categories it would be premature to estimate the magnitude of these effects. We are also aware of other cumulative impacts such as the presence of toxics in water and sediments of the LCRE (Johnson L et al. 2007). Also, there is evidence that relative sea-level rise will affect the Pacific Northwest coast in the next 50 years (NRC 2012) and that snow pack dynamics in the Cascade Mountains are changing (Mote et al. 2005), but specific predictions for flows and shallow-water habitats in the study area have not been published and potential effects are likely to range widely across the elevations and hydrological regimes present. Environmental flows in the study area are substantially modified by river regulation, water withdrawals, etc. (Kukulka and Jay 2003a, b), which are subject to change. The availability of partially connected shallow-water habitat for restoration and enhancement is subject to shifting baselines, e.g., as diked wetlands along the lower river are purchased for industrial development. The LCRE is not a region with oversight and management focused on salmon-habitat restoration, but a complex multi-jurisdictional environment with competing interests. The focus of this study was to quantify the effects of the CEERP and we did not attempt to weigh these types of past, present, or future impacts against the effects of the CEERP.

The early stage of the restoration program posed particular challenges regarding action-effectiveness data that we expect will be resolved in future evaluations when the CEERP monitoring program is more developed (BPA/USACE 2012). Some issues appear to relate to bookkeeping, and others to lack of data collection or confounding factors. For example, hatchery smolts in open waters near the mouth of the Columbia River far outnumber wild smolts (Weitkamp et al. 2012). Consequently, one of the largest challenges in the LCRE is actually measuring the benefits of habitat restoration for wild fish. Because of the dominant hatchery signal, even substantial growth or survival benefits to wild populations due to habitat restoration may be difficult to detect. Also, insufficient data on salmon at restored sites in the LCRE were available to evaluate ancillary hypotheses including residence time, survival, prey, diet, fullness, and growth. As a result, the evidence-based scoring of global literature from tidal rivers with salmon and restored wetland habitats was crucial to evaluation of the secondary hypothesis of fish response. The scoring of literature from analogous systems (Section 4.2) relied on a previously developed and tested weighting system (Norris et al 2012; Webb et al. 2012).

Data from only six restoration sites with paired reference sites were available for key habitat-response metrics such as water-surface elevation and temperature, sediment accretion rate, and vegetation similarity, and as a result we conducted a qualitative not quantitative estuary-wide meta-analysis. The reliance on paired reference sites and suites of reference sites to analyze rates of change that we previously recommended in this framework, may need to be revisited in future evaluations, because the ecosystem is so spatially variable and temporally dynamic. For example, suitable reference sites for the historically breached sites that we analyzed were not available in the existing network of reference sites, given factors of differences in landscape position (e.g., salinity, river flow) that have already been elucidated through analysis of the network (Borde et al. 2012a). Given inherent variability in the system and the quantity of data available at this time, the control charts for response variables proposed by Diefenderfer et al. (2011) have not yet been realized. Moreover, data on rates and timing of export of particulate organic matter from wetlands are available from only one modeling study on one tributary to the LCRE, not for sloughs or other tributaries. Sample sizes examined by the analyses supporting each line of evidence were sometimes composed of data from both the LCRE and the global literature, a step 
that we view as necessary in an emerging early-stage program such as the CEERP. Additional analyses or lines of evidence, such as a meta-analysis of bioenergetics across the LCRE, could usefully be added to this evaluation.

From a bookkeeping perspective, of 34 hydrologic reconnection projects documented as being completed by mid-2012, data on the area affected were available for 19 (total area $6.03 \mathrm{~km}^{2}$ ), data on the length of channel affected were available for an additional 8 (total length $38.95 \mathrm{~km}$ ), but no spatial measure of effect was available for 7 (Table 5). We assume that procedures have been developed to ensure such record-keeping in the future, and provisionally, if we assign the mean area to the remaining 15 projects then the total estimated area of completed projects is $10.79 \mathrm{~km}^{2}$ or $0.04 \%$ of the $1,468 \mathrm{~km}^{2}$ historical floodplain. Of course, the historical floodplain was not entirely accessible to salmon and tidalfluvial hydrodynamics made the available areas a constantly shifting mosaic (Coleman et al. In Review; Roegner et al. In Preparation). Our analysis revealed a gradient of hydrologic connectivity and associated benefits, typified by dike removal, dike breaching, and tide-gate installation, but the relative effects of these types of actions on different types of morphologic and hydrologic features of channels (e.g., channel gradient, flow, stream vs. slough, tidal vs. fluvial influence) remain to be quantified.

Two causal criteria were not evaluated herein because they have not been implemented in the CEERP; however, we suggest retaining them in the evaluative framework because in our view it would be beneficial for the adaptive management aspect of the program: experimentation and predictive performance.

Overall, we believe that the LCRE is greatly understudied compared to other aquatic areas of similar significance in the United States such as Chesapeake Bay, the Everglades, the lower Mississippi River and delta, and the Great Lakes. We have some information about the structures and processes of shallowwater habitats, but very little information for the rates depicted by arrows in the conceptual model (Figure 2). We are hopeful that more analyses will emerge in the literature in the near future that could be helpful to future evaluations, and encourage reevaluation of the conceptual model and biological plausibility causal criterion against new information.

\subsection{Recommendations}

Implementing the evidence-based assessment approach described herein permitted us to evaluate all available evidence, collect new evidence targeting uncertainties, and use quantitative methods and critical thinking to evaluate primary, secondary, and ancillary hypotheses.

Demonstrating benefits over time will require a dedicated, long-term effort in implementation, adaptive learning, and increased collection of monitoring data focused on critical uncertainties and salmon response. This assessment has occurred at a very early stage of the CEERP, both in terms of the number and area of restoration projects implemented, and in terms of the quantity of post-restoration monitoring data that has been collected at these sites. Implementation of the CEERP under the Biological Opinion is slated to be complete in 2018. We recommend an action-effectiveness research program and database be developed to enable future assessments. Because of these requirements, in our view, a follow-up assessment of this scope should be initiated only when substantial additions to information available from the LCRE or global literature have been made. Depending on the research effort, this may 
occur in perhaps 3 to 5 years. Some individual lines of evidence may be more conducive to interim assessment, in particular the CNEI model and meta-analysis.

We recommend that the remaining uncertainties be the subject of research in the near future to support decision-making in the CEERP. We strongly encourage the design of experiments (see related list below) that are controlled to the maximum extent possible in this highly dynamic and spatially variable ecosystem:

- Determine the growth of juvenile salmon at restoration, reference, and control sites; make physiological estimates of the relative amount of growth and change in the condition of fish during migration through the LCRE for listed interior basin stocks; and determine the sources of food during migration through the LCRE for listed interior basin stocks.

- Measure the production and flux of prey and biomass from restored and reference areas of the LCRE. Sampling designs should include restoration, reference, and control sites. In particular, quantify the dynamics of the function of invasive species reed canary grass for prey production (composition, quantity), biomass export (mass, export), and salmon habitat (stem density, stranding). This species is the dominant plant at freshwater tidal wetland sites sampled in the LCRE (Borde et al. 2012a, b).

- Determine the trend in early life history diversity (ELHD) and species-specific, unmarked juvenile salmon and steelhead density for interior basin stocks; i.e., ascertain whether ELHD and unmarked fish density are increasing. These data would be used to verify the results of this analysis relative to the causal criteria strength, consistency, and specificity of association. Intensive monitoring of sentinel sites would be one approach to this question.

- Ascertain the maximum potential function of tide gates for salmon across typical channel types of the LCRE, e.g., river tributaries, blind sloughs; across available operations scenarios; and across potential fluvial-tidal regimes. Develop best practices for the microhabitats of the LCRE. Other water-control structures may also require further research because their implementation is currently regarded as restoration in the region.

- Identify gaps in the network of reference sites in the LCRE from both spatial variability and temporal dynamics perspectives. Reference sites are an important source of information for trends analysis, increasing understanding of ecological relationships, and explaining variability. Similar reference or sentinel sites for salmon should be considered, e.g., to sample stomach fullness, genetic-stock origin.

- Implement studies of the effectiveness of restoration projects using formal experimental designs, because experimentation has the potential to inform our understanding of the effects of factors such as landscape position, e.g., whether placing numerous projects close to each other produces a synergistic effect as measured by any important indicator of habitat or fish response.

- In terms of the evidence-based evaluation framework, setting up our ancillary hypotheses such that a trend of restoration site conditions toward reference site conditions is the only test may be too ambitious for early-stage assessments. Rather, before-after change in condition in a way consistent with the conceptual model is in our view acceptable evidence that the restoration actions are a catalyst for positive change. 


\subsection{Conclusions}

We concluded that all five lines of evidence from the LCRE indicated positive habitat-based and fishbased responses to the restoration performed under the CEERP, although tide-gate replacements on small sloughs were an exception. The evidence supported the two secondary hypotheses: habitat-based indicators of ecosystem controlling factors, processes, and structures show positive effects from restoration actions; and fish-based indicators of ecosystem processes and functions show positive effects from restoration actions and habitats undergoing restoration. The global literature regarding the functions of restored tidal areas for juvenile salmon also supported the latter hypothesis. The evidence from the LCRE illustrated eight types of cumulative effects: synergistic, space crowding, indirect, time lags, crossboundary, nonlinear, compounding and landscape.

Our analyses suggested that hydrologic reconnections restore access for fish to move into floodplain wetlands to find prey produced there. Reconnections also restore the potential for the flux of prey from wetlands to the main-stem river, where our data show that they are consumed by salmon. The fastresponse habitat-based variables have changed as predicted by the conceptual model, and vegetation, which is slower to respond, is changing from the before condition. We infer that LCRE ecosystem restoration supports increased juvenile salmon growth and enhanced fitness (condition), thereby potentially improving survival rates during the early ocean stage. However, countervailing influences are also present. The land-cover change analysis of contributing watersheds and the floodplain from 1996 to 2006 indicated ongoing cumulative impacts from urbanization and decreased forest cover, which although outside of the control of the CEERP, could impair the development of resilient ecosystems on the river floodplain.

Based on the evidence, we concluded that the primary hypothesis was supported, i.e., that the habitat restoration activities in the LCRE are likely having a cumulative beneficial effect on juvenile salmon, including interior basin salmon. Salmon in restored wetland areas are directly affected by the habitat structures and processes. Salmon actively transiting main-stem river habitats are indirectly affected through the food web by allochthonous materials from floodplain wetlands. The beneficial effect of restoring tidal wetlands is expected to increase over time as existing restoration projects mature and new ones are implemented. 


\subsection{References}

50 CFR Section 402.02. Title 50 of the Code of Federal Regulations, Section 402.02. Wildlife and Fisheries, Section 402.02, "Definitions." Washington, D.C.

Allan JD. 2004. "Landscapes and riverscapes: the influence of land use on stream ecosystems." Annual Review of Ecology, Evolution, and Systematics 35:257-284.

Andrew ME and MA Wulder. 2011. Idiosyncratic responses of Pacific salmon species to land cover, fragmentation, and scale. Ecography 34:780-797.

Beamish RJ, C Mahnken, and CM Neville. 2004. "Evidence that reduced early marine growth is associated with lower marine survival of coho salmon." Transactions of the American Fisheries Society 133(1): 26-33.

Benkwitt CE, RD Brodeur, TP Hurst, and EA Daly. 2009. "Diel feeding chronology, gastric evacuation, and daily food consumption of juvenile Chinook salmon in Oregon coastal waters." Transactions of the American Fisheries Society 138:111-120.

Bernhardt ES, MA Palmer, JD Allan, G Alexander, K Barnas, S Brooks, J Carr, S Clayton, C Dahm, J Follstad-Shah, D Galat, S Gloss, P Goodwin, D Hart, B Hassett, R Jenkinson, S Katz, GM Kondolf, PS Lake, R Lave, JL Meyer, TK O’Donnell, L Pagano, B Powell, and E Sudduth. 2005. "Synthesizing U.S. River Restoration Efforts." Science 308:636-637.

Bisson PA, TP Quinn, GH Reeves, and SV Gregory. 1992. "Best management practices, cumulative effects, and long-term trends in fish abundance in Pacific Northwest river systems." Pages 189-232 in RJ Naiman (ed.), Watershed Management: Balancing Sustainability and Environmental Change. SpringerVerlag, New York.

Booth DB, JR Karr, S Schauman, CP Konrad, SA Morley, MG Larson, P Henshaw, EJ Nelson, and SJ Burges. 2001. Urban Stream Rehabilitation in the Pacific Northwest. Grant Report R82-5284-010, U.S. Environmental Protection Agency, Seattle, Washington.

Booth DB, D Hartley, and R Jackson. 2002. "Forest cover, impervious-surface area, and the mitigation of stormwater impacts." Journal of the American Water Resources Association 38:835-845.

Borde AB, SA Zimmerman, RM Kaufmann, HL Diefenderfer, NK Sather, and RM Thom. 2011. Lower Columbia River and Estuary Restoration Reference Site Study: 2010 Final Report and Site Summaries. PNWD-4262, prepared for the Lower Columbia River Estuary Partnership by Pacific Northwest National Laboratory, Marine Sciences Laboratory, Sequim, Washington.

Borde AB, VI Cullinan, HL Diefenderfer, RM Thom, RM Kaufmann, J Sagar, and C Corbett. $2012 \mathrm{a}$. Lower Columbia River and Estuary Ecosystem Restoration Program Reference Site Study: 2011 Restoration Analysis. PNNL-21433, prepared for the Lower Columbia River Estuary Partnership by Pacific Northwest National Laboratory, Richland, Washington. 
Borde AB, RM Kaufmann, VI Cullinan, SA Zimmerman, and CL Wright. 2012b. Lower Columbia River and Estuary Habitat Monitoring 2011 Annual Report. PNNL-21128, prepared for the Lower Columbia River Estuary Partnership by Pacific Northwest National Laboratory, Richland, Washington.

Borde AB, HL Diefenderfer, VI Cullinan, and RM Thom. In Preparation. "Vegetation and hydrologic relationships for tidal wetlands in the fluvially dominated Columbia River estuary."

Borja Á, DM Dauer, M Elliott, and CA Simenstad. 2010. "Medium- and Long-term Recovery of Estuarine and Coastal Ecosystems: Patterns, Rates and Restoration Effectiveness." Estuaries and Coasts $33: 1249-1260$.

Bottom DL, CA Simenstad, J Burke, AM Baptista, DA Jay, KK Jones, E Casillas, and M Schiewe. 2005a. Salmon at River's End: The Role of the Estuary in the Decline and Recovery of Columbia River Salmon. U.S. Department of Commerce, National Oceanic and Atmospheric Administration, Technical Memorandum NMFS-NWFSC-68, Northwest Fisheries Science Center, Seattle, Washington.

Bottom DL, KK Jones, TJ Cornwell, A Gray, and CA Simenstad. 2005b. "Patterns of Chinook Salmon Migration and Residency in the Salmon River Estuary (Oregon)." Estuarine Coastal and Shelf Science 64:79-93.

Bottom DL, A Baptista, J Burke, L Campbell, E Casillas, S Hinton, DA Jay, MA Lott, G McCabe, R McNatt, M Ramirez, GC Roegner, CA Simenstad, S Spilseth, L Stamatiou, D Teel, and JE Zamon. 2011. Estuarine Habitat and Juvenile Salmon: Current and Historical Linkages in the Lower Columbia River and Estuary. Final Report 2002-2008. Prepared for the U.S. Army Corps of Engineers, Portland, Oregon by the U.S. National Marine Fisheries Service, Seattle, Washington.

BPA/USACE (Bonneville Power Administration and U.S. Army Corps of Engineers). 2012. Columbia Estuary Ecosystem Restoration Program: 2013 Strategy Report. Final report. Portland, Oregon.

Brodeur RD and WG Pearcy. 1987. "Diel feeding chronology, gastric evacuation and estimated daily ration of juvenile coho salmon, Oncorhynchus kisutch (Walbaum), in the coastal marine environment." Journal of Fish Biology 31:465-477.

Bowen SH. 1996. "Quantitative description of the diet." Pages 513-532 in BR Murphy and DW Willis (eds), Fisheries Techniques, 2nd Edition. American Fisheries Society, Bethesda, Maryland.

Boyle CA, L Lavkulich, H Schreier and E Kiss. 1997. "Changes in land cover and subsequent effects on lower Fraser basin ecosystems from 1827 to 1990. Environmental Management 21:185-196.

Byrd KB, NM Kelly, and AM Merenlender. 2007. "Temporal and spatial relationships between watershed land use and salt marsh disturbance in a Pacific estuary." Environmental Management 39:98112.

Callaway JC, AB Borde, HL Diefenderfer, VT Parker, JM Rybczyk, and RM Thom. 2012. "Pacific Coast tidal wetlands." Pages 103-116 in DP Batzer and AH Baldwin (eds.), Wetland Habitats of North America: Ecology and Conservation Concerns. University of California Press, Berkeley. 
Carpenter SR and MG Turner. 2001. "Hares and tortoises: interactions of fast and slow variables in ecosystems." Ecosystems 3:495-497.

Chen C, RC Beardsley, and G Cowles. 2006. An Unstructured Grid, Finite-Volume Coastal Ocean Model, FVCOM User Manual. SMAST/UMASSD-06-060, University of Massachusetts-Dartmouth, Dartmouth, Massachusetts.

Christy JA and JA Putera. 1992. Lower Columbia River Natural Area Inventory. Report to The Nature Conservancy, Washington Field Office, Seattle, Washington by the Oregon Natural Heritage Program, Portland, Oregon.

Coleman AM, HL Diefenderfer, DL Ward, and AB Borde. In Review. "A spatially based area-time inundation index model for tidal wetlands and restoration sites of the lower Columbia River floodplain and estuary." Environmental Modelling and Software.

Cordell JR, M Stamey, CD Tanner, and JK Aitkin. 2001a. Fish Assemblages and Juvenile Salmon Diets at a Breached-Dike Wetland Site, Spencer Island, Washington 1999. Report SAFS-UW-0104, University of Washington School of Aquatic and Fishery Sciences, Seattle, Washington.

Cordell JR, LM Tear, and K Jensen. 2001b. Biological Monitoring at Duwamish River Coastal America Restoration and Reference Sites: A Seven-Year Retrospective. Report SAFS-US-0108 of the University of Washington School of Aquatic and Fishery Sciences, Seattle, Washington.

Cordell JR, JT Toft, A Gray, GT Ruggerone, M Cooksey. 2011. "Functions of restored wetlands for juvenile salmon in an industrialized estuary." Ecological Engineering 37:343-353.

Council on Environmental Quality (CEQ). 1997. "Considering cumulative effects under the National Environmental Policy Act.” Executive Office of the President, Washington, D.C.

Cornu C and S Sadro. 2002. "Physical and functional responses to experimental marsh surface elevation manipulation in Coos Bay's South Slough." Restoration Ecology 10:474-486.

CREST (Columbia River Estuary Study Taskforce). 2012. Habitat, Salmon, and Salmon Prey Effectiveness Monitoring. Ft. Clatsop South Slough \& Alder Creek Synthesis Report 2007-2011. Prepared for the Lower Columbia River Estuary Partnership, Portland, Oregon, by CREST, Astoria, Oregon.

Crooks S, J Schutten, GD Sheern, K Pye, and AJ Davy. 2002. "Drainage and elevation as factors in the restoration of salt marsh in Britain." Restoration Ecology 10:591-602.

Daly EA, RD Brodeur, JP Fisher, LA Weitkamp, DJ Teel, and BR Beckman. 2012. "Spatial and trophic overlap of marked and unmarked Columbia River basin spring Chinook salmon during early marine residence with implications for competition between hatchery and naturally produced fish."

Environmental Biology of Fishes 94:117-134.

Dawley EM, RD Ledgerwood, TH Blahm, CW Sims, JT Durkin, RA Kirn, AE Rankis, GCE Monan, and FJ Ossiander. 1986. Migrational Characteristics, Biological Observations, and Relative Survival of Juvenile Salmonids Entering the Columbia River Estuary, 1966-1983. Final report prepared for the 
Bonneville Power Administration, Portland, Oregon, by the National Marine Fisheries Service, Seattle, Washington.

Diefenderfer HL. 2007. Channel Morphology and Restoration of Sitka Spruce (Picea sitchensis) Tidal Forested Wetlands, Columbia River, U.S.A. Doctoral Dissertation, University of Washington, College of Forest Resources, Seattle, Washington.

Diefenderfer HL and JA Ward. 2002. Analysis of Potential Downstream Contamination from Dike Removal for Restoration: Willapa River Estuary, Washington. PNWD-3161, prepared for Ducks Unlimited and the Natural Resource Conservation Service by Battelle Marine Sciences Laboratory, Sequim, Washington.

Diefenderfer HL and DR Montgomery. 2009. "Pool spacing, channel morphology, and the restoration of tidal forested wetlands of the Columbia River, U.S.A.” Restoration Ecology 17:158-168.

Diefenderfer HL, GC Roegner, RM Thom, EM Dawley, AH Whiting, GE Johnson, KL Sobocinski, MG Anderson, and BD Ebberts. 2005. Evaluating Cumulative Ecosystem Response to Restoration Projects in the Columbia River Estuary, Annual Report 2004. PNNL-15102, report to the U.S. Army Corps of Engineers, Portland District, by Pacific Northwest National Laboratory, Richland, Washington.

Diefenderfer HL, AM Coleman, AB Borde, and IA Sinks. 2008. "Hydraulic geometry and microtopography of tidal freshwater forested wetlands and implications for restoration, Columbia River, U.S.A." Ecohydrology and Hydrobiology 8:339-361

Diefenderfer, HL, KL Sobocinski, RM Thom, CW May, AB Borde, SL Southard, J Vavrinec, and NK Sather. 2009. "Multiscale analysis of restoration priorities for marine shoreline planning."

Environmental Management 44:712-731.

Diefenderfer HL, AB Borde, GC Roegner, EM Dawley, MT Russell, and AS Cameron. 2010.

"Ecological Trajectories and Salmon Habitat Functions of Historical Dike Breaches and Created Islands in the Columbia River Floodplain, USA." Appendix C in: Evaluating Cumulative Ecosystem Response to Restoration Projects in the Lower Columbia River and Estuary, 2009, GE Johnson and HL Diefenderfer (eds.). PNNL-19440, prepared for the U.S. Army Corps of Engineers, Portland District, Portland, Oregon, by Pacific Northwest National Laboratory, Richland, Washington.

Diefenderfer HL, RM Thom, GE Johnson, JR Skalski, KA Vogt, BD Ebberts, GC Roegner, and EM Dawley. 2011. "A levels-of-evidence approach for assessing cumulative ecosystem response to estuary and river restoration programs." Ecological Restoration 29:111-132.

Diefenderfer HL, GE Johnson, JR Skalski, SA Breithaupt, and AM Coleman. 2012. "Application of the diminishing returns concept in the hydroecologic restoration of riverscapes." Landscape Ecology 27:671-682.

Diefenderfer HL, AB Borde, and VI Cullinan. 2013. A Synthesis of Environmental and Plant Community Data for Tidal Wetland Restoration Planning in the Lower Columbia River and Estuary. PNNL-22667, prepared for the U.S. Army Corps of Engineers, Portland District, Portland, Oregon, by the Pacific Northwest National Laboratory, Marine Sciences Laboratory, Sequim, Washington. 
Diefenderfer HL, AB Borde, VI Cullinan, GC Roegner, and LL Johnson. In Preparation. Disturbance history and ecology of juvenile salmon habitats in a fluvially dominated drowned-river estuary.

Dorward-King EJ, GW Suter II, LA Kapustka, DR Mount, DK Reed-Judkins, SM Cormier, SD Dyer, MG Luxon, R Parrish, and GA Burton Jr. 2001. "Distinguishing among factors that influence ecosystems." Pages 1-26 in DJ Baird and GA Burton Jr. (eds.), Ecological Variability: Separating Natural from Anthropogenic Causes of Ecosystem Impairment. SETAC Press, Pensacola, Florida.

Downes BJ, LA Barmuta, PG Fairweather, DP Faith, MJ Keough, PS Lake, BD Mapstone, and GP Quinn. 2002. Monitoring Ecological Impacts: Concepts and Practice in Flowing Waters. Cambridge University Press, UK.

Eaton CD. 2010. "Resource partitioning, habitat connectivity, and resulting foraging variation among salmonids in the estuarine habitat mosaic." Master's Thesis. University of Washington School of Aquatic and Fishery Sciences, Seattle, Washington.

Farley EV, Jr, JM Murphy, MD Adkison, LB Eisner, JH Helle, JH Moss, and J Nielsen. 2007. "Early marine growth in relation to marine stage survival rate for Alaska sockeye salmon (Oncorhynchus nerka)." Fisheries Bulletin 105:121-130.

Feyrer F, T Sommer, and W Harrell. 2006. "Importance of flood dynamics versus intrinsic physical habitat in structuring fish communities: evidence from two adjacent engineered floodplains on the Sacramento River, California." North American Journal of Fisheries Management 26:408-417.

Fox GA. 1991. "Practical causal inference for ecoepidemiologists." Journal of Toxicology and Environmental Health 33:359-374.

Frenkel RE and JC Morlan. 1990. Restoration of the Salmon River Salt Marshes: Retrospect and Prospect. Final Report to the U.S. Environmental Protection Agency, by the Department of Geosciences, Oregon State University Corvallis, Oregon.

Friedland KD, LP Hansen, DA Dunkley, and JC MacLean. 2000. "Linkage between ocean climate, postsmolt growth, and survival of Atlantic salmon (Salmo salar L.) in the North Sea area." ICES Journal of Marine Science 57(2):419-429 CrossRef, ISI.

Gardner RH. 1998. "Pattern, process, and the analysis of spatial scales." Pages 17-34 in DL Peterson and VT Parker (eds.), Ecological Scale: Theory and Applications. Columbia University Press, New York.

Gergel SE, MG Turner, JR Miller, JM Mclack, and EH Stanley. 2002. "Landscape indicators of human impacts to riverine systems." Aquatic Science 64:118-128.

Glaser EM. 1941. An experiment in the development of critical thinking. Bureau of Publications, Teachers College, Columbia University, New York.

Gosselink JG, GP Shaffer, LC Lee, DM Burdick, DL Childers, NC Leibowitz, SC Hamilton, R Boumans, D Cushman, S Fields, M Koch, and JM Visser. 1990. "Landscape conservation in a forested wetland watershed: can we manage cumulative impacts?" BioScience 40:588-600. 
Gray A, CA Simenstad, DL Bottom, and TJ Cornwell. 2002. "Contrasting functional performance of juvenile salmon habitat in recovering wetlands of the Salmon River Estuary, Oregon, U.S.A." Restoration Ecology 10:514-526.

Greene C, J Hall, E Beamer, R Henderson, and B Brown. 2012. Biological and Physical Effects of "Fish-Friendly" Tide Gates. Final Report for the Washington State Recreation and Conservation Office, January 2012. Report to The Estuary and Salmon Restoration Program. Seattle Washington, 43 pp.

Greet J, JA Webb, and RD Cousens. 2011. "The importance of seasonal flow timing for riparian vegetation dynamics: a systematic review using causal criteria analysis." Freshwater Biology 56:1231-1247.

Hale SS, JF Paul, and JF Heltshe. 2004. "Watershed landscape indicators of estuarine benthic condition." Estuaries 27:283-295.

Hanson KC, KG Ostrand, RA Glenn. 2012. "Physiological characterization of juvenile Chinook salmon utilizing different habitats during migration through the Columbia River Estuary." Comparative Biochemistry and Physiology 163:343-349.

Harnish R, G Johnson, G McMichael, M Hughes, and B Ebberts. 2012. "Effect of Migration Pathway on Travel Time and Survival of Acoustic-Tagged Juvenile Salmonids in the Columbia River Estuary." Transactions of the American Fisheries Society 141:507-519.

Haskell CA and KF Tiffan. 2011. Crims Island-Restoration and monitoring of juvenile salmon rearing habitat in the Columbia River Estuary, Oregon, 2004-10. Scientific Investigations Report 2011-5022, U.S. Geological Survey, Seattle, Washington.

Healey MC. 1979. "Detritus and juvenile salmon production in the Nanaimo Estuary: I. Production and feeding rates of juvenile chum salmon (Oncorhynchus keta)." Journal of the Fisheries Research Board of Canada 36:488-496.

Healey MC. 1980. "Utilization of the Nanaimo River estuary by juvenile Chinook salmon, (Oncorhynchus tshawytscha)." Fisheries Bulletin 77:653-668.

Healey MC. 1982a. "Juvenile Pacific salmon in estuaries: the life support system." Pages 315-341 in VS Kennedy (ed.), Estuarine Comparisons. Academic Press, New York.

Healey MC. 1982b. "Timing and relative intensity of size-selective mortality of juvenile chum salmon (Oncorhynchus keta) during early sea life." Canadian Journal of Fisheries and Aquatic Sciences, 39: 952-957.

Hering DK, DL Bottom, EF Prentice, KK Jones, and IA Fleming. 2010. "Tidal movements and residency of subyearling Chinook salmon (Oncorhynchus tshawytscha) in an Oregon salt marsh channel." Canadian Journal of Fisheries and Aquatic Sciences 67:524-533.

Hill AB. 1965. "The environment and disease: association or causation?" Proceedings of the Royal Society of Medicine 58:295-300. 
Independent Scientific Advisory Board (ISAB). 2011. Using a comprehensive landscape approach for more effective conservation and restoration. ISAB 2011-4, available from the Northwest Power and Conservation Council, Portland, Oregon.

Jacobson K, B Peterson, M Trudel, J Ferguson, C Morgan, D Welch, A Baptista, B Beckman, R Brodeur, E Casillas, R Emmett, J Miller, D Teel, T Wainwright, L Weitkamp, J Zamon, and K Fresh. 2012. The Marine Ecology of Juvenile Columbia River Basin Salmonids: A Synthesis of Research 1998-2011. Prepared for the Northwest Power and Conservation Council, Portland, Oregon by the U.S. National Marine Fisheries Service, National Oceanic and Atmospheric Administration, Fisheries and Oceans Canada, Kintama Research Services, Ltd., and Oregon State University, Seattle, Washington.

Jay DA, K Leffler, HL Diefenderfer, and AB Borde. In Revision. "Tidal-fluvial and estuarine processes in the lower Columbia River, I: Along-channel water level variations, Pacific Ocean to Bonneville Dam." Estuaries and Coasts.

Jay DA, AB Borde, and HL Diefenderfer. In Review. "Tidal-fluvial and estuarine processes in the lower Columbia River II: Water level models, floodplain wetland inundation, and reach classification." Estuaries and Coasts.

Johnson GE, GR Ploskey, NK Sather, and EM Dawley. In Preparation. "Residence Times of AcousticTagged Juvenile Chinook Salmon in Off-Channel Tidal Freshwater Habitats, Columbia River.”

Johnson J, S Ennis, J Poirier, and TA Whitesel. 2008. Lower Columbia River Channel Improvement: Assessment of Salmonid Populations and Habitat on Tenasillahe and Welch Islands. U.S. Fish and Wildlife Service, Vancouver, Washington.

Johnson J, J Poirier, S Ennis, and TA Whitesel. 2009. Julia Butler Hansen National Wildlife Refuge: Assessment of Fishes, Habitats, and Tide Gates in Sloughs on the Mainland, 2007, 2008 Progress Report. U.S. Fish and Wildlife Service, Vancouver, Washington.

Johnson J, J Poirier, and TA Whitesel. 2011. Julia Butler Hansen National Wildlife Refuge: Assessment of Fishes, Habitats, and Tide Gates in Sloughs on the Mainland, 2010 Progress Report. U.S. Fish and Wildlife Service, Vancouver, Washington.

Johnson LL, GM Ylitalo, CA Sloan, BF Anulacion, AN Kagley, MR Arkoosh, TA Lundrigan, K Larson, M Siipola, and TK Collier. 2007. "Persistent organic pollutants in outmigrant juvenile Chinook salmon from the Lower Columbia Estuary, USA." Science of the Total Environment 374:342-366.

Junk WJ, PB Bayley, and RE Sparks. 1989. "The flood pulse concept in river-floodplain systems." Canadian Special Publications in Fisheries and Aquatic Sciences 106:110-127.

Kareiva P, M Marvier, and M McClure. 2000. "Recovery and management options for spring/summer Chinook salmon in the Columbia River Basin." Science 290:977-979.

Ke Y, AM Coleman, and HL Diefenderfer. 2013. "Temporal land cover analysis for net ecosystem improvement." Ecohydrology \& Hydrobiology 13:84-96. 
Koed A, H Baktoft, and BD Bak. 2006. "Causes of mortality of Atlantic salmon (Salmo salar) and brown trout (Salmo trutta) smolts in a restored river and its estuary." River Research and Applications 22:69-78.

Koenings JP, HJ Geiger, and JJ Hasbrouck. 1993. "Smolt-to-adult survival patterns of sockeye salmon (Oncorhynchus nerka): effects of smolt length and geographic latitude when entering the sea." Canadian Journal of Fisheries and Aquatic Sciences 50(3):600-611.

Kukulka T and DA Jay. 2003a. "Impacts of Columbia River discharge on salmonid habitat 1: A nonstationary fluvial model." Journal of Geophysical Research 108(C9):3293. DOI:

10.1029/2002JC001382.

Kukulka T and DA Jay. 2003b. "Impacts of Columbia River discharge on salmonid habitat 2: Changes in shallow-water habitat." Journal of Geophysical Research 108(C9):3294. DOI: 10.1029/2003JC001829.

Kunze LM. 1994. Preliminary classification of native, low elevation, freshwater wetland vegetation in Western Washington. Washington State Department of Natural Resources, Olympia, Washington.

Lee, KH, TM Isenhart, and RC Schultz. 2003. "Sediment and nutrient removal in an established multispecies riparian buffer." Journal of Soil and Water Conservation 58:1-8.

Levings CD. 1982. "Short-term use of a low tide refuge in a sandflat by juvenile Chinook (Oncorhynchus tshawytscha), Fraser River estuary." Canadian Technical Report of Fisheries and Aquatic Sciences No. 1111.

Levings CD. 1994. "Feeding behavior of juvenile salmon and significance of habitat during estuary and early sea phase." Nordic Journal of Freshwater Research 69:7-16.

Levings CD. 2004. "Two decades of fish habitat restoration and bioengineering on the Fraser River Estuary, British Columbia, Canada.” Pp. 164-168, Proceedings of Oceans '04/Techno-Ocean '04. Kobe, Japan.

Levy DA and TG Northcote. 1982. "Juvenile salmon residency in a marsh area of the Fraser River Estuary." Canadian Journal of Fisheries and Aquatic Sciences 39:270-276.

Levings CD and D Bouillon. 1997. "Criteria for evaluating the survival value of estuaries for salmonids." Pages 159-168 in RL Emmett and MH Schiewe (eds.), Estuarine and Ocean Survival of Northeastern Pacific Salmon: Proceedings of the Workshop. NOAA Tech. Memo, NMFS-NWFSC-29, U.S. Department of Commerce, Seattle, Washington.

Levings CD and DJH Nishimura. 1997. "Created and restored marshes in the lower Fraser River, British Columbia: summary of their functioning as fish habitat." Water Quality Research Journal of Canada 32:599-618.

Levings CD, CD McAllister, and BD Chang. 1986. "Differential use of the Campbell River estuary, British Columbia, by wild and hatchery-reared juvenile Chinook salmon (Oncorhynchus tshawytscha)." Canadian Journal of Fisheries and Aquatic Sciences 43(7):1386-1397. 
Levings CD, K Conlin, and B Raymond. 1991. "Intertidal habitats used by juvenile Chinook salmon (Oncorhynchus tshawytscha) rearing in the North Arm of the Fraser River Estuary." Marine Pollution Bulletin 22(1):20-26.

Lindenmayer DB and JF Franklin. 2002. Conserving Forest Biodiversity: A Comprehensive Multiscaled Approach. Island Press, Washington, D.C.

Lott MB. 2004. "Habitat-specific feeding ecology of ocean-type juvenile Chinook salmon in the lower Columbia River estuary." Master's Thesis. University of Washington School of Aquatic and Fishery Sciences, Seattle, Washington.

MacDonald KB. 1984. Tidal Marsh Plant Production in the Columbia River Estuary. Prepared for the Columbia River Estuary Data Development Program and the Columbia River Estuary Study Task Force, Astoria, Oregon by Woodward-Clyde Consultants, San Diego, California.

Maier GO and CA Simenstad. 2009. "The role of marsh-derived macrodetritis to the food webs of juvenile Chinook salmon in a large altered estuary." Estuaries and Coasts 32:984-998.

Magnusson A and R Hilborn. 2003. "Estuarine influence on survival rates of Coho (Oncorhynchus kisutch) and Chinook salmon (Oncorhynchus tshawytscha) released from hatcheries on the U.S. Pacific Coast." Estuaries 26(4B):1094-1103.

Mangel M. 1994. "Climate change and salmonid life history variation." Deep Sea Res. Part II Top. Stud. Oceanogr. 41(1):75-106 CrossRef, ISI.

MacFarlane RB and EC Norton. 2002. "Physiological ecology of juvenile Chinook salmon (Oncorhynchus tshawytscha) at the southern end of their distribution, the San Francisco Estuary and Gulf of the Farallones, California." Fish Bulletin 100:244-257.

McMichael GA, RA Harnish, JR Skalski, KA Deters, KD Ham, RL Townsend, PS Titzler, MS Hughes, JA Kim, and DM Trott. 2011. Migratory Behavior and Survival of Juvenile Salmonids in the Lower Columbia River, Estuary, and Plume in 2010. PNNL-20443, prepared for the U.S. Army Corps of Engineers, Portland District, Portland, Oregon by the Pacific Northwest National Laboratory, Richland, Washington.

Miller JA and CA Simenstad. 1997. "A comparative assessment of a natural and created estuarine slough as rearing habitat for juvenile Chinook and coho salmon." Estuaries 20:792-806.

Morace JL. 2012. Reconnaissance of Contaminants in Selected Wastewater-Treatment-Plant Effluent and Stormwater Runoff Entering the Columbia River, Columbia River Basin, Washington and Oregon, 2008-2010. U.S. Geological Survey Scientific Investigations Report 2012-5068, USGS, Portland, Oregon.

Mote PW, AF Hamlet, MP Clark, and DP Lettenmaier. 2005. "Declining mountain snowpack in western North America." Bulletin of the American Meteorological Society 86:39-49. 
Naiman RJ, JR Alldredge, DA Beauchamp, PA Bisson, J Congleton, CJ Henny, N Huntly, R Lamberson, C Levings, EN Merrill, WG Pearcy, BE Rieman, GT Ruggerone, D Scarnecchia, PE Smouse, and CC Wood. 2012. "Developing a broader scientific foundation for river restoration: Columbia River food webs." PNAS 109 (52):21201-21207.

Naiman RJ and H Décamps. 1997. "The ecology of interfaces: riparian zones." Annual Review of Ecology and Systematics 28:621-58.

Nakano S and M Murakami. 2001. "Reciprocal subsidies: Dynamic interdependence between terrestrial and aquatic food webs. Proceedings of the National Academy of Sciences 98:166-170.

National Environmental Policy Act (NEPA) of 1969, as amended. 42 USC 4321 et seq.

National Marine Fisheries Service (NMFS). 2008. Biological Opinion-Consultation on Remand for Operation of the Federal Columbia River Power System, 11 Bureau of Reclamation Projects in the Columbia Basin and ESA Section 10(a)(1)(A) Permit for Juvenile Fish Transportation Program. NOAA's National Marine Fisheries Service - Northwest Region, Seattle, Washington. Available at http://www.salmonrecovery.gov/.

National Oceanic and Atmospheric Administration Coastal Change Analysis Program (NOAA C-CAP). 2004. "C-CAP Zone 2 and Zone 7 1996-2001-Era Land Cover Change Analysis Metadata, NOAA's Ocean Service, Coastal Services Center (CSC).” Available at http://www.csc.noaa.gov/crs/lca

NRC (National Research Council). 2012. Sea-Level Rise for the Coasts of California, Oregon, and Washington: Past, Present and Future. National Academies Press, Washington, D.C.

Norris RH, JA Webb, SJ Nichols, MJ Stewardson, and ET Harrison. 2012. "Analyzing cause and effect in environmental assessments: using weighted evidence from the literature." Freshwater Science $31: 5-21$.

Pedersen ML, JM Andersen, K Nielsen, and M Linnemann. 2007. "Restoration of Skjern River and its valley: Project description and general ecological changes in the project area." Ecological Engineering 30:131-144.

Pickett STA, ML Cadenasso, and S Bartha. 2001. "Implications from the Buell-Small succession study for vegetation restoration." Applied Vegetation Science 4:41-52.

Ramirez MF. 2008. "Emergent Aquatic Insects: Assemblage Structure and Patterns of Availability in Freshwater Wetlands of the Lower Columbia River Estuary." Master's Thesis. University of Washington School of Aquatic and Fishery Sciences, Seattle, Washington.

Reimers PE. 1973. "The length of residence of juvenile fall Chinook salmon in Sixes River, Oregon." Oregon Fish Commission Research Report 4.

Roegner GC, EW Dawley, M Russell, A Whiting, and DJ Teel. 2010. "Juvenile Salmonid Use of Reconnected Tidal Freshwater Wetlands in Grays River, Lower Columbia River Basin." Transactions of the American Fisheries Society 139:1211-1232. 
Roegner GC, HL Diefenderfer, AB Borde, RM Thom, EM Dawley, AH Whiting, SA Zimmerman, and GE Johnson. 2009. Protocols for monitoring habitat restoration projects in the lower Columbia River and estuary. NOAA Tech. Memo. NMFS-NWFSC-97, U.S. Department of Commerce, Seattle, Washington

Roegner GC, GE Johnson, and AM Coleman. In Preparation. "Indexing habitat opportunity for juvenile salmon in tidal wetlands."

Roegner GC, R McNatt, DJ Teel, and DL Bottom. 2012. "Distribution, size, and origin of juvenile Chinook salmon in shallow-water habitats of the lower Columbia River and estuary, 2002-2007." Marine and Coastal Fisheries: Dynamics, Management, and Ecosystem Science 4:450-472.

Roni R, TJ Beechie, RE Bilby, FE Leonetti, MM Pollock, and GR Pess. 2002. “A Review of Stream Restoration Techniques and a Hierarchical Strategy for Prioritizing Restoration in Pacific Northwest Watersheds." North American Journal of Fisheries Management 22:1-20.

Ruggerone GT, JL Nielsen, and BA Agler. 2009. "Linking marine and freshwater growth in western Alaska Chinook salmon, Oncorhynchus tshawytscha." Journal of Fish Biology 75:1287-1301.

Sagar, JP, AB Borde, LL Johnson, CA Corbett, JL Morace, KH Macneale, WB Temple , J Mason, RM Kaufmann, VI Cullinan, SA Zimmerman, R M Thom, CL Wright, PM Chittaro, OP Olson, SY Sol, DJ Teel, GM Ylitalo and ND Jahns. 2013. Juvenile Salmon Ecology in Tidal Freshwater Wetlands of the Lower Columbia River and Estuary: Synthesis of the Ecosystem Monitoring Program, 2005-2010. Prepared for the Bonneville Power Administration by the the Lower Columbia Estuary Partnership, Portland, OR.

Sather NK, GE Johnson, AJ Storch, DJ Teel, JR Skalski, TA Jones, EM Dawley, SA Zimmerman, AB Borde, C Mallette, and RA Farr. 2009. Ecology of Juvenile Salmon in Shallow Tidal Freshwater Habitats in the Vicinity of the Sandy River Delta, Lower Columbia River, 2008. PNNL-18450, Pacific Northwest National Laboratory, Richland, Washington.

Sather NK, D Teel, A Storch, G Johnson, E Van Dyke, E Dawley, D Kuligowski, T Jones, A Bryson, and K Sobocinski. 2011. "Juvenile Salmon and Fish Community Characteristics." In: Ecology of Juvenile Salmon in Shallow Tidal Freshwater Habitats of the Lower Columbia River, 2007-2010. Johnson et al., pp. 2.1-2.35, PNNL-20083, Pacific Northwest National Laboratory, Richland, Washington.

Scott KJ and R Susanto. 1993. Analysis of fish occurrence in restored, unvegetated and natural habitats in the Fraser River estuary, March through August, 1992. Prepared for the Department of Fisheries and Oceans by Scott Resource Services, Mission, British Columbia.

Shreffler DK, CA Simenstad, and RM Thom. 1990. "Temporary residence by juvenile salmon in a restored estuarine wetland." Canadian Journal of Fisheries and Aquatic Sciences 47:2079-2084.

Shreffler DK, CA Simenstad, and RM Thom. 1992. "Foraging by juvenile salmon in a restored estuarine wetland." Estuaries 15:204-213.

Simenstad CA and RM Thom. 1996. "Functional equivalency trajectories of the restored Gog-Le-Hi-Te estuarine wetland.” Ecological Applications 6:38-56. 
Simenstad CA and JR Cordell. 2000. "Ecological assessment criteria for restoring anadromous salmonid habitat in Pacific Northwest estuaries." Ecological Engineering 15:283-302.

Simenstad CA, WG Hood, RM Thom, DA Levy, and DL Bottom. 2000. "Landscape structure and scale constraints on restoring estuarine wetlands for Pacific Coast juvenile fishes. Pages 597-630 in MP Weinstein and DA Kreeger (eds.), Concepts and Controversies in Tidal Marsh Ecology. Kluwer Academic Publishers, Dordrecht.

Simenstad CA, C Tanner, J Cordell, C Crandell, and J White. 2005. "Challenges of habitat restoration in a heavily urbanized estuary: evaluating the investment." Journal of Coastal Research 40:6-23.

Simenstad CA, JL Burke, JE O’Connor, C Cannon, DW Heatwole, MF Ramirez, IR Waite, D Counihan, and KL Jones. 2011. Columbia Estuary Ecosystem Classification-Concept and Application. U.S. Geological Survey Open File Report 2011-1228, USGS, Portland, Oregon.

Skalski JR, SG Smith, RN Iwamoto, JG Williams, and A Hoffmann. 1998. "Use of passive integrated transponder tags to estimate survival of migrant juvenile salmonids in the Snake and Columbia Rivers." Canadian Journal of Fisheries and Aquatic Sciences 55: 1484-1493.

Skalski JR and R Townsend. 2011. “Analysis of Estuary PIT-Tag Detections.” Appendix I, in Evaluation of Life History Diversity, Habitat Connectivity, and Survival Benefits Associated with Habitat Restoration Actions in the Lower Columbia River and Estuary, Annual Report 2010, Diefenderfer, HL and 13 others. PNNL-20295, prepared for the U.S. Army Corps of Engineers, Portland District, Portland, Oregon, by the Pacific Northwest National Laboratory, U.S. Fish and Wildlife Service, and University of Washington, Richland, Washington.

Small L (ed.). 1990. Columbia River: Estuarine System. Special Issue. Progress in Oceanography 25:1-4.

Society for Ecological Restoration International Science \& Policy Working Group. 2004. The SER International Primer on Ecological Restoration. Version 2. Society for Ecological Restoration International, Tuscon, Arizona. (www.ser.org)

Sommer T, B Harrell, M Nobriga, R Brown, P Moyle, W Kimmerer, and L Schemel. 2001a. "California's Yolo Bypass: Evidence that flood control can be compatible with fisheries, wetlands, wildlife and agriculture." Fisheries 26:6-16.

Sommer TR, ML Nobriga, WC Harrell, W Batham, and WJ Kimmerer. 2001b. " Floodplain rearing of juvenile Chinook salmon: Evidence of enhanced growth and survival." Canadian Journal of Fisheries and Aquatic Sciences 58:325-333.

Sommer TR, WC Harrell, and ML Nobriga. 2005. "Habitat use and stranding risk of juvenile Chinook salmon on a seasonal floodplain." North American Journal of Fisheries Management 25:1493-1504.

Stefansson SO, B Björnsson, K Sundell, G Nyhammer, and SD McCormick. 2003. "Physiological characteristics of wild Atlantic salmon post-smolts during estuarine and coastal migration." Journal of Fish Biology 63(4):942-955. 
Stefansson SO, M Haugland, BT Björnsson, SD McCormick, M Holm, LO Ebbesson, JC Holst, and TO Nilsen. 2011. "Growth, osmoregulation and endocrine changes in wild Atlantic salmon smolts and postsmolts during marine migration." Aquaculture 362-363:127-136.

Stewart-Oaten A. and WW Murdoch. 1986. 'Environmental impact assessment: 'pseudoreplication' in time?" Ecology 67:929-940.

Storch AJ and NK Sather. 2011. "Feeding Ecology." In Ecology of Juvenile Salmon in Shallow Tidal Freshwater Habitats of the Lower Columbia River, 2007-2010, pp. 4.1-4.20. PNNL-20083, Pacific Northwest National Laboratory, Richland, Washington.

Storch AJ and NK Sather. In Review. The role of shallow tidal freshwater habitats in the lower Columbia River for juvenile Chinook salmon: an energetic assessment.

Strand JET, JG Davidsen, EH JØrensen, AH Rikardsen. 2011. "Seaward migrating Atlantic salmon smolts with low levels of gill $\mathrm{Na}+, \mathrm{K}+$-ATPase activity; is sea entry delayed?" Environmental Biology of Fishes 90:317-321

Suter GW II, SB Norton, and SM Cormier. 2002. "A methodology for inferring the causes of observed impairments in aquatic ecosystems." Environmental Toxicology and Chemistry 21:1101-1111.

Suter GW II, SB Norton, and SM Cormier. 2010. "The science and philosophy of a method for assessing environmental causes." Human and Ecological Risk Assessment 16:19-34.

Swanson FJ, SV Gregory, JR Sedell, and AG Campbell. 1982. "Land-water interactions: the riparian zone." Pp. 267-291 in RL Edmonds (ed.), Analysis of Coniferous Forest Ecosystems in the Western United States. Hutchinson Ross, Stroudsburg, Pennsylvania.

Tanner CD, JR Cordell, J Rubey, and LM Tear. 2001. "Restoration of freshwater intertidal habitat functions at Spencer Island, Everett, Washington." Restoration Ecology 10:564-576.

Tear TH, JM Scott, PH Hayward, and B Griffith. 1995. "Recovery Plans and the Endangered Species Act: Are Criticisms Supported by Data?" Conservation Biology 9:182-195.

Teel DJ, C Baker, DR Kuligowski, TA Friesen, and B Shields. 2009. "Genetic Stock Composition of Subyearling Chinook Salmon in Seasonal Floodplain Wetlands of the Lower Willamette River, Oregon." Transactions of the American Fisheries Society 138: 211-217.

Thom RM. 1992. "Accretion rates of low intertidal salt marshes in the Pacific Northwest." Wetlands 12:147-156.

Thom RM. 1997. "System-development matrix for adaptive management of coastal ecosystem restoration projects." Ecological Engineering 8:219-232.

Thom RM, R Zeigler, and AB Borde. 2002. "Floristic Development Patterns in a Restored Elk River Estuarine Marsh, Grays Harbor, Washington." Restoration Ecology 10:487-496. 
Thom RM, AB Borde, NR Evans, CW May, GE Johnson, and JA Ward. 2004. A Conceptual Model for the Lower Columbia River Estuary. Final report to the U.S. Army Corps of Engineers, Portland District, Portland, Oregon, by Pacific Northwest National Laboratory, Richland Washington. Available at www.nwp.usace.army. $\mathrm{mil} / \mathrm{pm} / \mathrm{lcr} / \mathrm{science}$.asp.

Thom RM, H Diefenderfer, A Coleman, A Borde, C Roegner, J Tagestad, and G Johnson. 2012. "Ecology and Hydrology of Restoring Wetlands in the Lower Columbia River and Estuary." Pp. 2.12.101 in Johnson GE, HL Diefenderfer, RM Thom, GC Roegner, BD Ebberts, JR Skalski, AB Borde, EM Dawley, AM Coleman, DL Woodruff, SA Breithaupt, AS Cameron, CA Corbett, EE Donley, DA Jay, Y Ke, KE Leffler, CB McNeil, CA Studebaker, and JD Tagestad. 2012. Evaluation of Cumulative Ecosystem Response to Restoration Projects in the Lower Columbia River and Estuary, 2010. PNNL20296, prepared for the U.S. Army Corps of Engineers, Portland District, Portland, Oregon, by Pacific Northwest National Laboratory, Richland, Washington.

Thom RM, NK Sather, GC Roegner, and DL Bottom. 2013. Columbia Estuary Ecosystem Restoration Program: 2012 Synthesis Memorandum. Final report prepared for the U.S. Army Corps of Engineers, Portland, Oregon by Pacific Northwest National Laboratory, Sequim, Washington, and National Marine Fisheries Service, Seattle, Washington.

Thom RM, SA Breithaupt, GC Roegner, DL Woodruff, GE Johnson. In Preparation(a). Particulate Organic Matter Export from a Restored Tidal Freshwater Wetland in the Columbia River estuary.

Thom RM, H Diefenderfer, A Coleman, A Borde, C Roegner, J Tagestad, and G Johnson. In Preparation(b). Ecology and Hydrology of Restoring Wetlands in the Lower Columbia River and Estuary.

Thomas DW. 1983. Changes in the Columbia River Estuary Habitat Types over the Past Century. Columbia River Estuary Data Development Program, Columbia River Estuary Study Task Force, Astoria, Oregon.

Thorpe JE. 1994. "Salmonid fishes and the estuarine environment.” Estuaries 17:76-93.

Tomaro LM, DJ Teel, WT Peterson, and JA Miller. 2012. "When is bigger better? Early marine residence of middle and upper Columbia River spring Chinook salmon." Marine Ecology Progress Series 452:237-252.

Trudel M, S Tucker, JE Zamon, J Morris, DA Higgs,. and DW Welch. 2002. "Bioenergetic response of coho salmon to climate change." North Pacific Anadromous Fish Commission, Tech. Rep. pp. 59-61.

Trudel M, ME Thiess, JFT Morris, T Zubkowski, and DL Mackas. 2011. Canada-USA Salmon Shelf Survival Study. Annual Report submitted to the Bonneville Power Administration, Portland, Oregon.

USDHEW (U.S. Department of Health, Education, and Welfare). 1964. Smoking and Health: Report of the Advisory Committee to the Surgeon General of the Public Health Service. PHS Publication No. 1103, Public Health Service, Center for Disease Control, Washington, D.C. 
USDHEW (U.S. Department of Health, Education, and Welfare). 2006. The Health Consequences of Involuntary Exposure to Tobacco Smoke: A Report of the Surgeon General - Executive Summary. U.S. Department of Health and Human Services, Centers for Disease Control and Prevention, Coordinating Center for Health Promotion, National Center for Chronic Disease Prevention and Health Promotion, Office on Smoking and Health, Rockville, Maryland.

U.S. Fish \& Wildlife Service and National Marine Fisheries Service. 1998. Final Endangered Species Consultation Handbook: Procedures for Conducting Consultation and Conference Activities Under Section 7 of the Endangered Species Act. March, 1998. Washington, D.C. http://www.fws.gov/endangered/esa-library/index.html

Webb JA, EM Wallis, and MJ Stewardson. 2012. "A systematic review of published evidence linking wetland plants to water regime components." Aquatic Botany 103:1-14.

Weed DL. 1997. "On the use of causal criteria." International Journal of Epidemiology 26:1137-1141.

Weitkamp LA, PB Bentley, and MNC Litz. 2012. "Seasonal and interannual variation in juvenile salmonids and associated fish assemblage in open waters of the lower Columbia River estuary, U.S.A." U.S. Fishery Bulletin 110(4):426-450.

Welch DW, EL Rechisky, MC Melnychuk, AD Porter, CJ Walters, S Clements, BJ Clemens, RS McKinley, and C Schreck. 2008. "Survival of migrating salmon smolts in large rivers with and without dams.” Public Library of Science Biology 6:2101-2108.

Welcomme RL. 1979. Fisheries ecology of Floodplain Rivers. Longman, London.

Wimberly MC and JL Ohmann. 2004. "A multi-scale assessment of human and environmental constraints on forest land cover change on the Oregon (USA) coast range. Landscape Ecology 19:631646.

Winemiller KO, AS Flecker and DJ Hoeinghaus. 2010. "Patch dynamics and environmental heterogeneity in lotic ecosystems." Journal of the North American Benthological Society 29(1): 84-99. 


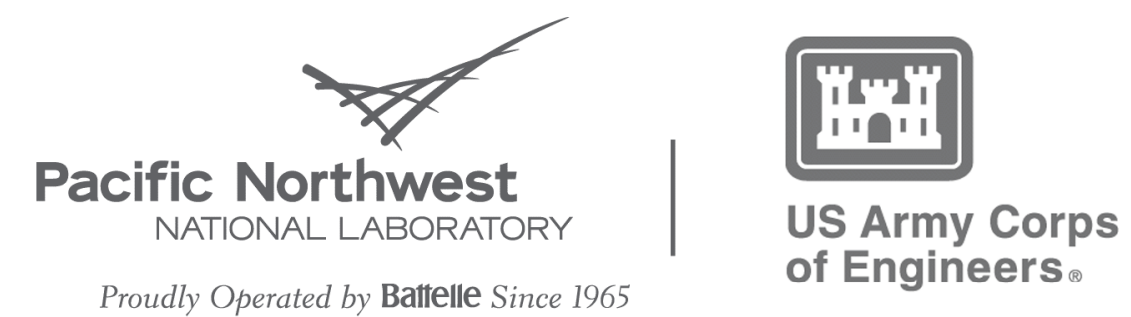

Proudly Operated by Battelle Since 1965

902 Battelle Boulevard

P.O. Box 999

Richland, WA 99352

1-888-375-PNNL (7665)

www.pnl.gov 